Published in final edited form as:

Nat Med. 2019 November ; 25(11): 1761-1771. doi:10.1038/s41591-019-0633-x.

\title{
Exercise reduces inflammatory cell production and cardiovascular inflammation via instruction of hematopoietic progenitor cells
}

\author{
Vanessa Frodermann ${ }^{1,14}$, David Rohde ${ }^{1,14}$, Gabriel Courties ${ }^{1}$, Nicolas Severe ${ }^{2,3}$, Maximilian \\ J. Schloss ${ }^{1}$, Hajera Amatullah ${ }^{4}$, Cameron S. McAlpine ${ }^{1}$, Sebastian Cremer $^{1}$, Friedrich F. \\ Hoyer $^{1}$, Fei Ji ${ }^{5,6}$, lan D. van Koeverden ${ }^{7}$, Fanny Herisson ${ }^{1}$, Lisa Honold ${ }^{1}$, Gustavo Santos \\ Masson ${ }^{1}$, Shuang Zhang ${ }^{1}$, Jana Grune ${ }^{1}$, Yoshiko Iwamoto ${ }^{1}$, Stephen P. Schmidt ${ }^{1}$, Gregory \\ R. Wojtkiewicz ${ }^{1}$, I-Hsiu Lee ${ }^{1}$, Karin Gustafsson ${ }^{2,3}$, Gerard Pasterkamp ${ }^{8}$, Saskia C.A. de \\ Jager $^{7,9}$, Ruslan I. Sadreyev ${ }^{6,10}$, Jean MacFadyen ${ }^{11}$, Peter Libby ${ }^{11}$, Paul Ridker ${ }^{11}$, David T. \\ Scadden $^{2,3}$, Kamila Naxerova ${ }^{1}$, Kate L. Jeffrey ${ }^{4}$, Filip K. Swirski ${ }^{1}$, Matthias \\ Nahrendorf ${ }^{1,12,13,{ }^{*}}$
}

${ }^{1}$ Center for Systems Biology, Department of Radiology, Massachusetts General Hospital, Harvard Medical School, Boston, MA, USA ${ }^{2}$ Department of Stem Cell and Regenerative Biology, Harvard University, Cambridge, MA, USA ${ }^{3}$ Center for Regenerative Medicine and Cancer Center, Massachusetts General Hospital, Boston, MA, USA ${ }^{4}$ Gastrointestinal Unit and Center for the Study of Inflammatory Bowel Disease, Massachusetts General Hospital and Harvard Medical School, Boston, MA, USA 5 Department of Genetics, Harvard Medical School, Boston, USA ${ }^{6}$ Department of Molecular Biology, Massachusetts General Hospital, Boston, MA, USA ${ }^{7}$ Laboratory of Experimental Cardiology, Department of Cardiology, University Medical Center Utrecht, Utrecht, The Netherlands ${ }^{8}$ Laboratory for Clinical Chemistry and Haematology, University Medical Center Utrecht, Utrecht, The Netherlands ${ }^{9}$ Laboratory of Translational Immunology, University Medical Center Utrecht, Utrecht, The Netherlands ${ }^{10}$ Department of Pathology, Massachusetts General Hospital and Harvard Medical School, Boston, MA, USA ${ }^{11}$ Division of Cardiovascular Medicine, Department of Medicine, Brigham and Women's Hospital and Harvard Medical School, Boston, MA, USA ${ }^{12}$ Cardiovascular Research Center, Massachusetts General Hospital and Harvard Medical School, Boston, MA, USA ${ }^{13}$ Department of Internal Medicine I, University Hospital Wuerzburg, Wuerzburg, Germany

\footnotetext{
Users may view, print, copy, and download text and data-mine the content in such documents, for the purposes of academic research, subject always to the full Conditions of use:http://www.nature.com/authors/editorial_policies/license.html\#terms

*Correspondence to: Matthias Nahrendorf, Center for Systems Biology, 185 Cambridge Street, Boston, MA 02114, Tel: (617) 643-0500, Fax: (617) 643-6133, mnahrendorf@mgh.harvard.edu.

Author contributions

V.F., D.R. and M.N. designed experiments. V.F., D.R., G.C., N.S., M.J.S., H.A., S.C., F.F.H., F.J., I.D.v.K., F.H., L.H., C.S.M., G.S.M., S.Z., J.G., Y.I., S.P.S., G.R.W., I.-H.L., K.G. performed experiments and collected data. V.F., D.R., G.C., N.S., F.J., I.D.v.K., G.P., S.C.A.d.J., R.I.S., I.-H.L., J.M., K.N. analyzed data. V.F., M.J.S., D.R., S.C., F.F.H., G.S.M. performed surgeries. V.F., D.R., G.C., N.S., H.A., P.L., G.P., P.R., D.T.S., K.N., K.L.J., F.S., M.N. discussed results and strategy. V.F., D.R. and M.N. wrote the manuscript, which was edited by all co-authors. M.N. supervised, directed and managed the study.

${ }^{14}$ These authors contributed equally: V. Frodermann, D. Rohde.

Competing interests

Authors declare no competing interests.
} 


\section{Abstract}

A sedentary lifestyle, chronic inflammation and leukocytosis propel atherosclerosis; however, it remains unclear if regular physical activity influences leukocyte production. Here we show that voluntary running decreases hematopoietic activity in mice. Exercise protects mice and humans with atherosclerosis from chronic leukocytosis but does not compromise emergency hematopoiesis in mice. Mechanistically, exercise diminishes leptin production in adipose tissue, augmenting quiescence-promoting hematopoietic niche factors in leptin receptor-positive stromal bone marrow cells. Induced deletion of the leptin receptor in $\operatorname{Prx} 1-\mathrm{creER}^{\mathrm{T} 2}: \operatorname{Lepr}^{\mathrm{fl} / \mathrm{fl}}$ mice reveals that leptin's effect on bone marrow niche cells regulates hematopoietic stem and progenitor cell (HSPC) proliferation and leukocyte production, as well as cardiovascular inflammation and outcomes. Whereas running wheel withdrawal quickly reverses leptin levels, the impact of exercise on leukocyte production and on the HSPC epigenome and transcriptome persists for several weeks. Together, these data show that physical activity alters HSPCs via modulation of their niche, reducing hematopoietic output of inflammatory leukocytes.

\section{Introduction}

Even though cardiovascular therapeutics have advanced rapidly, the global number of patients with atherosclerosis and its complications is on the rise. Changes in life style including an unhealthy diet, low physical activity and obesity contribute to this worldwide epidemic. Despite current management strategies, many individuals still develop first or recurrent cardiovascular events such as myocardial infarction, stroke, heart failure or limb ischemia. Mechanistically, inflammation accounts for some of this residual risk ${ }^{1}$. Indeed, the Canakinumab Anti-inflammatory Thrombosis Outcomes Study (CANTOS) documented that targeting inflammatory pathways, specifically the cytokine IL-1 $\beta$, can lower cardiovascular events in selected patients already receiving aggressive management including highly effective statin treatment ${ }^{2}$.

The cellular protagonists of arterial wall inflammation include leukocytes of several classes, notably macrophages, monocytes and neutrophils. Monocyte and neutrophil blood counts associate with cardiovascular disease progression and death ${ }^{3}$. Because these cells only live for a day or less, their production rates influence systemic cell abundance and recruitment to cardiovascular organs. Hence, understanding the signals that lead to overproduction of inflammatory leukocytes may provide strategies to reduce inflammatory cardiovascular events ${ }^{4}$.

Leukocytes derive from hematopoietic stem and progenitor cells (HSPC). HSPC may increase proliferation and thus leukocyte production in response to cytokines, growth factors and danger signals. Recent research has unraveled mechanisms that influence hematopoiesis in cardiovascular disease by illuminating pathways through which hyperlipidemia ${ }^{5}$, psychosocial stress ${ }^{6}$, insufficient sleep ${ }^{7}$ and obesity ${ }^{8}$ increase HSPC proliferation and the marrow's myeloid cell output. These well-known risk factors either act directly on HSPC or via the hematopoietic niche, an ensemble of stromal bone marrow cells that protects HSPC and instructs their proliferation, migration and lineage bias ${ }^{9}$. 
Sedentary life style is a risk factor for myocardial infarction, while physical activity appears to protect against cardiovascular disease ${ }^{10}$. One observational study followed 55,137 adults over 15 years and reported that persistent running associates with a $50 \%$ lower cardiovascular mortality ${ }^{11}$. Most available data ${ }^{10}$ indicate that this relationship rests on metabolic and anti-hypertensive effects which counter aging processes; however, the mechanisms by which physical activity could mitigate cardiovascular inflammation remain uncertain. Exercise has clear effects on the immune ${ }^{12}$ and cardiovascular system ${ }^{13-15}$. Whether and how regular physical activity affects the hematopoietic system is incompletely understood. We therefore studied the hematopoietic system, which is well-characterized in mice, as a function of regular voluntary physical activity.

\section{Results}

\section{Voluntary running promotes HSPC quiescence}

To explore if regular physical activity modulates hematopoiesis and the systemic supply of leukocytes, we provided mice with running wheels, which they used avidly (Extended Data Fig. 1a,b), for six weeks (Fig. 1a). Habitual voluntary running, which increases activity 20fold compared to sedentary mice ${ }^{16}$, reduced body weight, augmented food consumption (Extended Data Fig. 1c-e) and did not change skeletal muscle leukocyte recruitment (Extended Data Fig. 1f,g) or bone architecture (Extended Data Fig. 1h-k). Voluntary running promoted HSPC quiescence: Lin- Sca-1+ c-Kit+ (LSK) proliferated 34\% less, as assessed by BrdU incorporation (Fig. 1b,c). The reduction in proliferation occurred at the stage of multipotent progenitors (MPP, a subset of LSK) (Fig. 1c) and in all leukocyte progenitors, regardless of myeloid or lymphoid lineage (Extended Data Fig. 2a-d). BrdU washout assays confirmed that all progenitors downstream of $\mathrm{CD} 48^{-} \mathrm{CD} 150^{+}$long-term $\mathrm{HSC}$ and $\mathrm{CD} 48^{-} \mathrm{CD} 150^{-}$short-term HSC proliferated less in running mice (Extended Data Fig. 2e,f). Progenitors formed fewer myeloid and lymphoid colonies, while the erythroid lineage was less affected (Fig. 1d, Extended Data Fig. 2g,h). Running mice mobilized fewer HSPC to the circulation from the marrow (Fig. 1e), which, viewed together with decreased differentiation into mature leukocytes (Extended Data Fig. 2i), explains why HSPC numbers in the marrow were preserved (Extended Data Fig. 2j).

The hematopoietic effects of exercise reduced circulating leukocyte numbers (Fig. 1f-j). Differences between running and sedentary cohorts peaked at Zeitgeber time 7 in the blood (Fig. 1f), indicating decreased leukocyte release when mice rest, and at Zeitgeber time 13 in the bone marrow (Fig. 1g), indicating reduced nocturnal leukocyte production. Physical activity lowered all leukocyte subsets (Fig.1 i,j, Extended Data Fig. 2i). We further observed a decrease in platelets but not in red blood cells, hemoglobin or hematocrit (Extended Data Fig. 2k). We found that voluntary running did not change the marrow's autonomic nervous system activity, as mass spectrometry documented unchanged bone marrow norepinephrine and acetylcholine concentration (Extended Data Fig. 3a). Nor did we observe any differences in local leukocyte acetylcholine production (Extended Data Fig. 3b), after muscarinic cholinergic receptor inhibition (Extended Data Fig. 3c) or in levels of the stress hormone corticosterone (Extended Data Fig. 3d). Given the habitual voluntary running wheel use by mice in our study, higher blood leukocyte levels in sedentary mice indicate that 
lack of physical activity in humans partially confers cardiovascular risk via increased systemic leukocyte supply.

\section{Exercise increases CXCL12 in the hematopoietic niche via lowering leptin}

To investigate how physical activity alters leukocyte supply, we examined the hematopoietic niche that instructs HSPC activity ${ }^{9} 21$. The bone marrow of exercising mice displayed increased expression of important HSPC quiescence and retention genes, specifically CXc112, Vcam1, Scf and Angpt1, as well as increased CXCL12 protein levels (Fig. 2a-c). It is well understood that these signals instruct hematopoiesis in many settings ${ }^{9,21}$; however, their modulation by physical activity was previously unknown. We next assessed gene expression among key stromal cells defining the hematopoietic niche. In running mice, only leptin receptor ${ }^{+}\left(\mathrm{LepR}-\mathrm{YFP}^{+}\right)$stromal cells express more Cxcl12, Vcam1, Scf and Angpt1 (Fig. 2d). Expression of these genes did not change in other hematopoietic niche cells, including Nestin-GFP ${ }^{+}$mesenchymal, $\mathrm{OCN}_{-} \mathrm{GFP}^{+}$osteoblastic, endothelial cells and macrophages (Extended Data Fig. 3e-h). Overall niche cell numbers did not differ between sedentary and exercising mice (Extended Data Fig. 3i). Expression of other niche factors (Csf1-3, Ccl2, Il7, Tgfb1 and Pfa4) and adipocyte-(Lpl, Fabp4) and osteolineage-specific (Osx, Ocn, Runx2) genes was unaltered (Extended Data Fig. 3j,k).

Hematopoietic niche profiling indicated that leptin receptor ${ }^{+}$stromal cells relay exercise effects, hence we investigated potential pathways related to the hormone leptin, which decreases appetite and is a pro-inflammatory adipokine ${ }^{22}$. Exercise reduced body fat (Extended Data Fig. 4a), adipose tissue expression of inflammatory cytokines (Extended Data Fig. 4b) as well as adipose tissue macrophage numbers and their proliferation (Extended Data Fig. 4c-e). In running mice, visceral adipose tissue produced less leptin (Fig. 2e), leading to decreased levels of the hormone in blood and bone marrow (Fig. 2f,g). While exercise led to smaller marrow adipocytes in the red marrow of the proximal tibia, adipocyte differentiation and numbers did not change (Extended Data Fig. $4 \mathrm{f}-\mathrm{h}$ ) and the overall marrow fat content remained constant (Extended Data Fig. 4i,j). Leptin expression in the marrow was low and unaffected by exercise (Extended Data Fig. 4k) and the marrow leptin concentration did not correlate with tibial adipocyte size (Extended Data Fig. 41), supporting a prominent role of visceral fat as the source of leptin.

Viewing these data together with previous reports that leptin deficiency impairs hematopoiesis ${ }^{23}$, that leptin levels correlate with leukocytes in adolescent Japanese males ${ }^{24}$ and that exercise reduces leptin levels ${ }^{25}$, we reasoned that exercise-induced changes in hematopoiesis may result from reduced adipose tissue-derived leptin. To test this hypothesis, we elevated leptin to sedentary levels during exercise using mini-pump supplementation (Fig. 2h; Extended Data Fig. 5a). This intervention restored circulating leukocytes (Fig. 2h) and LSK proliferation (Extended Data Fig. 5b), while bone marrow Cxc112, Vcam1 and Angpt1 expression declined to the levels seen in sedentary mice (Extended Data Fig. 5c). The chosen leptin concentration did not affect the running distance (Extended Data Fig. 5d). In sedentary mice, leptin neutralizing antibody treatment reduced hematopoiesis while leptin injections had the opposite effect (Extended Data Fig. 5e). 
Prior reports state that short-term ablation of leptin receptor-positive stromal cells and deletion of niche factors in leptin receptor-positive cells depletes HSC $^{26,27}$. However, constitutive leptin receptor deficiency in stromal cells does not affect hematopoiesis but rather remodels the bone marrow niche ${ }^{28}$. Leptin may also act directly on $\mathrm{HSPC}^{23}$. Therefore, we aimed to clarify how leptin affects hematopoiesis: via direct action on HSPC or indirectly via leptin receptor ${ }^{+}$stromal cells in the hematopoietic niche. Using LepRtdTomato reporter mice, we profiled hematopoietic and stromal bone marrow cells by flow cytometry. While there was a distinct tdTomato+ stromal cell population expressing the leptin receptor, leukocytes and HSPC were tdTomato-negative (Extended Data Fig. 6a-c). Adding increasing concentrations of leptin to a colony forming unit assay did not change the number of colonies (Extended Data Fig. 6d). Further, exercise effects on hematopoiesis were preserved in wild type mice that had received lethal irradiation followed by bone marrow transplantation from $\mathrm{db} / \mathrm{db}$ mice which lack the leptin receptor (Extended Data Fig. 6e-i). Tamoxifen-induced, stromal cell-specific deletion of the leptin receptor in adult Prx1creER $^{\mathrm{T} 2}: L e p r^{\mathrm{fl} / \mathrm{fl}}$ mice, which show no differences in systemic leptin levels (Extended Data Fig. 6j), increased expression of HSPC maintenance niche factors in the bone marrow, reduced LSK proliferation and decreased circulating leukocytes (Fig. 2i-l), an exact phenocopy of running mice. Developmental compensation likely accounts for the differences between our observations two weeks after tamoxifen-induced leptin receptor deletion in adult mice and previously reported data ${ }^{28}$ obtained in mice with constitutive leptin receptor knock out in stromal cells. In line with this notion, two weeks after tamoxifen injections, we do not observe effects on osteogenesis (Extended Data Fig. 6k,1) previously described in mice with constitutive leptin receptor deficiency ${ }^{28}$. We conclude that reduced leptin signaling leads to increased production of quiescence-promoting niche factors by leptin receptor-positive stromal cells, which in turn lowers HSPC proliferation and leukocyte output.

\section{Voluntary running reduces LSK chromatin accessibility}

To explore how long exercise effects persist, we provided mice with running wheels for six weeks followed by three weeks of running wheel withdrawal (post-exercise-sedentary group, Fig. 3a). Although running-induced leptin reduction and effects on hematopoietic niche factors waned in this cohort (Extended Data Fig. 7a-c), circulating leukocytes and LSK proliferation remained lower than in sedentary mice (Fig. 3b). By six weeks after cessation of running, the exercise effects on LSK proliferation and blood leukocytes vanished completely (Extended Data Fig. 7d,e). These observations suggest that adaptations to exercise convey short-term memory effects in hematopoietic cells. To test this hypothesis, we transplanted LSK obtained from CD45.1 ${ }^{\text {STEM }}$ (reference ${ }^{29}$ ) sedentary and CD45.2 exercising mice in a 1:1 ratio into irradiated sedentary UBC-GFP recipients (Fig. 3c). In agreement with the quiescent LSK phenotype in exercising mice, LSK obtained from sedentary donors contributed 1.8-fold more circulating leukocytes (Fig. 3d,e) even though LSK engrafted equally (Fig. 3f). LSK derived from running mice proliferated less after transplantation into sedentary recipients, while LT-HSC numbers were similar (Fig. 3g). Competitive LSK transplantation from sedentary versus post-exercise-sedentary donors yielded equal contribution to blood leukocytes, while competition of LSK from exercising versus post-exercise sedentary mice led to a transitional result (Extended Data Fig. 7f). 
These data indicate that exercise effects on HSPC last several weeks longer than those on leptin, leptin-receptor-positive stromal cells and the niche factors produced by them. To test whether exercise memory in hematopoietic cells arises from epigenetic alterations, we performed an assay for transposase-accessible chromatin using sequencing (ATAC-seq) on LSK sorted from sedentary, exercising and post-exercise-sedentary cohorts (Fig. 3h). Most ATAC-seq peaks in LSK mapped to promoter regions (Fig. 3i) in close proximity to transcriptional start sites (TSS, Fig. 3j). Overall chromatin accessibility at promoters was reduced in LSK from exercising mice compared to sedentary mice (Fig. 3j), while the background signal was comparable in all groups excluding experimental bias (Extended Data Fig. 8a). Reduced chromatin accessibility of LSK was maintained in mice that had stopped exercising (Fig. 3j). Comparing LSK from different activity groups revealed that chromatin proximal to 2480 genes was significantly less accessible following exercise, while only 12 genes were more accessible (FDR $<0.01$; Fig. 3k-m; Extended Data Fig. 8b; Supplementary Table 1). The reduced chromatin accessibility in LSK persisted in postexercise sedentary mice (Fig. 3k-m; Extended Data Fig. 8c-e). Pathway enrichment analysis revealed that the genes with significantly reduced chromatin accessibility in LSK following exercise are involved in transcription and cell cycle regulation (Fig. 3n). Similar to exercising mice, LSK from post-exercise-sedentary mice showed reduced accessibility among genes involved in cell cycle, nucleosome organization and mRNA processing (Extended Data Fig. 8d). Several genes involved in proliferation, myelopoiesis and B lymphopoiesis were significantly less accessible in LSK of exercising and post-exercisesedentary mice (Fig. 3k-n; Extended Data Fig. 8c-e; Supplementary Table 1). Therefore, voluntary exercise induces alterations in the LSK epigenome that suppress accessibility and expression of genes involved in HSPC proliferation and lineage fate decisions. Not only are these changes maintained three weeks following running wheel withdrawal, they also functionally translate to the observed exercise effects on hematopoiesis and circulating leukocytes.

We complemented ATAC-seq with RNA-seq in LSK sorted from the marrow of sedentary, exercising and post-exercise-sedentary cohorts (see Supplementary Table 2 for differentially expressed genes). A direct comparison of individual genes that scored in ATAC-seq as being less accessible after exercise with genes whose transcripts declined did not reach formal significance. This result is not unexpected, as a lack of direct overlap between chromatin accessibility and differential expression on the single gene level has been reported previously ${ }^{30}$. Moreover, it has been shown that establishment of chromatin architecture in mouse and human HSPC reveal the differential potential of progeny prior to the execution of an RNA transcriptional program ${ }^{31-33}$. Nonetheless, similar biological themes did emerge from our ATAC- and RNA-seq data analysis, reflecting heightened hematopoiesis in sedentary mice, which was reduced by voluntary exercise and maintained for a period following exercise withdrawal. Gene set enrichment analysis (GSEA) revealed a significant downregulation of the "Reactome Cell Cycle" gene set in LSK of exercising mice. Specifically, "Reactome Cell Cycle" was the second most significantly downregulated gene set (out of 410 Reactome gene sets) in exercising mice (FDR=0.004), \#49 out of 410 in postexercise-sedentary mice ( $\mathrm{FDR}=0.01$, likely reflecting their gradual return to sedentary state), and when both of these groups were jointly compared to sedentary mice (\#13 out of 410, 
FDR=0) (Fig. 3o). Gene ontology biological process categories featuring immune activation including phagocytosis, complement activation, and several immune responses (Fig. 3p) enriched in downregulated genes of exercising and post-exercising-sedentary mice.

Reactome gene sets enriched in downregulated genes of exercising mice included G-protein coupled receptor signaling (Fig. 3q). These receptors are critically involved in regulating HSPC retention, migration, proliferation and lineage bias ${ }^{34}$. Finally, GSEA documented a metabolic switch from glycolysis in LSK from exercising mice towards oxidative phosphorylation in sedentary mice (Fig. 3r), which typically occurs if HSPC transition from quiescence towards proliferation ${ }^{35}$.

\section{Exercise augments emergency hematopoiesis and improves survival in sepsis}

Given our finding that exercise reduces circulating leukocytes and that clearance of infections relies on swift leukocyte supply, we wondered if this relative leukopenia exposes the host to a greater risk from infections, as described after acute exercise $\mathrm{s}^{36,37}$. To explore if physical activity alters emergency hematopoiesis, we challenged mice with intraperitoneal injections of lipopolysaccharide (LPS), a bacterial cell wall component that induces the inflammatory responses in sepsis. Runners' hematopoietic progenitors responded vigorously with a 1.4-fold increase of colony-forming units compared to sedentary littermates (Fig. 4a,b). Higher HSPC numbers (Fig. 4c) gave rise to more neutrophils, monocytes, B cells and $\mathrm{T}$ cells in the blood and peritoneal cavity (Fig. 4d,e). When exposed to sepsis after cecal ligation and puncture, exercising mice had a significantly lower mortality than sedentary mice (Fig. $4 \mathrm{f}-\mathrm{h}$ ). These findings, together with the earlier observation that exercise increases macrophage inflammatory cytokine production ${ }^{38}$, argue against a compromised immune response in individuals that exercise regularly, and indicate that exercise does not inhibit emergency hematopoiesis in the setting of infection.

\section{Leptin receptor deletion dampens infarct inflammation}

In cardiovascular disease, emergency hematopoiesis is triggered by organ ischemia; we therefore studied how exercise influences the hematopoietic response after acute myocardial infarction (MI). Leptin increases in the blood of patients ${ }^{39,40}$ and in the blood and tibia of mice with MI (Fig. 5a). On day 6 after MI, leptin levels were comparable in exercising and sedentary mice (Extended Data Fig. 9a,b). Leukocyte numbers in the acute infarct did not change with exercise and rose further with leptin minipump supplementation (Extended Data Fig. 9c,d). Functional post-MI recovery was similar between sedentary and exercising mice (Extended Data Fig. 9e). Disrupting post-MI leptin sensing by stromal bone marrow niche cells in $\operatorname{PrX} 1$-creER ${ }^{\mathrm{T} 2}:$ Lepr $^{\mathrm{fl}}{ }^{\mathrm{fl}}$ mice augmented production of hematopoietic niche factors and reduced LSK proliferation (Fig. 5b-d). Marrow harvested from PrX1$\operatorname{creER}^{\mathrm{T} 2}:$ Lepr $^{\mathrm{fl} / \mathrm{fl}}$ mice after MI gave rise to fewer colonies (Fig. 5e). As a result of blunted post-MI emergency hematopoiesis, systemic and cardiac leukocyte numbers declined in $\operatorname{Pr} \times 1$-creER ${ }^{\mathrm{T} 2}:$ Lepr $^{\mathrm{fl} / \mathrm{fl} \mathrm{l}}$ mice (Fig. $5 \mathrm{f}, \mathrm{g}$ ). Such dampening of emergency hematopoiesis was replicated by leptin-neutralizing antibody treatment 30 minutes after MI, which decreased bone marrow colony forming units, GMP proliferation and monocytes in the blood and infarct (Extended Data Fig. 9f-j). In accord with clinical data correlating post-MI leukocyte levels with heart failure severity ${ }^{41}$ and post-MI outcomes ${ }^{42}$, reduced leukocytosis in PrX1$\operatorname{creER}^{\mathrm{T} 2}:$ Lepr $^{\mathrm{f} 1 / f 1}$ mice improved recovery and reduced heart failure post-MI, indicated by 
lower ventricular volumes and preserved ejection fraction measured by magnetic resonance imaging 3 weeks after MI (Fig. 5h-j). Histological analyses of the infarct border zone 7 days after MI indicated that this improved recovery is due to faster resolution of inflammation and lessened fibrosis (Extended Data Fig. 9k,1). Taken together, these data indicate that exercise does not inhibit emergency hematopoiesis after acute MI; however, disruption of leptin signaling by deleting its receptor exerts beneficial effects on post-MI recovery via dampening leukocyte supply to the heart.

\section{Sedentary lifestyle accelerates leukocyte supply in mice and patients with atherosclerosis}

Systemic leukocyte availability correlates with atherosclerosis severity in mice ${ }^{43}$ and humans $^{3}$, exercise prevents atherosclerotic plaque initiation ${ }^{13}$ and progression ${ }^{14,15}$ and a sedentary life style associates strongly with cardiovascular risk. Since we found that physical activity in healthy mice influences leukocyte supply, we argued that exercise, at least to some extent, affects atherosclerosis via dampening of leukocyte production and plaque inflammation. We thus gave $\mathrm{ApoE}^{-/-}$mice with established atherosclerosis access to running wheels, which significantly reduced blood and tibial leptin concentration, inhibited progression of hyperlipidemia-associated leukocytosis, lowered immune cell accumulation in the aorta and decreased the size of atherosclerotic plaques in the aortic root (Fig. 6a-j). To examine the role of leptin in atherosclerosis mechanistically, we induced atherosclerosis in PrX 1 -creER ${ }^{\mathrm{T} 2}:$ Lepr $^{\mathrm{fl} / \mathrm{fl}}$ mice using a combination of atherogenic diet and PCSK9 AAV. Compared to littermate $L e p r^{\text {fl/fl }}$ controls, deletion of the leptin receptor resulted in reduced atherosclerotic plaque size and macrophage content (Extended Data Fig. 10a-d).

Mechanistically, this was tied to lower HSC and GMP proliferation and reduced circulating neutrophils and monocytes (Extended Data Fig. 10e-h). Of note, in contrast to mice without atherosclerosis, we here observed exercise effects even on the level of $\mathrm{CD} 48^{-} \mathrm{CD} 150^{+}$longterm HSC, possibly because of combined effects of hyperlipidemia, atherosclerosis and sedentary behavior.

These observations raised the question whether exercise also has beneficial effects on hematopoiesis in patients with existing CVD. We assessed the association between selfreported exercise and plasma leptin levels or the total white blood cell count measured at baseline among 4,892 participants in the Canakinumab Anti-inflammatory Thrombosis Outcomes Study (CANTOS) that enrolled individuals who had sustained an $\mathrm{MI}^{2}$. Plasma levels of leptin and the total leukocyte count were lower among CANTOS participants who exercised 4 or more times per week as compared to those with lower exercise levels $(\mathrm{P}<0.001$ in both univariate and multivariate analyses, Fig. 6k). CVD patients enrolled in the Athero-Express Study ${ }^{44}$ showed a similar relationship between blood leukocyte numbers, leptin and physical activity even when corrected for age, sex, BMI, smoking, diabetes, hypercholesterolemia and statin use (Fig. 61, Extended Data Fig. 10i, Supplementary Table $3-5)$. The association observed in two independent clinical cohorts, viewed together with the data obtained in mice, indicates that physical activity exerts beneficial effects on leptin and leukocytosis in CVD patients. 


\section{Discussion}

Our preclinical data show that voluntary physical activity protects against CVD via reduced chronic hematopoietic output of inflammatory leukocytes, due to diminished leptin signaling to the stromal hematopoietic bone marrow niche (Fig. 6m). Leptin levels increase when energy is abundant ${ }^{45}$. The hormone's role in regulating energetically costly hematopoiesis may have evolved to produce blood cells at times of resource sufficiency. However, contemporary sedentary behavior, which increases leptin and consequently hematopoiesis, may have rendered this adaption a risk factor for CVD, and perhaps also for other diseases with inflammatory components.

The leukocyte reduction in voluntary-running mice contrasts sharply with increased hematopoiesis, increased cell mobilization from the marrow and leukocytosis reported for forced endurance training $17,19,20$. This difference may arise from exercise intensity and the stressful electric shocks used to enforce running ${ }^{17,20}$. Such stress may activate sympathetic signaling and consequently accelerate HSPC proliferation ${ }^{6}$.

The associations between sedentary life style, leptin and leukocyte levels in the two independent, large cardiovascular patient cohorts we describe here extend previous human data ${ }^{24,25,46,47}$ and support the clinical relevance of the pathways we target in sedentary mice. In accord with these clinical data, leukocytosis and plaque size increase in sedentary mice with established atherosclerosis. The observed health benefits of physical activity are likely multifactorial and not limited to leptin-dependent regulation of hematopoiesis. Since exercise improves sepsis survival in mice, molecular alterations produced by voluntary running may inform anti-inflammatory drug discovery by identification of targets that do not compromise host defenses.

The insight that regular voluntary physical activity reduces hematopoiesis illuminates a new pathway by which sedentary lifestyle contributes to cardiovascular risk via oversupply of disease-promoting leukocytes. These data also support the notion that physical activity lessens existing chronic inflammation. Implementing guidelines ${ }^{48}$ that recommend $150 \mathrm{~min}$ of exercise per week and the development of drugs that mimic the effects of voluntary exercise on hematopoiesis offer modalities to mitigate inflammation in cardiovascular disease.

\section{Methods \\ CANTOS.}

We assessed for evidence of association between self-reported exercise and plasma levels of leptin or the total white blood cell count measured at baseline among 4,892 participants in the Canakinumab Anti-inflammatory Thrombosis Outcomes Study (CANTOS) who had a prior history of myocardial infarction and who were receiving aggressive secondary preventive care including high-intensity statin therapy ${ }^{2}$. Leptin levels (R\&D Systems) and the total leucocyte count were evaluated in a central laboratory while exercise levels were categorized as rarely, 1 to 3 sessions per week, 4 to 6 sessions per week, or daily. Tests for significance across exercise categories were evaluated in univariate analyses using the 
Kruskal-Wallis test, while multivariate regression analyses were used to address for effects after adjustment for age, gender, body mass index, education level, history of heart failure and hemoglobin A1c. The study protocol was approved at participating centers by the responsible institutional review board or ethics committee, as applicable in the 39 countries involved.

\section{Athero-Express.}

All patients included in the present analysis were enrolled in the Athero-Express Biobank Study $(\mathrm{AE})^{44,49}$. The AE is an ongoing, longitudinal biobank that combines blood and atherosclerotic plaque specimens with baseline characteristics and three-year follow-up data from patients undergoing surgical revascularization to treat carotid or ilio-femoral stenosis. Patient characteristics were obtained through standardized preoperative questionnaires and preoperative admission charts. All patients underwent surgery between 2005 and 2016 in the University Medical Center Utrecht (UMCU). Indication for surgery was based on international guidelines for carotid and peripheral surgical revascularization ${ }^{50}$. This study was conducted in accordance with the Declaration of Helsinki, and all patients provided written informed consent. Patients were first stratified into two groups based on the information provided in response to the question about whether they performed any exercise. Patients who did not perform any exercise served as the reference group. To study dosedependent effects of exercise, patients were further stratified into tertiles based on the number of hours exercised per week. A flowchart of the study design is provided in Extended Data Fig. 10i. Hematological measurements were obtained from the Utrecht Patient Orientated Database (UPOD) ${ }^{51}$. Hematological parameters were measured using the Abbott CELL-DYN Sapphire (Abbott Diagnostics) ${ }^{52,53}$.

Leptin measurements were performed in 44 patients per exercise group on blood drawn before surgeries. A custom-built Leptin Human Magnetic Luminex Assay (Standard Curve $493-119830 \mathrm{pg} / \mathrm{mL}$, sensitivity $10.2 \mathrm{pg} / \mathrm{mL}, \mathrm{R} \& \mathrm{D}$ Systems) was used in combination with the Bio-Plex Multiplex system (Bio-Rad). Analyses were performed according to the manufacturers' protocol. Patients with Leptin levels that were below the detection limit of the assay $(n=2)$ were excluded.

Patients were categorized in four exercise groups, based on hours of exercise per week. Differences in binary characteristics between the four groups were analyzed with Pearson's Chi square test. Differences in continuous variables among the four groups were tested using one-way analysis of variance. White blood cell counts were compared among groups using one-way analysis of variance and multivariate linear regression models. Possible confounders were selected based on differences in baseline characteristics among the four exercise groups, and association with the hematologic parameter of interest ( $\mathrm{p}$ value $<0.10$ ). SPSS 21.0 (SPSS Inc) was used for all statistical analyses. The study protocol was approved by the medical ethics committee of the UMCU.

\section{Mice.}

Seven- to eight-week-old male C57BL/6J mice were used for exercise studies if not indicated otherwise. UBC-GFP (C57BL/6-Tg(UBC-GFP)30Scha/J, 004353), CD45.1 
(B6.SJL-Ptprc ${ }^{\mathrm{a} P e p c}$ /BoyJ, 002014) and $\mathrm{ApoE}^{-/-}$mice (B6.129P2-Apoe $\mathrm{tm}^{\mathrm{tm} \text { Unc/J, 002052) }}$ were purchased from The Jackson Laboratory. Stromal cell reporter mice (Nestin-GFP ${ }^{54,55}$, LeptinRcre-R26-YFP or R26-Tdtomato ${ }^{27,56}$ and OCN-GFPtopaz 57, CD45.1 ${ }^{\text {STEM }}$ mice $^{29}$ and Prx1-creER ${ }^{\text {T2 }}$-(B6.Cg-Tg(Prrx1-cre/ERT2,-EGFP)1Smkm/J; JAX: 029211) crossed with Lepr $^{\mathrm{fl}}$ (B6.129P2-Lepr ${ }^{\mathrm{tm} 1 \mathrm{Rck} / J}$; JAX: 008327) were bred in-house. Genotyping for each strain was performed as described on the Jackson Laboratory website. For the Nestin-GFP and OCN-GFP ${ }^{\text {topaz }}$ mice, we used genotyping primers that target specifically the GFP construct (Forward primer: 5'-CTGGTCGAGCTGGACGGCGACGTAAC-3'; Reverse primer: 5'-ATTGATCGCGCTTCTCGTTGGGG-3'). For inducible deletion of the leptin receptor, we intraperitoneally administered $75 \mathrm{mg} / \mathrm{kg}$ tamoxifen (T5648, Sigma-Aldrich) dissolved in corn oil (C8267, Sigma-Aldrich), according to the Jackson laboratory protocol, every second day for 5 days ( 3 injections total). In all experiments, littermate control mice were subjected to the same tamoxifen regimen.

For atherosclerosis experiments in Lepr ${ }^{\mathrm{fl} / \mathrm{fl}}$ and Prx $1-\mathrm{creER}^{\mathrm{T} 2}:$ Lepr $^{\mathrm{fl} / \mathrm{fl}}$ strains, mice received a single IV injection of AAV-PCSK9 ( $10^{12}$ genome copies in $200 \mu \mathrm{L}$ of PBS 2 weeks after the initial tamoxifen injections as described previously ${ }^{58}$. pAAV/D377Y-mPCSK9 was a gift from Jacob Bentzon (Addgene plasmid \#58376; http://n2t.net/addgene:58376 ;

RRID:Addgene_58376). Following AAV-PCSK9 injection, mice were placed on a high fat diet (D12108C, Research Diets Inc.) and underwent single injections of $75 \mathrm{mg} / \mathrm{kg}$ tamoxifen at 4 and 8 weeks after start of high fat diet.

All mice were housed in separate cages in a pathogen-free environment of the Massachusetts General Hospital animal facility and maintained on a 12-hour light/dark cycle with a room temperature of $22 \pm 1^{\circ} \mathrm{C}$. Mice received standard mouse chow and water ad libitum, except for $\mathrm{ApoE}^{-/-}$mice, which consumed a Western-type diet (TD.88137, Teklad Custom Diets, Envigo), and mice subjected to IV AAV-PCSK9 injections, which were fed an atherogenic diet (D12108C, Research Diets Inc.). All experiments were approved by the Subcommittee on Animal Research Care at Massachusetts General Hospital. All efforts were made to minimize suffering. If not bred in-house, mice were acclimatized for 1-2 weeks before experiments. Mice were randomized to experimental groups; $\mathrm{ApoE}^{-/-}$mice were randomized according to leukocyte blood levels and weight at the beginning of exercise. The analysis of the effect of exercise prior to cecal ligation and puncture and myocardial infarction, as well as the effect of leptin inhibition after myocardial infarction were done in a blinded fashion.

\section{Voluntary running wheels.}

Mice were individually housed in cages with low-profile wireless running wheels (ENV-047, Med Associates) for 6 or 10 weeks. These open surface running wheels enabled unobstructed running by mice with mini-osmotic pump implantations. Sedentary mice were also single housed without running wheels but received a similar-size igloo for enrichment. We initially housed mice with fixed running wheels in our pilot study but did not find a significant difference to housing mice with igloos. 


\section{Sepsis induction.}

LPS ( $0.5 \mathrm{mg} / \mathrm{kg}$, from Escherichia coli 055:B5, Sigma-Aldrich) was administered

intraperitoneally to mice that either had or had not previously exercised for six weeks. Cecal ligation and puncture, a model for sepsis, was carried out as previously described ${ }^{59}$. In brief, a small incision was made to open the peritoneal cavity under general anesthesia (1-2\% isoflurane) and the cecum was exteriorized and ligated at $\sim 30 \%$ of the cecum with a nonabsorbable 7-0 suture. The distal end of the cecum was perforated using a $23 \mathrm{G}$ needle, and a small amount of feces was extruded through the puncture. The cecum was relocated into the peritoneal cavity, and the peritoneum was closed with sutures. Mice received buprenorphine prior to surgery and twice daily thereafter for the first three days. $1 \mathrm{~mL}$ of saline was administered intraperitoneally to alleviate fluid loss. Rectal temperature was measured by inserting a temperature sensor under anesthesia.

\section{Myocardial infarction.}

For myocardial infarction, thoracotomy was performed in the fourth left intercostal space. The left coronary artery was identified and permanently ligated with a monofilament nylon 8-0 suture. The thorax wound was then closed with sutures. Throughout the experiment mice were intubated and ventilated with $2 \%$ isoflurane supplemented with oxygen. Anti-leptin antibody (AF498) or IgG isotype control antibody (AB-108-C, both R\&D Systems) were administered at a concentration of $1 \mathrm{mg} / \mathrm{kg}, 30$ minutes after coronary artery ligation. AF498 has previously been shown to block binding of leptin to its receptor in C57BL/6J mice ${ }^{60}$.

\section{Osmotic minipump implantation.}

Osmotic pumps (Model 2006, Alzet) were implanted subcutaneously via a small incision between the scapulae, under general anesthesia (1-2\% isoflurane). Subcutaneous connective tissue was spread to create a pocket for the pump. After pump insertion, the wound was closed with sutures. Animals were given buprenorphine $(0.1 \mathrm{mg} / \mathrm{kg}$ s.c.) before surgery and twice daily for the first 72 hours after implantation. Experiments were started 72 hours after implantation to allow pumping rate to reach a steady state and to avoid any effect of surgery on exercise motivation. Pump filling was performed according to manufacturer's protocol. The rate of infusion was $0.15 \mu \mathrm{l} / \mathrm{hour}$, which delivers $0.3 \mathrm{mg} / \mathrm{kg} /$ day leptin for a period of 6 weeks. This dose was previously shown to not affect locomotor activity, weight gain, food intake and insulin or glucose levels ${ }^{61}$. Recombinant leptin (498-OB, R\&D Systems) was dissolved in saline for infusion. To verify delivery, serum leptin levels and residual pump volume were routinely confirmed at the end of the experiment.

\section{Tissue processing.}

Peripheral blood was collected by retro-orbital bleeding using heparinized capillary tubes (BD Biosciences). For flow cytometry analysis, red blood cells were lysed with 1x red blood cell lysis buffer (BioLegend). Blood was sampled and analyzed by automated complete blood count for the platelets, red blood cells, hemoglobin and hematocrit on the Element Ht5 Auto Hematology analyzer. For organ harvest, mice were perfused through the left ventricle with $20 \mathrm{~mL}$ of ice-cold PBS. 
Bone marrow for qPCR analysis and bone marrow plasma was isolated by centrifugation. The metaphysis of one end of the tibia was removed, and the bone was spun with this 'open end' facing down at $6000 \mathrm{~g}$. For bone marrow plasma, the bone marrow pellet of one tibia was resuspended in $100 \mathrm{uL}$ PBS, spun down again and supernatant was kept for ELISA at $-80{ }^{\circ} \mathrm{C}$. For qPCR analysis, bone marrow was stored in RLT buffer (Qiagen) at $-80{ }^{\circ} \mathrm{C}$ for further analysis. For flow cytometry analysis, bone marrow from the femurs was flushed with FACS buffer (1x PBS supplemented with $0.5 \%$ BSA). For the LSK and stromal cell sorts, we isolated bone marrow of all long bones and pelvis. For stromal cell isolations, the bone marrow fraction was digested to isolate nestin ${ }^{+}$and $\mathrm{LepR}^{+}$cells, and the bone fraction was digested to isolate $\mathrm{OCN}^{+}$and nestin+ cells. The bone marrow fraction was isolated by flushing the bone marrow plug with a syringe into PBS supplemented with 2\% FBS. After the bone marrow plug sank to the bottom of tube, the supernatant was removed and replaced by the digestion mix: $1 \mathrm{mg} / \mathrm{ml}$ collagenase IV (Sigma Aldrich, C5138), 2mg/ml Dispase (Gibco by Life technology, 17105-041) and $5 \mu \mathrm{l} / \mathrm{ml}$ DNAse I (Thermo scientific, 90083) in HBSS buffer (Gibco by Life Technology, 14025-092). The bone marrow plug was digested 3 $\times 15$ minutes at $37^{\circ} \mathrm{C}$, as previously described ${ }^{62}$. Bones without the bone marrow plug were crushed and then cut in small pieces on a $70 \mu \mathrm{m}$ cell strainer. Cells were washed with PBS supplemented with $2 \% \mathrm{FBS}$, and the bone fraction was collected and digested with Collagenase I (Stem Cell Technology, 07902), $2 \mathrm{mg} / \mathrm{mL}$ Dispase and $5 \mu \mathrm{l} / \mathrm{ml}$ DNAse I for 45 minutes at $37^{\circ} \mathrm{C}$ under agitation (120 rpm).

Peritoneal cells were recovered by lavage with $10 \mathrm{~mL}$ of ice-cold PBS supplemented with $2 \mathrm{mM}$ EDTA. Spleens were triturated, filtered through a $40 \mu \mathrm{m}$ filter to obtain single-cell suspensions and red blood cells were lysed with 1x red blood cell lysis buffer (BioLegend). Visceral adipose tissue (VAT) was either snap frozen for qPCR analysis or minced into small pieces and subjected to enzymatic digestion according to Orr et al. ${ }^{63}$ for flow cytometry. Briefly, no more than 300mg VAT was subjected to enzymatic digestion in $1 \mathrm{~mL}$ digestion mix (1x PBS supplemented with $0.5 \%$ BSA, $10 \mathrm{mM} \mathrm{CaCl}_{2}$ and $4 \mathrm{mg} / \mathrm{mL}$ collagenase type II, Worthington Biochemical Corporation) for 20 minutes at $37{ }^{\circ} \mathrm{C}$ under agitation (200 rpm).

Infarct and border zone heart tissue and abdominal aortas were minced into small pieces and subjected to enzymatic digestion with $450 \mathrm{U} / \mathrm{mL}$ collagenase I (C0130), $125 \mathrm{U} / \mathrm{mL}$ collagenase XI (C7657), $60 \mathrm{U} / \mathrm{mL}$ DNase I (D5319) and $60 \mathrm{U} / \mathrm{mL}$ hyaluronidase (H3506, all Sigma-Aldrich) for 30 minutes at $37^{\circ} \mathrm{C}$ under agitation (750 rpm). Gastrocnemius muscle was minced into small pieces and subjected to enzymatic digestion with $5 \mathrm{mg} / \mathrm{mL}$ collagenase type II and $60 \mathrm{U} / \mathrm{mL}$ DNase I (Sigma, D5319) in PBS supplemented with 2 $\mathrm{mg} / \mathrm{ml}$ glucose and $50 \mathrm{mM} \mathrm{CaCl}_{2}$. All digested tissues were then triturated and filtered through a $40 \mu \mathrm{m}$ (heart, spleen, muscle) and $70 \mu \mathrm{m}$ (VAT) nylon mesh (Falcon), washed and centrifuged to obtain single-cell suspensions.

\section{Flow cytometry.}

All single cell suspensions were stained at $4{ }^{\circ} \mathrm{C}$ in $300 \mu$ FACS buffer (1x PBS supplemented with $0.5 \% \mathrm{BSA})$. For HSPC staining, isolated bone marrow cells were first stained with biotin-conjugated anti-mouse antibodies directed against mouse hematopoietic lineage markers, including CD3 (100304, clone 145-2C11), CD4 (100404, clone GK1.5), CD8a (100704, clone 53-6.7), CD49b (108904, clone DX5), CD90.2 (105304, clone 30- 
H12), CD19 (115503, clone 6D5), B220 (103204, clone RA3-6B2), NK1.1 (108704, clone PK136), TER119 (116204, clone TER-119), CD11b (101204, clone M1/70), CD11c (117304, clone N418), Gr1 (108404, clone RB6-8C5; all 1:300, BioLegend). This was followed by a second staining with antibodies for CD16/32-BV711 (101337, clone 93), CD34-FITC (553733, clone RAM34, 1:150, BD Biosciences), CD48-AF700 (103426, clone HM48-1), CD115-BV421 (135513, clone AFS98), CD150-PerCP/Cy5.5 (115922, clone TC15-12F12.2), c-kit-PE/Cy7 (105814, clone 2B8), Sca-1-BV605 (108133, clone D7), streptavidin-APC/Cy7 (405208; all 1:300, BioLegend unless otherwise indicated). Where applicable, cells were further stained with BrdU-APC (1:50, 552598, BD Biosciences) and Ki-67-FITC (11-5698-82, clone SolA15, Thermo Fisher Scientific) during the corresponding manufacturer's staining protocols. For aortic and cardiac leukocyte staining, cells were first stained with PE-conjugated mouse hematopoietic lineage markers: B220 (103208, clone RA3-6B2), CD19 (115508, clone 6D5), CD3 (100206, clone 17A2), CD90.2 (140308, clone 53-2.1), and for cardiac leukocytes additionally CD49b (108908, clone DX5), CD103 (121406, clone 2E7), NK1.1 (108708, PK136) and Ter119 (116208, clone TER-119; all 1:300, BioLegend). This was followed by a second staining for CD11b-APC (101212, clone M1/70), CD45-BV711 (103147, clone 30-F11), F4/80-PECy7 (1:150, 123114, clone BM8), Ly-6C-BV605 (128035) and Ly-6G-FITC (127605; all 1:300 unless indicated otherwise, BioLegend). For blood and bone marrow leukocyte staining, cells were stained with B220PE/Cy7 (103222, clone RA3-6B2) or B220-APC/Cy7 (103224, clone RA3-6B2), CD3-PE (100206, clone 17A2), CD4-PerCP/Cy5.5 (100434, clone GK1.5), CD8a-BV711 (100748, clone 53-6.7), CD19-PE/Cy7 (115520, clone 6D5) or CD19-APC/Cy7 (115530, clone 6D5), CD45-BV711 (103147, clone 30-F11) or CD45.2-AF700 (109822, clone 104), CD90.2-PE (140308, clone 53-2.1), Ly-6C-BV605 (128035, clone HK1.4), Ly-6G-FITC (127605, clone 1A8), CD11b-APC (101212, clone M1/70), and NK1.1-APC/Cy7 (108730, clone PK136, 1:300), CD115-BV421(135513, clone AFS98; all 1:600 unless indicated otherwise, BioLegend). Blood and bone marrow leukocyte staining samples were fixed with BD Cytofix (BD Biosciences) and analyzed within 24 hrs.

All cells were routinely incubated with a viability dye (FxCycle ${ }^{\mathrm{TM}}$ Violet Stain, F10347, or LIVE/DEAD ${ }^{\circledR}$ Fixable Aqua Dead Cell Stain Kit for 405 nm excitation, L-34966, both Thermo Fisher Scientific, or 7-AAD, 559925, BD Biosciences) and anti-CD16/32 Fc block (553142, BD Biosciences; except HSPC staining), according to the manufacturer's protocol.

All cells were pregated on viable and single cells (FSC-A vs FSC-W, and SSC-A vs SSCW). LSK were identified as $\mathrm{Lin}^{-} \mathrm{c}-\mathrm{kit}^{+} \mathrm{Sca}-1^{+}$. These were further divided into long-term hematopoietic stem cells (LT-HSCs; $\mathrm{Lin}^{-} \mathrm{c}-\mathrm{kit}^{+} \mathrm{Sca}-1^{+} \mathrm{CD} 150^{+} \mathrm{CD} 48^{-}$), short-term HSCs (ST-HSCs; Lin $^{-}$c-kit ${ }^{+}$Sca-1 ${ }^{+}$CD150 ${ }^{-} \mathrm{CD}^{-} 8^{-}$) and multipotent progenitors (MPPs; Lin ${ }^{-}$c$\mathrm{kit}^{+} \mathrm{Sca}-1^{+} \mathrm{CD} 150^{-} \mathrm{CD} 48^{+}$). Common myeloid progenitors (CMP) were identified as Lin ${ }^{-}$ c-kit ${ }^{+}$Sca-1- CD16/32 mid CD34 ${ }^{+}$, megakaryocyte erythroid progenitors (MEP) as Lin ${ }^{-}$c-kit ${ }^{+}$Sca-1- CD16/32- CD34-, granulocyte macrophage progenitors (GMP) as $\mathrm{Lin}^{-} \mathrm{c}^{-} \mathrm{kit}^{+}$ Sca-1- CD16/32+ CD34+, macrophage and dendritic cell progenitors (MDP) as Lin $^{-}$c-kit $^{+}$ Sca-1 ${ }^{-}$CD16/32 ${ }^{+} \mathrm{CD}_{34}{ }^{+} \mathrm{CD} 115^{+}$and B cell progenitors (B cell prog) as $\mathrm{Lin}^{-} \mathrm{IgM}^{-} \mathrm{IgD}^{-}$ B220+. Monocytes were identified as B220 ${ }^{-} \mathrm{CD}^{-}$CD19- CD90.2 ${ }^{-} \mathrm{NK}^{-} 1^{-} \mathrm{Ly}^{-6 \mathrm{G}^{-}} \mathrm{SSC}^{\text {low }}$ $\mathrm{CD}_{11 b^{+}} \mathrm{CD} 115^{+}$, neutrophils as B220- CD3- CD19- CD90.2- $\mathrm{NK} 1.1^{-} \mathrm{CD}^{-} 15^{-} \mathrm{SSC}^{\text {low }}$ $\mathrm{CD}_{11 b^{+}} \mathrm{Ly}_{-} 6 \mathrm{G}^{+}$, NK cells as B220- $\mathrm{CD}^{-} \mathrm{CD}^{-} 9^{-} \mathrm{CD}^{-} 0.2^{-} \mathrm{CD}^{-115^{-}} \mathrm{Ly}^{-6 \mathrm{G}^{-}} \mathrm{SSC}^{\mathrm{low}}$ 
$\mathrm{CD} 11 \mathrm{~b}^{+} \mathrm{NK} 1.1^{+}$, eosinophils as B220- ${ }^{-} \mathrm{CD} 3^{-} \mathrm{CD} 19^{-} \mathrm{CD} 90.2^{-} \mathrm{CD}^{-115^{-}} \mathrm{Ly}^{-6 \mathrm{G}^{-}} \mathrm{NK} 1.1^{-}$

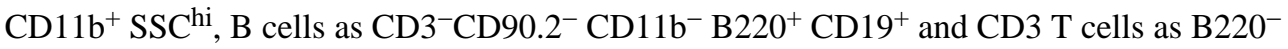
$\mathrm{CD}^{-} 9^{-} \mathrm{CD} 11 \mathrm{~b}^{-} \mathrm{CD}^{+} \mathrm{CD} 90.2^{+}$. $\mathrm{CD} 3 \mathrm{~T}$ cells were further subdivided into $\mathrm{CD} 4^{+}$and $\mathrm{CD} 8^{+}$ T cells. Osteolineage cells $\left(\mathrm{OCN}^{+}\right)$cells were identified as $\mathrm{CD}^{-} 5^{-} \mathrm{Ter} 119^{-} \mathrm{CD} 31^{-} \mathrm{GFP}^{+}$of OCN-GFP mice. Leptin receptor $\left(\mathrm{LepR}^{+}\right)$cells were identified as $\mathrm{CD}^{-} 5^{-}$Ter119- ${ }^{-} \mathrm{CD}^{-}$ $\mathrm{YFP}^{+}$or TdTomato ${ }^{+}$of LeptinRcre-R26-YFP or -Tdtomato mice. Nestin ${ }^{+}$cells were were identified as CD45- Ter119- CD31- GFP $^{+}$of Nestin-GFP mice. Endothelial cells were identified as $\mathrm{CD}^{-} 5^{-}$Ter119- $\mathrm{CD} 31$ of the bone marrow fraction of Nestin-GFP mice. For compensation, the aforementioned antibodies were conjugated to OneComp eBeads (01-1111-42, Affymetrix Inc). Unstained, $\mathrm{YFP}^{+}, \mathrm{GFP}^{+}$and TdTomato ${ }^{+}$control samples were used for compensation and to control the gating strategy. All data were acquired on an LSRII (BD Biosciences) and analyzed with FlowJo software. Please also see the Life Sciences Reporting Summary for additional information.

\section{Cell sorting and transplantation.}

To purify bone marrow stromal cells, samples were stained with CD31-BUV737 (565097, BD Biosciences), CD45-APC/Cy7 (103116, Biolegend), Ter119-APC/Cy7 (560509, BD Biosciences), 7-AAD (BD Biosciences) and FAC-sorted with a FACSAria II cell sorter (BD Biosciences).

To purify LSK, a PE-lineage depletion was performed with MACS columns (130-042-401, Miltenyi Biotec), according to the manufacturer's protocol. Briefly, single cell suspensions were stained with a lineage cocktail of PE-conjugated antibodies: CD3 (100206, clone 17A2), CD4 (130310, clone H129.19), CD8 (100708, clone 53-6.7), CD49b (108908, clone DX5), CD90.2 (140308, clone 53-2.1), CD19 (115508, clone 6D5), B220 (103208, clone RA3-6B2), NK1.1 (108708, clone PK136), TER119 (116208, clone TER-119), CD11b (101208, clone M1/70), CD11c (117308, clone N418), Gr1 (108408, clone RB6-8C5; all 1:150, BioLegend), followed by incubation with anti-PE microbeads (130-048-801, Miltenyi Biotec). Lineage-depleted bone marrow cells were then stained with CD48-AF700 (103426, clone HM48-1), CD150-PerCP/Cy5.5 (115922, clone TC15-12F12.2), c-kit-PE/Cy7 (105814, clone 2B8), Sca-1-BV605 (108133, clone D7; all 1:150, all BioLegend) and FACsorted using a FACSAria II cell sorter (BD Biosciences).

All cells were pregated on single cells (as determined by FSC-A vs FSC-W, and SSC-A vs SSC-W) and viable cells (DAPI ${ }^{-}$for $\mathrm{LSK}$ and $7 \mathrm{AAD}^{-}$for stromal cells).

For bone marrow transplantations, each lethally irradiated $(9.5 \mathrm{~Gy})$ recipient UBC-GFP mouse received 5,000 LSK of exercising CD45.2C57BL/6J mice and 5,000 LSK of sedentary CD45.1 ${ }^{\text {STEM }}$ mice. Each recipient CD45.1 ${ }^{\text {STEM }}$ mouse received 5.000 LSK of post-exercise sedentary GFP mice and 5,000 LSK of either sedentary or exercising CD45.2 C57BL/6J mice. Additionally, 500,000 bone marrow cells of a UBC-GFP mouse or CD45.1 ${ }^{\text {STEM }}$ mouse were transferred matching the recipient mouse. We used CD45.1 ${ }^{\text {STEM }}$ mice for competitive transplantation as these are equivalent in competitive bone marrow transplantation assays to CD45.2 C57BL/6J mice ${ }^{50}$. 


\section{Real-time qPCR.}

Total RNA from tissues was extracted using the RNeasy Mini kit (74104, Qiagen) and from FACS-purified cells using the NucleoSpin RNA XS kit (740902.50, Takara Bio), according to the manufacturers' protocols. RNase-free DNase Set (79254, Qiagen) was used for DNase digestion during RNA purification. RNA quality was assessed by nano drop for RNA isolated from tissues and with the Agilent RNA 6000 Pico kit (5067-1513, Agilent Technologies) on the Agilent 2100 Bioanalyzer for RNA of FACS-purified cells. First-strand cDNA was synthesized using the High-Capacity RNA-to-cDNA kit (4387406, Applied Biosystems). TaqMan gene expression assays were used to quantify target genes, using TaqMan Fast Universal PCR Master Mix (4366072, Applied Biosystems) and primers for Cxcl12(Mm00445553_m1), Vcam1 (Mm01320970_m1), Scf(Mm00442972_m1), Angpt1 (Mm00456503_m1), II1b(Mm00434228_m1), Pfa4 (Mm00451315_g1), Ccl2 (Mm00441242_m1), Il6(Mm00446190_m1), II7(Mm01295803_m1), Tgfb1 (Mm01178820_m1), Csf1 (Mm00432686_m1), Csf2 (Mm01290062_m1), Csf3 (Mm00438334_m1), Osx (Sp7, Mm01266652_m1), Ocn (Bglap, Mm03413826_mH), Runx2(Mm00501584_m1), Lpl(Mm00434764_m1), Fabp4 (Mm00445878_m1), Leptin (Mm00434759_m1) (all FAM probes, Applied Biosystems) and Actb (4352341E, VIC probe, Applied Biosystems). Samples were run on a 7500 thermal cycler (Applied Biosystems) and the relative changes were normalized to Actb mRNA using the 2-DDCT method and normalized to sedentary controls.

\section{Assay for transposase-accessible chromatin using sequencing (ATAC-seq).}

Sorted LSKs underwent ATAC-seq as previously described ${ }^{64,65}$. Briefly, 20.000 sorted LSK cells were initially resuspended in lysis buffer and centrifuged. The nuclei pellets were then subjected to transposition reaction using the Nextera Tn5 transposase enzyme (Illumina). Tagmented DNA was purified with the MinElute PCR Purification Kit and eluted in $10 \mu \mathrm{L}$ of elution buffer (Qiagen). Barcoded libraries were prepared and PCR amplified. Doublesided bead purification was performed using AMPure XP beads to remove primer dimers and large $>1,000 \mathrm{bp}$ fragments. Libraries were sequenced $50 \mathrm{bp}$ paired end on an Illumina HiSeq 2500.

Sequencing reads were first mapped to mm10 reference genome using BWA-MEM ${ }^{66}$ with default parameters, followed by calling peaks using HOTSPOT $2{ }^{67}$. As a result, at each time point we identified $8000-10000$ peaks, which showed high consistency between biological duplicates. The union of these peak sets (14313 peaks total) was used to calculate the ATACseq coverage over each peak region across all samples. Peaks with differential accessibility between conditions were identified using edge $\mathrm{R}^{68}$, with the cutoffs of at least 1.5 -fold difference in normalized read density and $\mathrm{FDR}<0.01$.

\section{RNA-seq.}

LSK were sorted and RNA was isolated as described above and sequencing-ready cDNA libraries were prepared using the Takara SMART-Seq v4 kit, paired with the NexteraXT Library Prep kit for Illumina, following the manufacturer's protocol. Bioanalyzer DNA High Sensitivity traces were used to confirm cDNA size distribution after the SMART-Seq step, and Agilent High Sensitivity D1000 Tapestation traces were used to check the final library 
size distribution. The libraries were quantified by real-time qPCR using the KAPA Library Quantification kit, and then sequenced as single-end 75 base reads on a Illumina NextSeq 500 in high-output mode.

Transcripts abundance from RNA-seq reads was quantified by Salmon ${ }^{69}$, and gene-level counts were obtained with tximport ${ }^{70}$. Subsequently, raw counts were processed with edge $\mathrm{R}^{71}$ to determine differentially expressed genes. Gene set enrichment analysis (GSEA) was performed on gene lists ranked by the edgeR fold change. We used 1000 gene set permutations and the classic enrichment statistic. Gene set collections were from MSigDB (http://software.broadinstitute.org/gsea/msigdb). Furthermore, we used the R package ClusterProfiler ${ }^{72}$ to determine Gene Ontology and Reactome categories that were enriched in genes downregulated in exercising vs. sedentary groups. Raw counts from the experiment are available at Gene Expression Omnibus under the accession ID GSE124799.

\section{Enzyme-linked immunosorbent assay.}

For the leptin ELISA (MOB00, R\&D Systems) measurements, blood plasma was 20x diluted and bone marrow plasma was 2x diluted. For the CXCL12 ELISA (ab100741, Abcam) measurements, bone marrow plasma was $4 \mathrm{x}$ diluted. For corticosterone ELISA (ab108821, Abcam) measurements, blood plasma was 50x diluted. Samples were analyzed according to the manufacturers' instructions.

\section{Histology.}

Tibiae were harvested and fixed immediately in $15 \mathrm{~mL}$ of formalin solution $10 \%$ (HT501128, Sigma-Aldrich) overnight at $4^{\circ} \mathrm{C}$. Tibiae were then washed with distilled water, decalcified in 0.5 M EDTA (BM-711, Boston BioProducts) for 3 days and placed in 70\% ethanol prior to paraffin embedding and processing. Paraffin-embedded sections were deparaffinized in xylene using two changes for 5 minutes each and rehydrated in gradually graded ethanol. For Runx 2 staining, antigen retrieval was performed with $20 \mathrm{ug} / \mathrm{mL}$ Proteinase K (P2308, Sigma-Aldrich) for 15 minutes at $37^{\circ} \mathrm{C}$ and endogenous peroxidase activity was blocked with $3 \% \mathrm{H}_{2} \mathrm{O}_{2} / \mathrm{MeOH}$ for 20 minutes at room temperature. Sections were stained with Runx2 antibody (1:200, 12556, Cell Signaling) followed by secondary goat anti-rabbit IgG antibody (1:500, BA-1000, Vector Laboratories). Further, TSA biotin detection kit (NEL700A, Perkin Elmer) was used and slides were stained with DAB Peroxidase (HRP) substrate kit (SK-4100, Vector Laboratories). For perilipin staining, antigen retrieval was performed using Retrievagen A (pH6.0) (550524, BD Biosciences) and sections were stained for Perilipin A (1:500, P1998, Sigma-Aldrich) followed by a biotinylated goat anti-rabbit IgG antibody (1:100, BA-1000, Vector Laboratories). Streptavidin DyLight 594 (1:600, SA-5594, Vector Laboratories) was applied to detect adipocytes and DAPI (1:3000, D21490, ThermoFisher Scientific) was used to identify nuclei.

Aortic roots were dissected and embedded in Tissue-Tek O.C.T. compound (4583, Sakura Finetek), frozen in 2-Methylbutane (78-78-4, Fisher Scientific) cooled with dry ice and sectioned into $6 \mu \mathrm{m}$ slices. To compare lesion size among the groups, Masson's Trichrome (HT15-1KT, Sigma-Aldrich) and Oil red O (O0625, Sigma-Aldrich) stainings were 
performed according to the manufacturers' protocol and maximum lesion areas were measured. To quantify lesion macrophage content, immunohistochemistry was performed with anti-CD68 (1:50, clone FA-11, 137002, BioLegend), Vectastain ABC kit (Vector Laboratories, Inc.) and AEC substrate (Dako). Slides were counterstained with Harris haematoxylin (Sigma-Aldrich). Images were captured on a NanoZoomer 2.0RS (Hamamatsu, Japan). Hearts were harvested and embedded in O.C. T compound. The sections were stained for CD11b (1:25, clone M1/70, 550282, BD Biosciences), collagen I (1:50, ab21286, Abcam) and alpha smooth muscle actin (1:50, aSMA, ab5694, Abcam). Biotinylated secondary antibodies were applied followed by VECTASTAIN ABC kit (PK-6100, Vector Laboratories, Inc.) and AEC substrate (K3464, Dako) for color development. Sections were counterstained with Harris hematoxylin (HHS32, SigmaAldrich). All slides were scanned by a digital slide scanner, NanoZoomer 2.0RS (Hamamatsu, Japan) and quantification was done using ImageJ software.

\section{In vivo calcein labeling and calculation of mineral apposition rate.}

Mice were intraperitoneally injected with $20 \mathrm{mg} / \mathrm{kg}$ of calcein (C0875, Sigma-Aldrich) 7 days prior and $30 \mathrm{mg} / \mathrm{kg}$ of Alizarin red S (A5533, Sigma-Aldrich) in a 2\% sodium bicarbonate solution 2 days prior to harvest. Femurs were fixed for $2 \mathrm{hrs}$ in formalin at $4{ }^{\circ} \mathrm{C}$ and then embedded in OCT and sectioned. Images were acquired on an Olympus IV100 microscope and post-processing was performed using Image $\mathbf{J}$ software (NIH). Mineral apposition rate (MAR) is the distance between the midpoints of the two labels divided by the time between the midpoints of the interval.

\section{In vitro adipocyte differentiation assay.}

The bone marrow fraction was isolated from all long bones and pelvic bones and digested as previously described. All cells were plated in a-MEM (SH30265.01, Fisher Scientific) supplemented with 10\% FBS and 1\% penicillin/streptomycin (both Sigma-Aldrich). Medium was changed after 24 hours to remove non-adherent hematopoietic cells. Stromal cells were then plated in 12 well plates at a concentration of $50 \times 10^{3}$ cells per well in differentiation medium (a-MEM supplemented with 10\% FBS, 1\% P/S, $100 \mathrm{nM}$ dexamethasone and $10 \mathrm{mg} / \mathrm{ml}$ human insulin, 1285-014, Gibco). The differentiation medium was changed twice a week, and at day 21, cells were fixed in $4 \%$ paraformaldehyde for 10 minutes, washed with 60\% isopropanol, and stained with Oil Red O (O0625, SigmaAldrich) for 10 minutes and immediately washed with distilled water. After taking pictures, we extracted the Oil Red O with 100\% isopropanol for 5 minutes with gentle rocking and the absorbance measurement was done at $492 \mathrm{~nm}$. 100\% isopropanol was used as background control to substract the background signal.

\section{Microcomputed tomography $(\mu \mathrm{CT})$.}

A high-resolution desktop micro-tomographic imaging system ( $\mu$ CT40, Scanco Medical AG, Brüttisellen, Switzerland) was used to assess trabecular bone microarchitecture and cortical bone morphology, in the proximal metaphysis and diaphysis of the tibia, respectively. Scans were acquired using a $10 \mu \mathrm{m}^{3}$ isotropic voxel size, $70 \mathrm{kVp}$ peak $\mathrm{x}$-ray tube potential, $114 \mu \mathrm{A}$ $\mathrm{x}$-ray intensity, $200 \mathrm{~ms}$ integration time, and were subjected to Gaussian filtration and segmentation. Image acquisition and analysis protocols adhered to guidelines for $\mu \mathrm{CT}$ 
assessment of rodent bone microstructure ${ }^{73}$. Trabecular bone microarchitecture was analyzed in a $1000 \mu \mathrm{m}$ (100 transverse slices) long region that began $100 \mu \mathrm{m}$ inferior to the proximal growth plate and extended distally. The endocortical region was manually contoured and then bone was segmented from soft-tissue using a threshold of $345 \mathrm{mgHA} /$ $\mathrm{cm}^{3}$. The segmented images were analyzed with the standard Scanco trabecular bone morphology script to measure trabecular bone volume fraction (\%), trabecular bone mineral density $\left(\mathrm{mgHA} / \mathrm{cm}^{3}\right)$, trabecular thickness $(\mathrm{mm})$, trabecular number $\left(\mathrm{mm}^{-1}\right)$, and trabecular separation ( $\mathrm{mm}$ ). Cortical bone morphology was analyzed in a $500 \mu \mathrm{m}$ (50 transverse slices) long region that began $2 \mathrm{~mm}$ superior to the distal tibiofibular junction and extended distally. Cortical bone was segmented using a threshold of $700 \mathrm{mgHA} / \mathrm{cm}^{3}$ and the standard Scanco script for cortical bone morphology was used to measure total cross-sectional area $\left(\mathrm{mm}^{2}\right)$, cortical bone area $\left(\mathrm{mm}^{2}\right)$, cortical thickness $(\mathrm{Ct} . \mathrm{Th}, \mathrm{mm})$, and polar moments of inertia $\left(\mathrm{mm}^{4}\right)$.

\section{Osmium Tetroxide $\mu \mathrm{CT}$.}

Marrow adipose tissue (MAT) was quantified via osmium tetroxide staining followed by $\mu \mathrm{CT}$ using previously described methods ${ }^{74}$. Following $\mu \mathrm{CT}$ scanning for trabecular and cortical structure, the tibiae were demineralized in $4.1 \%$ EDTA for 21 days. The demineralized tibiae were then stained at room temperature for 48 hours in a solution containing $1 \%$ osmium tetroxide and $2.5 \%$ potassium dichromate. After being washed with cold water to remove unbound osmium tetroxide, the stained tibiae were $\mu \mathrm{CT}$ imaged using the previously mentioned $\mu C T$ scanner. Scans of the proximal tibia were acquired using a 10 $\mu \mathrm{m}^{3}$ isotropic voxel size, $55 \mathrm{kVp}$ peak x-ray tube potential, $145 \mu \mathrm{A}$ x-ray intensity, $300 \mathrm{~ms}$ integration time, and were subjected to Gaussian filtration and segmentation. The medullary cavity for each tibia was manually contoured in a region beginning $100 \mu \mathrm{m}$ distal to the proximal growth plate and extending distally $2 \mathrm{~mm}$. Osmium tetroxide staining in this region was segmented using a threshold equivalent to $800 \mathrm{mgHA} / \mathrm{cm}^{3}$ and volumetric analysis was run to measure marrow adipose tissue volume (MAT.V, $\mathrm{mm}^{3}$ ). The medullary volume (MV, $\mathrm{mm}^{3}$ ) in this region was quantified in the $\mu \mathrm{CT}$ scans of the mineralized bone as total volume minus bone volume (medullary volume $=$ total volume - bone volume). MAT volume was normalized by the medullary volume and is reported as the MAT volume fraction (MAT.V/MV, \%).

\section{MRI.}

Cardiac magnetic resonance imaging was done 21 days after coronary ligation to assess left ventricular dilatation and ejection fraction. MRI short axis views of the entire left ventricle were acquired on a Bruker 4.7 Tesla phamascan magnet (Billerica, MA) with a cine fast low angle shot sequence with intraGate technology using the following parameters: Echo Time: $2.945 \mathrm{~ms}$, Repetition Time: $10.0 \mathrm{~ms}$, Flip Angle: $18 \mathrm{deg}$, Oversampling: 250, Frames: 16, Matrix $200 \times 200 \times 1$ and Voxel size $0.150 \times 0.150 \times 1 \mathrm{~mm}$. Left ventricular wall and cavity were segmented manually at systole and diastole using Horos software (https:// horosproject.org). 


\section{Mass Spectrometry.}

For analysis of norepinephrine (NE) and acetylcholine (ACh), bone marrow samples were homogenized in cold $10 \mathrm{mM} \mathrm{NH} 4 \mathrm{COOH}, \mathrm{pH} 3$ in $57 \% \mathrm{ACN}$ with isotopic labeled internal standards (ACh-d4 and NE-d6). $\mathrm{CHCl} 3$ was added to achieve $\mathrm{CH} 3 \mathrm{CN}-\mathrm{H} 2 \mathrm{O}-\mathrm{CHCl} 3$ (2:1.5:1) to denature proteins, and the mixture was centrifuged for $20 \mathrm{~min}$ at $4{ }^{\circ} \mathrm{C}$ for phase separation. The upper phase was used for UPLC-MS/MS analysis.

ACQUITY UPLC H-Class system and a Xevo TQ-S micro triple quadrupole mass spectrometer with an electrospray source, (all from Waters Inc) were used for UPLCMS/MS analysis. Separation was performed on two types of columns. An Acquity UPLC HSS PFP $(150 \mathrm{~mm} \times 2.1 \mathrm{~mm}, 1.8 \mu \mathrm{m})$ column was used for analysis of NE with a binary gradient (Solvent A was $0.2 \%$ formic acid and solvent B was methanol) at a flow rate of 0.4 $\mathrm{mL} / \mathrm{min}$. An Acquity UPLC BEH HILIC $(50 \mathrm{~mm} \times 2.1 \mathrm{~mm}, 1.7 \mu \mathrm{m})$ column was used for analysis of acetylcholine with a binary gradient (Solvent A was 50\% ACN 10mM $\mathrm{NH} 4 \mathrm{COOH} \mathrm{pH} 3$ and solvent B was $95 \% \mathrm{ACN} 10 \mathrm{mM} \mathrm{NH} 4 \mathrm{COOH} \mathrm{pH} 3$ ) at a flow rate of $0.55 \mathrm{~mL} / \mathrm{min}$. Three multiple reaction monitoring (MRM) transitions were set up for each analyte: one for quantification (ACh 146->87; NE 152 -> 107), one for confirmation (ACh 146->43; NE 152 -> 79), and one for labeled internal standard (ACh-d4 150->91; NE-d6 158 -> 139). These MRMs were scheduled around the retention time of the analytes. Optimized cone voltage and collision energy were used for each of the individual MRMs. No less than 12 data points were collected for each peak.

\section{Statistical analyses.}

All statistical analyses of mouse studies were conducted with GraphPad Prism Software Version 7.0c. Data are presented as mean \pm s.e.m. The sample size for each experiment is reported in the text and Figure Legends. All experiments were at least done in duplicate.

All data were first tested for normality by D'Agostino-Pearson omnibus normality test. To compare two groups of mice, we used a two-tailed Student's t-test to compare normally distributed data and a two-tailed Mann-Whitney U test for non-normal distribution. To compare three groups of mice, the Kruskal-Wallis test with Dunn's post hoc test was used for non-normal distribution. To compare two groups of mice with analysis at different timepoints, a two-way analysis of variance with Sidak's post hoc test was used. The Mantel-Cox $\log$ rank test was performed to compare survival of sedentary versus exercising mice after cecal ligation and puncture. $\mathrm{p}<0.05$ was considered to denote significance. Statistical outliers (not more than one per experiment) were determined with the two-sided Grubbs' outlier test (Graphpad Software) and excluded.

\section{Data and materials availability.}

All data are included in this published article and its supplementary information files. Raw sequencing data are available from Gene Expression Omnibus, Accession Numbers GSE110639 and GSE124799. Raw data other than sequencing data that support the findings of this study are available from the corresponding author upon reasonable request. All materials used are available commercially. Correspondence and requests for materials should be addressed to mnahrendorf@mgh.harvard.edu. 


\section{Life Sciences Reporting Summary.}

Further information on experimental design and reagents is available in the Life Sciences Reporting Summary.

\section{Extended Data}


a

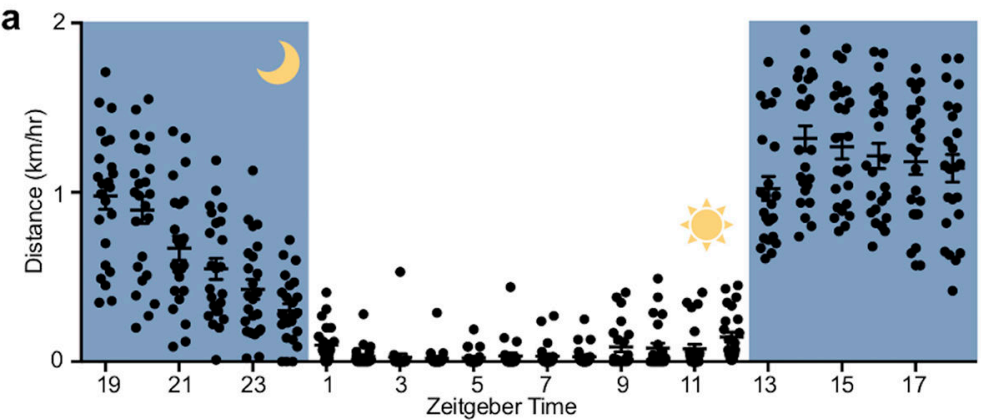

d

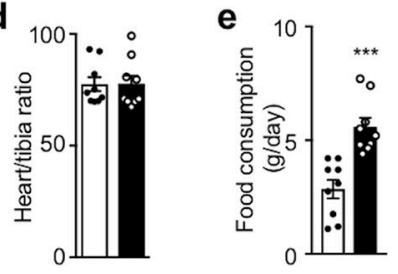

f Gated on singlets, live $\mathrm{CD} 45^{+}$cells

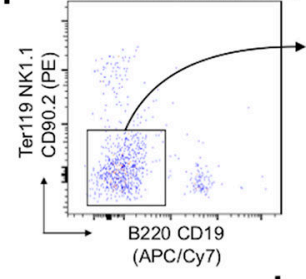

b

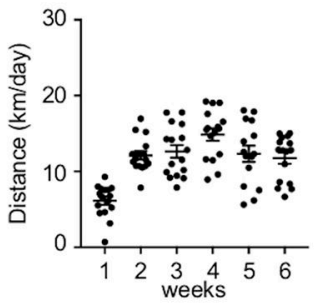

C

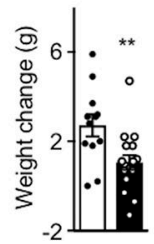

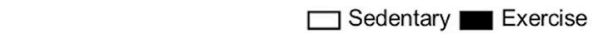
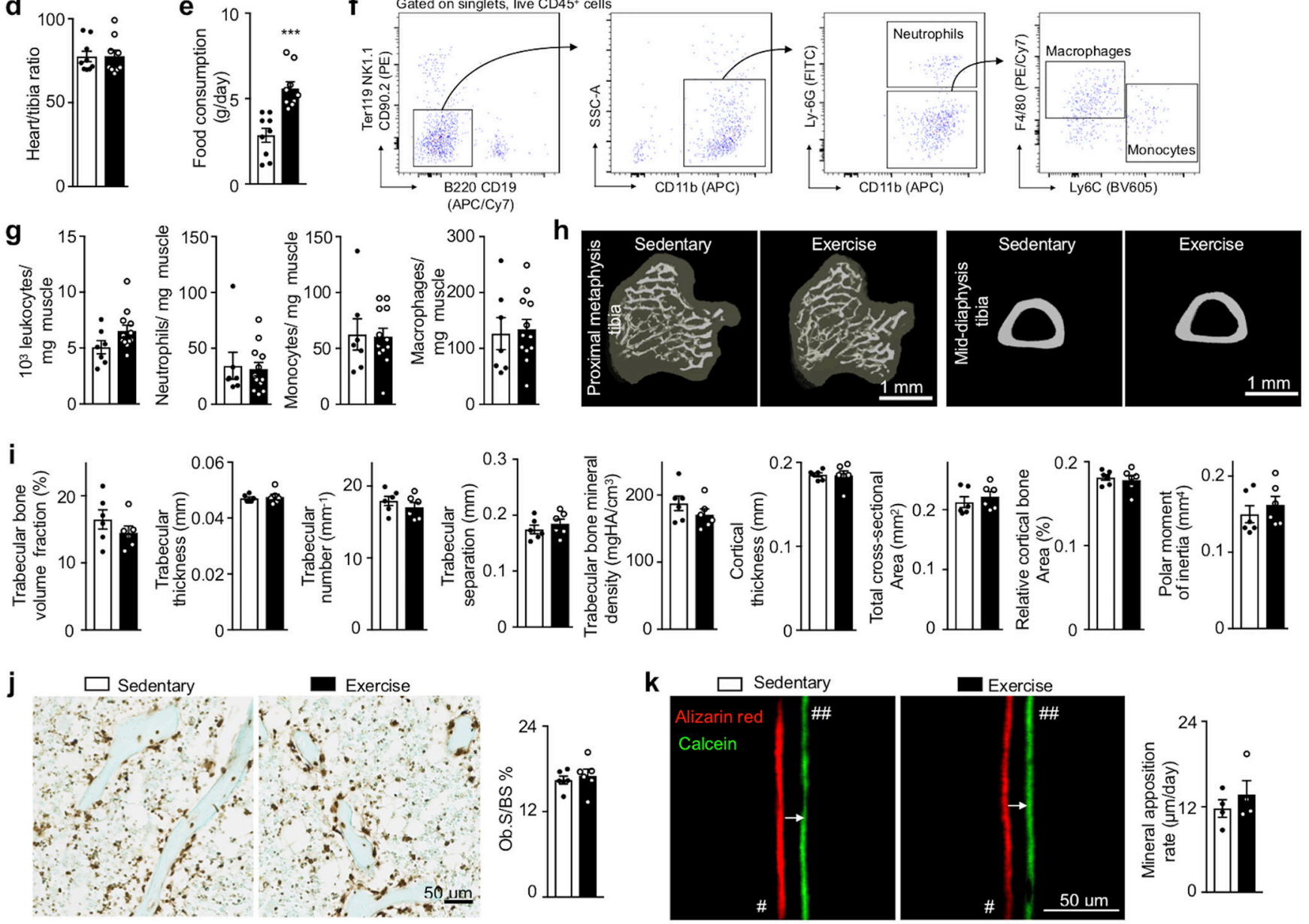

Extended Data Figure 1. Effects of 6 weeks of running.

(a) Mean distance run per hour ( $\mathrm{n}=24$ animals). (b) Mean daily distance over the course of 6 weeks ( $\mathrm{n}=16$ animals). (c) Bodyweight changes in sedentary $(\mathrm{n}=12)$ and exercising mice ( $\mathrm{n}=17,{ }^{*} \mathrm{p}=0.0076$, two-tailed Mann-Whitney $\mathrm{U}$ test) compared to initial bodyweight six weeks prior. (d) Heart weight adjusted for tibia length ( $\mathrm{n}=9$ animals per group). (e) Food consumption during the last week of exercise $(* * * \mathrm{p}=0.0002, \mathrm{n}=9$ animals per group, twotailed Student's t-test). (f) Flow cytometry gating strategy for leukocytes in skeletal muscle. (g) Total leukocytes, neutrophils, monocytes and macrophages per mg muscle tissue by flow cytometry ( $\mathrm{n}=7$ animals for sedentary, $\mathrm{n}=12$ for exercise). (h) Representative microCT images of the proximal metaphysis and mid-diaphysis tibia of exercising and sedentary 
mice. (i) Parameters of bone microstructure, including trabecular and cortical thickness, bone mineral density and polar moment of inertia by $\mu \mathrm{CT}$ ( $\mathrm{n}=6$ animals per group). (j) Representative Runx2 staining of tibial proximal metaphysis. Osteoblast surface per bone surface (Ob.S/BS, $\mathrm{n}=6$ animals per group). (k) Bone formation rate as observed by incorporation of calcein $(20 \mathrm{mg} / \mathrm{kg}, 7$ days prior) and alizarin red $(30 \mathrm{mg} / \mathrm{kg}, 2$ days prior to sacrifice) during bone mineralization at the diaphysis of femurs. Distance of fluorescent label indicated by the arrow demarcates the mineralization front at different times of administration. '\#' denotes medullary cavity and '\#\#' trabecular bone ( $\mathrm{n}=4$ animals). Data are mean \pm s.e.m. 

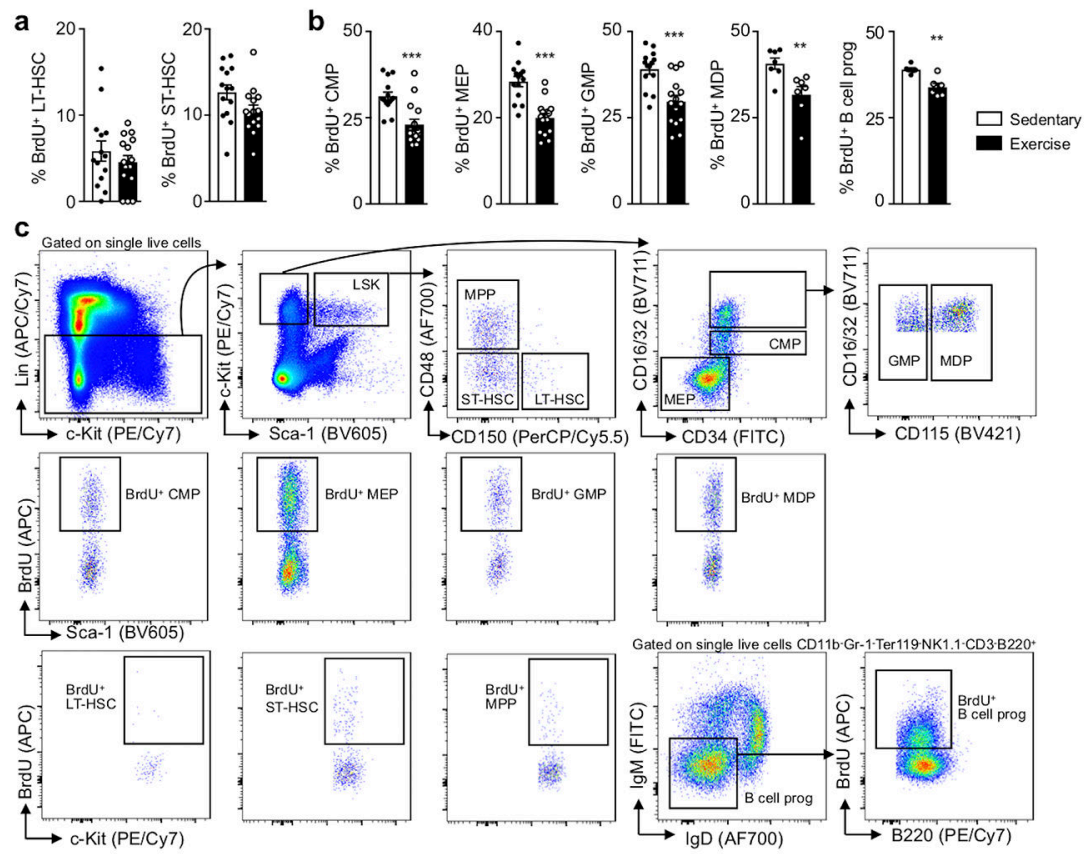

Gated on single live cells CD11b-Gr-1-Ter119-NK1.1-CD3-B220*
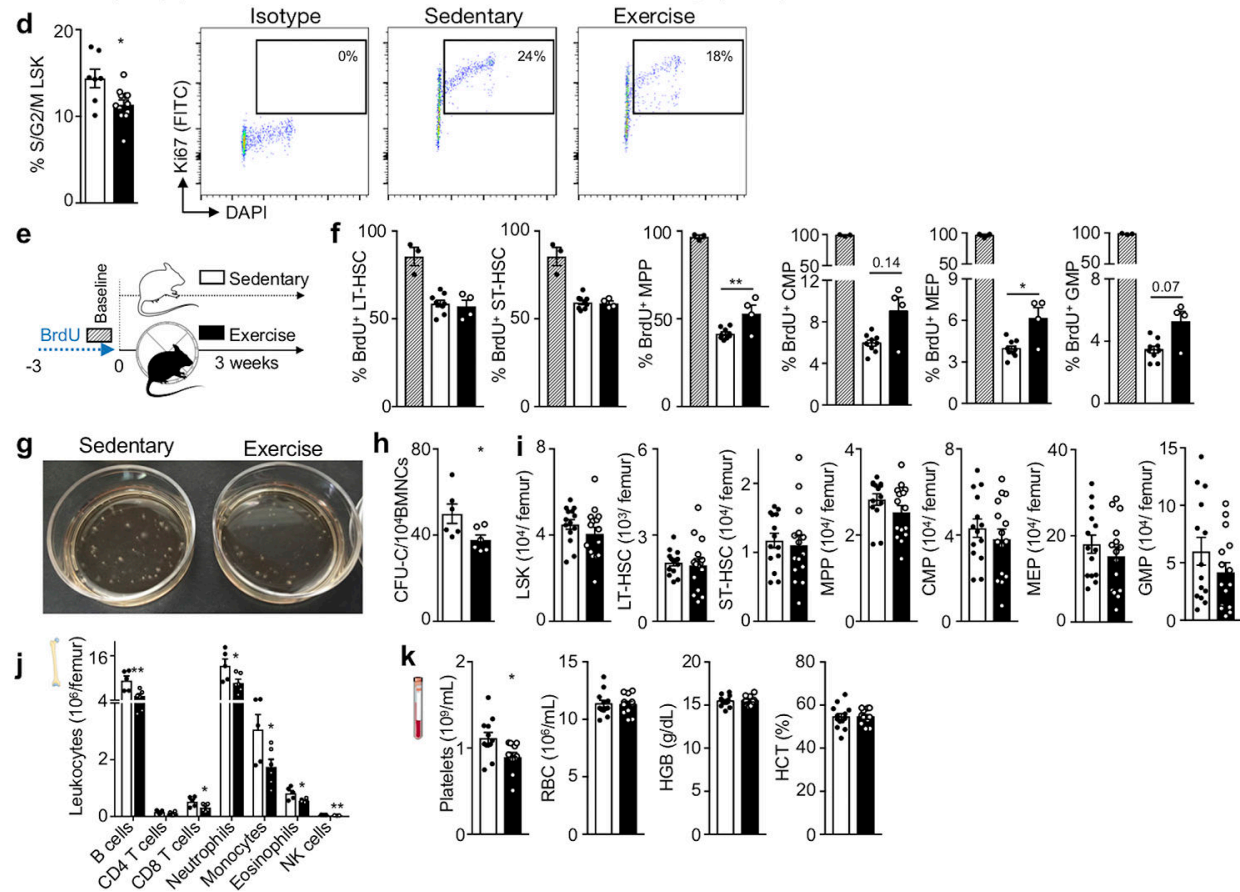

Extended Data Figure 2. Increased stem and progenitor cell quiescence after 6 weeks of exercise. Mice were given 5-bromo-2-deoxyuridine (BrdU) intraperitoneally $(1 \mathrm{mg})$. BrdU incorporation in (a) long-term hematopoietic stem cells (LT-HSC), short-term HSC (STHSC), (b) common myeloid progenitors (CMP, *** $\mathrm{p}=0.00026$ ), megakaryocyte erythroid progenitors (MEP, $* * * \mathrm{p}=1.028 \times 10^{-5}$ ), granulocyte macrophage progenitors (GMP, $* * * \mathrm{p}=4.17 \times 10^{-4}$, all $\mathrm{n}=14$ animals for sedentary, $\mathrm{n}=15$ for exercise), macrophage and dendritic cell progenitors (MDP, $* * \mathrm{p}=0.0070, \mathrm{n}=7$ animals per group) and $\mathrm{B}$ cell progenitors (B cell prog, ${ }^{* *} \mathrm{p}=0.0065, \mathrm{n}=6$ animals per group) were analyzed 22 hours later (two-tailed 
Mann-Whitney U test for CMP, MDP and B cell prog; two-tailed Student's t test for MEP and GMP). (c) Flow cytometry gating for hematopoietic progenitors and representative flow cytometry plots of BrdU gating. (d) Cell cycle analysis in LSK assessed by Ki-67/ DAPI staining. Representative flow cytometry dot plots of Ki67 ${ }^{+}$LSK $(* \mathrm{p}=0.038, \mathrm{n}=7$ animals for sedentary, $\mathrm{n}=12$ for exercise, 2 independent experiments, two-tailed Mann-Whitney $\mathrm{U}$ test). (e) Experimental outline for BrdU pulse-chase experiment. Mice received BrdU in drinking water for 3 weeks (baseline, $\mathrm{n}=3$ animals) prior to 3 weeks of exercise. (f) BrdU incorporation into LT-HSC, ST-HSC, multipotent progenitors (MPP, ** $\mathrm{p}=0.0074$ ), CMP $(\mathrm{p}=0.14), \operatorname{MEP}(* \mathrm{p}=0.034)$ and GMP $(\mathrm{p}=0.07, \mathrm{n}=9$ animals for sedentary, $\mathrm{n}=4$ for exercise, two-tailed Mann-Whitney U test comparing sedentary and exercise). (g) Representative images of granulocyte macrophage colonies from sedentary and running mice. (h) Bone marrow colony forming unit assay (CFU) of bone marrow mononuclear cells (BMNCs) for complete colonies $\left({ }^{*} \mathrm{p}=0.036, \mathrm{n}=6\right.$ animals per group, 2 independent experiments, two-tailed Mann-Whitney U test). (i) Number of HSPC per femur in sedentary and exercising mice ( $n=15$ animals per group). (j) Number of marrow leukocytes at Zeitgeber 13: B cells (** $\mathrm{p}=0.0089), \mathrm{CD} 4 \mathrm{~T}$ cells, CD8 T cells $(* \mathrm{p}=0.048)$, neutrophils $(* \mathrm{p}=0.044)$, monocytes ( $\left.{ }^{*} \mathrm{p}=0.041\right)$, eosinophils $(* \mathrm{p}=0.019, \mathrm{n}=5$ animals for sedentary, $\mathrm{n}=6$ for exercise) and NK cells $(* * \mathrm{p}=0.00099, \mathrm{n}=3$ per group, two-tailed Mann-Whitney $\mathrm{U}$ test). (k) Numbers of platelets $\left({ }^{*} \mathrm{p}=0.016\right.$, two-tailed Student's t test), red blood cells (RBC), hemoglobin (HGB) and hematocrit (HCT, $n=12$ animals for sedentary and $n=11$ for exercise, 4 independent experiments). Data are mean \pm s.e.m. 

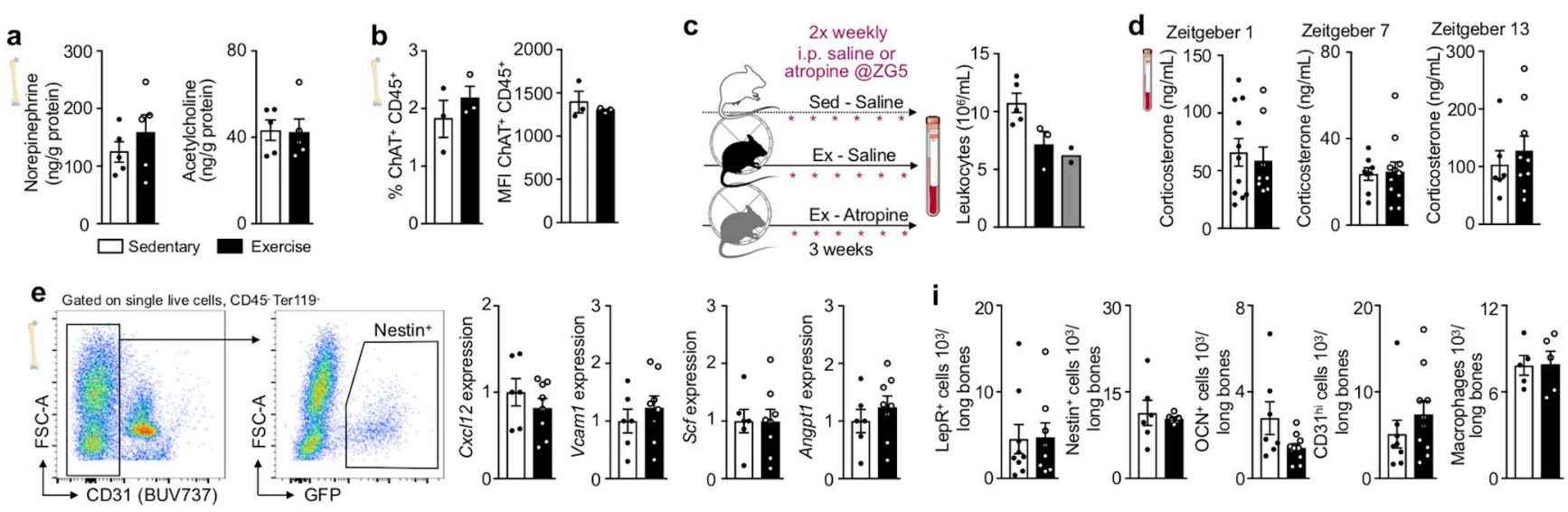

f Gated on single live cells, CD45-Ter119.
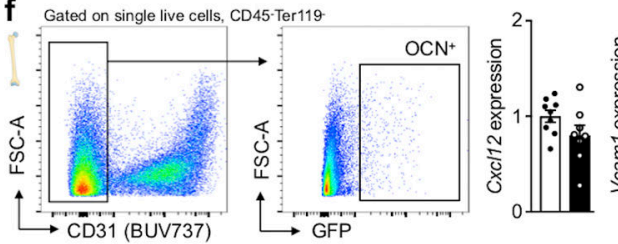

g Gated on singlets live cells
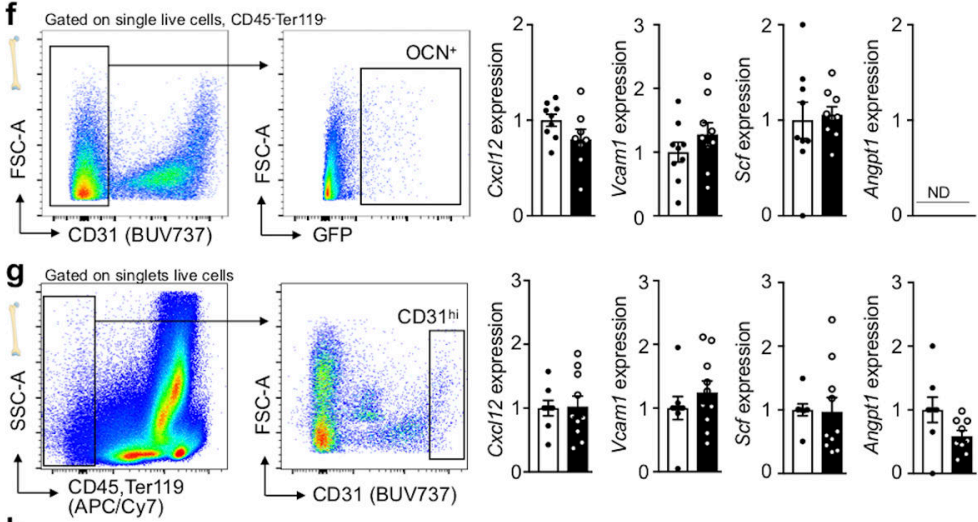

h Gated on singlets live cells, CD11 $\mathrm{b}^{+} \mathrm{Gr} 1 \cdot \mathrm{CD} 11 \mathrm{C}^{+} \mathrm{CX} 3 \mathrm{CR} 1 \mathrm{G}^{\mathrm{G}}$
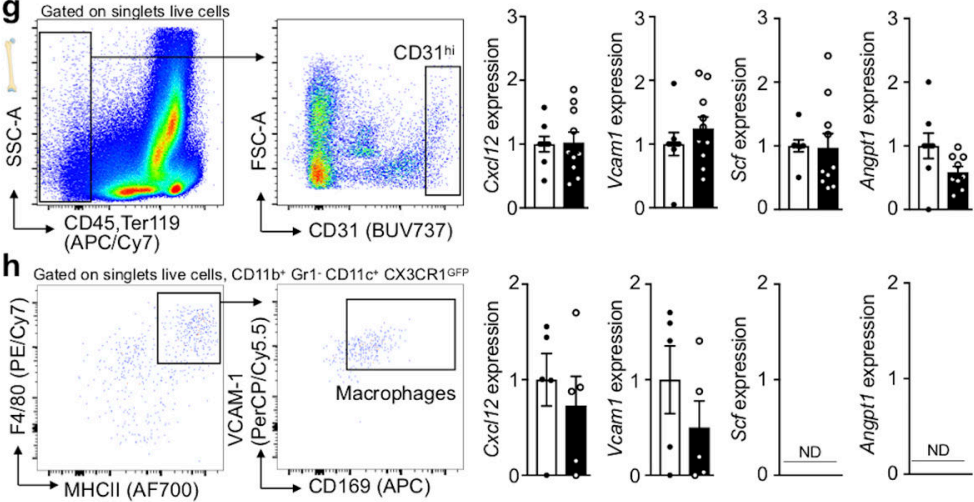

j
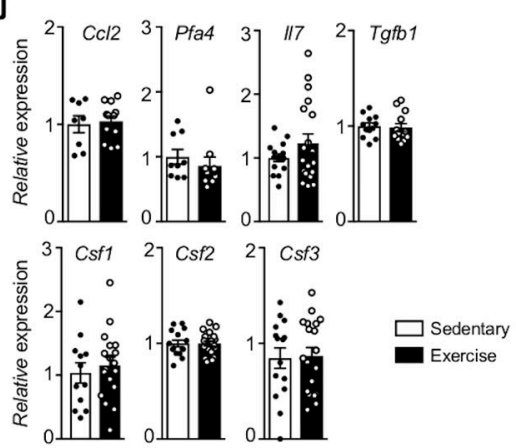

Extended Data Figure 3. Neutral running effects on bone marrow neurotransmitters, corticosterone and selected hematopoietic niche cells.

(a) Mass spectrometry of norepinephrine and acetylcholine in the bone marrow after 6 weeks of exercise ( $\mathrm{n}=5$ animals per group). (b) Choline acetyltransferase (ChAT) expression by bone marrow $\mathrm{CD} 45^{+}$leukocytes ( $\mathrm{n}=3$ animals per group). (c) Experimental outline, administration of a competitive antagonist of the muscarinic acetylcholine receptors (atropine) during 3 weeks exercise. Leukocytes in circulation ( $\mathrm{n}=5$ animals for Sed-Saline, $\mathrm{n}=3$ for Ex-Saline, $\mathrm{n}=2$ for Ex-Atropine). (d) Plasma corticosterone at Zeitgeber time (ZG) 1 ( $\mathrm{n}=11$ animals for sedentary, $\mathrm{n}=8$ for exercise), ZG 7 ( $\mathrm{n}=8$ sedentary, $\mathrm{n}=11$ exercise), ZG 13 ( $\mathrm{n}=6$ sedentary, $\mathrm{n}=9$ exercise) after exercise for 6 weeks. (e) Nestin ${ }^{+}$stromal cells ( $\mathrm{n}=6$ animals for sedentary, $\mathrm{n}=8$ for exercise, 3 independent experiments), (f) $\mathrm{OCN}^{+}$osteoblasts, ( $\mathrm{n}=9$ animals per group, 4 independent experiments) (g) endothelial cells ( $\mathrm{n}=8$ animals for sedentary, $\mathrm{n}=10$ for exercise, 6 independent experiments) and (h) bone marrow macrophages ( $\mathrm{n}=5$ animals per group, 2 independent experiments) were isolated by fluorescence-activated cell sorting. GFP stromal reporter mice either had access to exercise wheels for 6 weeks or remained sedentary. Representative dot plots are shown. Expression of Cxc112, Vcam1, Scf and Angpt 1 was assessed by qPCR, ND: not detectable. (i) Numbers of stromal niche cells 
in sedentary and exercising mice $\left(n=9\right.$ and $n=8$ for LepR $R^{+}, n=6$ and $n=8$ for Nestin ${ }^{+}, n=9$ and $\mathrm{n}=9$ for $\mathrm{OCN}^{+}, \mathrm{n}=8$ and $\mathrm{n}=10$ for $\mathrm{CD} 31^{\text {high }}, \mathrm{n}=5$ and $\mathrm{n}=5$ animals for sedentary and exercise, respectively). (j) Gene expression of several niche factors in total bone marrow by qPCR (n=8 animals for sedentary for $C c l 2$ and Pfa4, n=12 for sedentary for $T g f b, C s f 1$, $\mathrm{n}=16$ for sedentary for $I 17, C s f 2, \mathrm{Csf} 3, \mathrm{n}=13$ for exercise for $C c l 2, T g f b, \mathrm{n}=19$ for exercise for II7, Csf1, Csf2, Csf3, 4 independent experiments). (k) Markers for osteolineage cells (OsX, Ocn, Runx 2 ) and adipocytes ( $L p l, F a b p 4)$ by qPCR in total bone marrow (n=8 animals per group, 2 independent experiments). All mRNA levels were normalized to $A c t b \mathrm{Ct}$ values. Data are mean \pm s.e.m., where appropriate. 


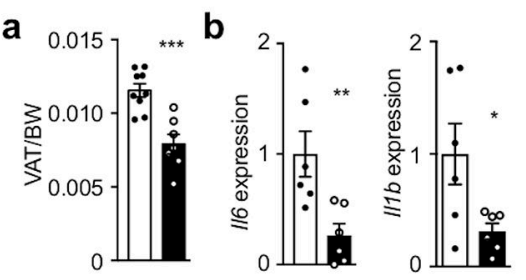

C

d

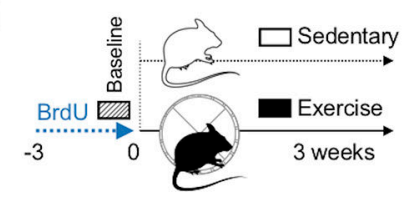

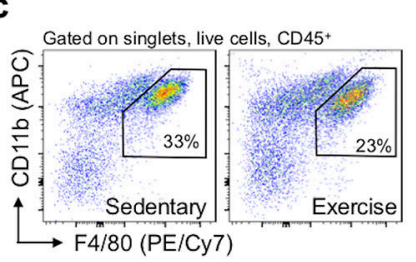
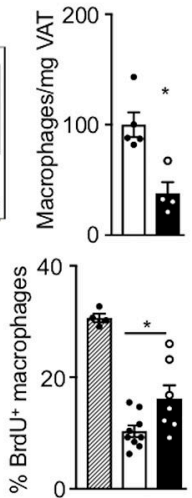

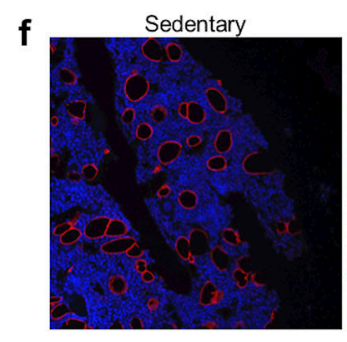

h

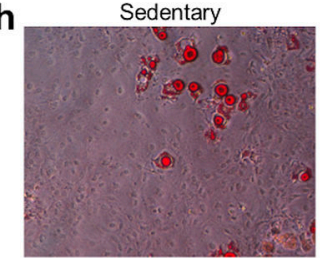

i

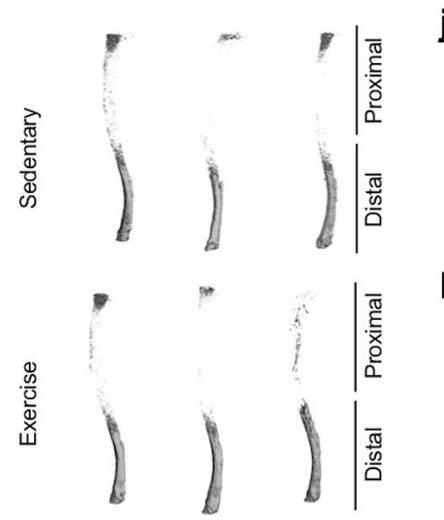

e

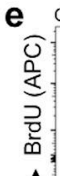

Exercise

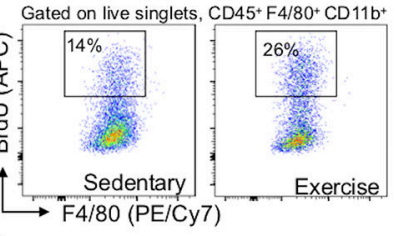

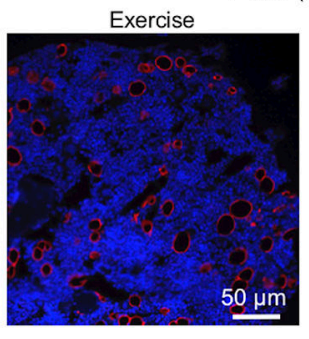

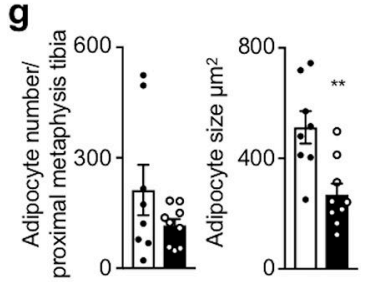

Exercise
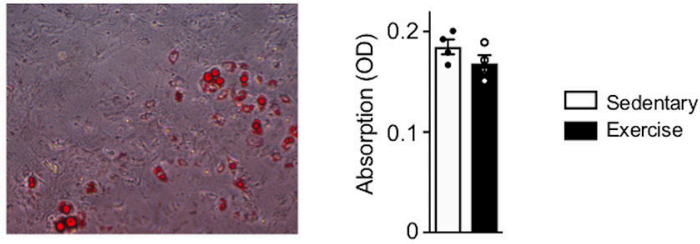

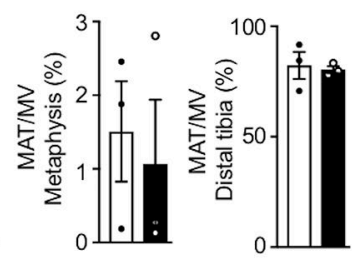

k

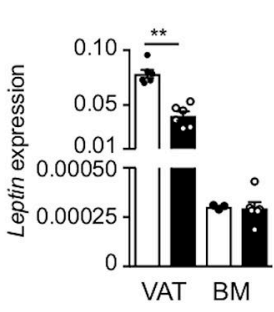

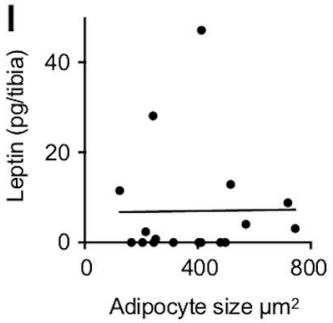

Extended Data Figure 4. Exercise reduces visceral adipose tissue macrophages.

(a) Visceral adipose tissue (VAT) per mouse adjusted for bodyweight (BW; ***p=0.00069, $\mathrm{n}=9$ animals for sedentary, $\mathrm{n}=7$ for exercise, 2 independent experiments, two-tailed MannWhitney $\mathrm{U}$ test). (b) Cytokine production by visceral adipose tissue by qPCR (* $\mathrm{*}=0.034$, ** $\mathrm{p}=0.0087, \mathrm{n}=6$ animals per group, 2 independent experiments, two-tailed Mann-Whitney $\mathrm{U}$ test). (c) Macrophages per mg VAT. Representative dot plots are shown $(* \mathrm{p}=0.016, \mathrm{n}=5$ animals for sedentary, $\mathrm{n}=4$ for exercise, two-tailed Mann-Whitney $\mathrm{U}$ test). (d) Experimental outline for e. Mice received BrdU in drinking water for 3 weeks (baseline, $\mathrm{n}=4$ animals) 
prior to 3 weeks of exercise. (e) BrdU incorporation into VAT macrophages $(* \mathrm{p}=0.045, \mathrm{n}=9$ animals for sedentary, $\mathrm{n}=7$ for exercise, 2 independent experiments, two-tailed MannWhitney $\mathrm{U}$ test comparing sedentary and exercise). Representative dot plots are shown. (f) Longitudinal sections of tibias were stained by perilipin (red) and counterstained by DAPI (blue). (g) Quantification of adipocyte numbers and size in the proximal metaphysis of tibias (** $\mathrm{p}=0.0055, \mathrm{n}=8$ animals for sedentary, $\mathrm{n}=9$ for exercise, 3 independent experiments, twotailed Mann-Whitney U test). (h) In vitro adipocyte differentiation assay of bone marrow stromal cells from all long bones and pelvic bones. Representative images with 100x magnification are shown ( $\mathrm{n}=4$ animals per group). (i,j) Visualization of marrow adipose tissue in tibias by osmium stain by $\mu \mathrm{CT}$ and marrow adipose tissue (MAT) per marrow volume (MV) ( $\mathrm{n}=3$ animals per group). (k) Leptin expression by qPCR in visceral adipose tissue (VAT; ** $=0.0022, \mathrm{n}=6$ animals per group, two-tailed Mann-Whitney $\mathrm{U}$ test) and bone marrow (BM; $\mathrm{n}=3$ animals for sedentary, $\mathrm{n}=6$ for exercise). mRNA levels were normalized to $A c t b \mathrm{Ct}$ values. Data are mean \pm s.e.m. (l) Lack of correlation between tibial adipocyte size and leptin concentration $\left(\mathrm{R}^{2}=0.0002, \mathrm{P}=0.96, \mathrm{n}=17\right.$ animals, linear regression analysis). 
a

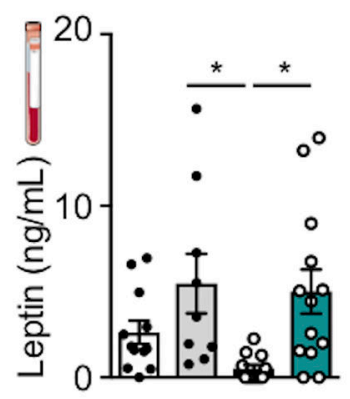

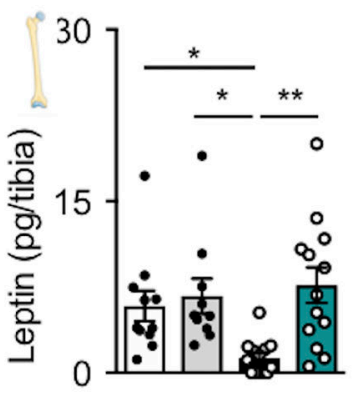

b
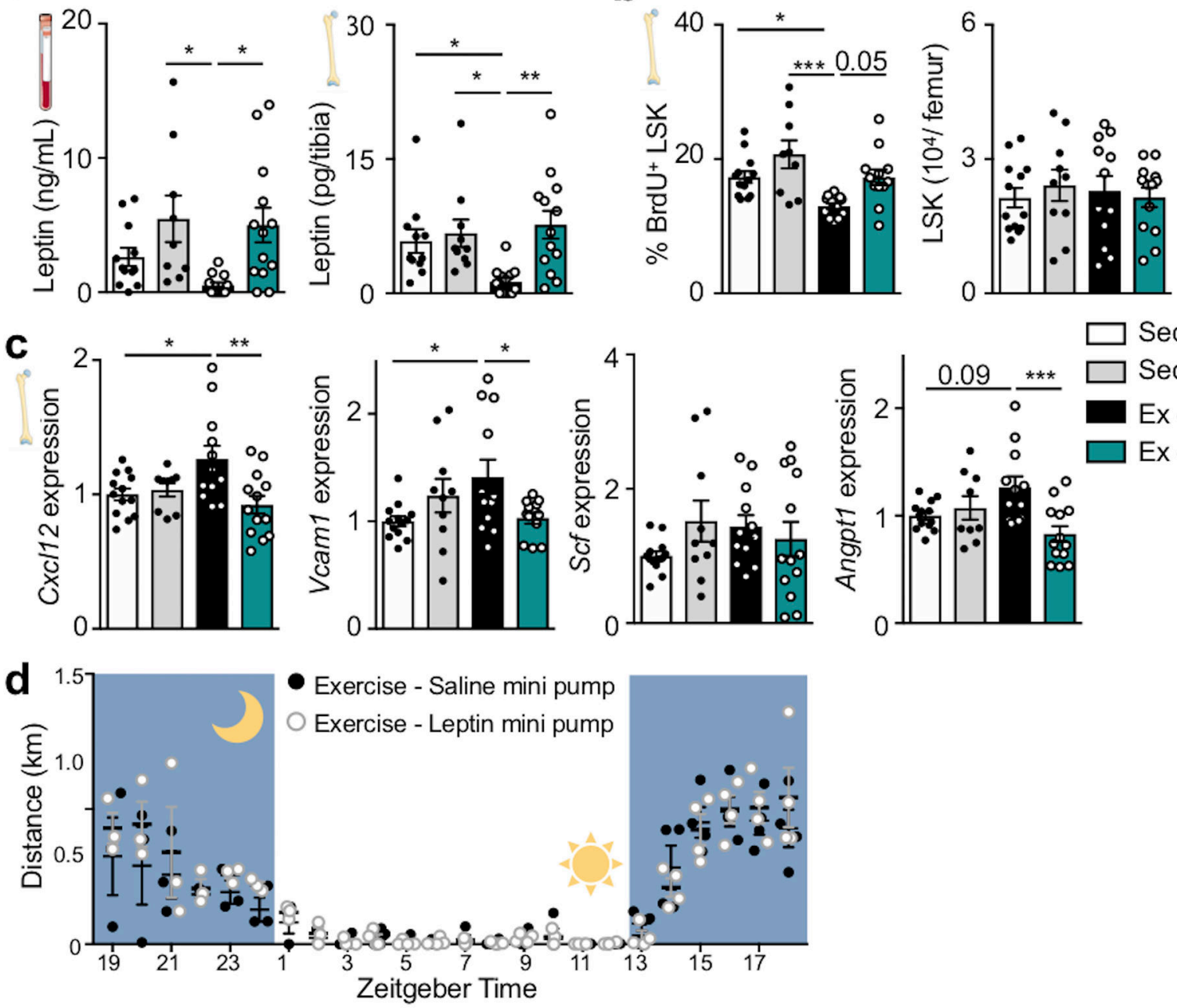

e

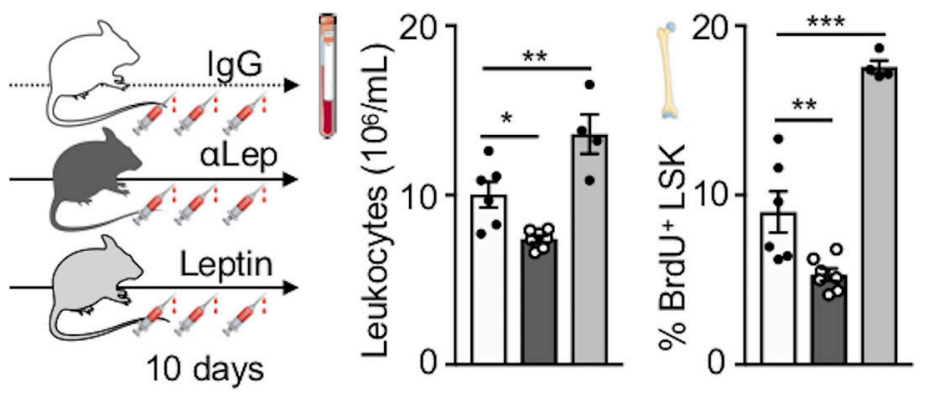

Extended Data Figure 5. Leptin supplementation and antibody neutralization.

(a) Leptin levels in blood (*p=0.19 for both Sed-Leptin vs Ex-Saline and Ex-Saline vs ExLeptin, one-way analysis of variance with Sidak's post hoc test) and bone marrow (* $\mathrm{p}=0.013$ Sed-Leptin vs Ex-Saline, ${ }^{*} \mathrm{p}=0.042$ Sed-Saline vs Ex-Saline, ${ }^{* *} \mathrm{p}=0.0038$ Ex-Saline vs ExLeptin, $n=12$ animals for Sed-Saline and Ex-Saline, $n=10$ for Sed-Leptin, $n=13$ for ExLeptin, 5 independent experiments, Kruskal-Wallis with Dunn's post hoc test) as measured by ELISA. (b) LSK proliferation $22 \mathrm{hrs}$ after intraperitoneal injection of $\mathrm{BrdU}\left({ }^{*} \mathrm{p}=0.047\right.$ Sed-Saline vs Ex-Sal, p=0.05 Ex-Saline vs Ex-Leptin, ***p=0.00031 Sed-Leptin vs Ex-Sal, 
$\mathrm{n}=12$ animals for Sed-Saline and Ex-Saline, $\mathrm{n}=10$ for Sed-Leptin, $\mathrm{n}=13$ for Ex-Leptin, 5 independent experiments, one-way analysis of variance with Sidak's post hoc test), LSK numbers and (c) expression of hematopoietic factors in bone marrow of exercising and sedentary mice implanted with osmotic minipumps as described in Fig. $2 \mathrm{~h}$ (*p=0.016 and ** $\mathrm{p}=0.0026$ for $C x c 112,{ }^{*} \mathrm{p}=0.025$ Sed-Saline vs Ex-Saline and * $\mathrm{p}=0.046$ Ex-Saline vs ExLeptin for Vcam1, *** $=0.00074$ Ex-Saline vs Ex-Leptin and $\mathrm{p}=0.09$ Sed-Saline vs ExSaline for Angpt1, n=12 animals for Sed-Saline and Ex-Saline, n=10 for Sed-Leptin, n=13 for Ex-Leptin). (d) Running distance with either saline or leptin mini pumps and access to exercise wheels for 6 weeks. Mean distance run per hour ( $n=4$ animals per group). (e) Injection of leptin neutralizing antibody or leptin into sedentary mice. Circulating leukocytes levels at Zeitgeber time 7 ( ${ }^{*} \mathrm{p}=0.010 \mathrm{IgG}$ vs aLep, $* * \mathrm{p}=0.0072$ aLep vs Leptin) and LSK proliferation $22 \mathrm{hrs}$ after intraperitoneal injection $(* * \mathrm{p}=0.0038 \mathrm{IgG}$ vs aLep, *** $\mathrm{p}=1.52 \times 10^{-5}, \mathrm{n}=6$ animals for $\mathrm{IgG}, \mathrm{n}=7$ for $\mathrm{aLep}, \mathrm{n}=4$ for Leptin, 2 independent experiments, one-way analysis of variance with Sidak's post hoc test). Data are mean \pm s.e.m. 

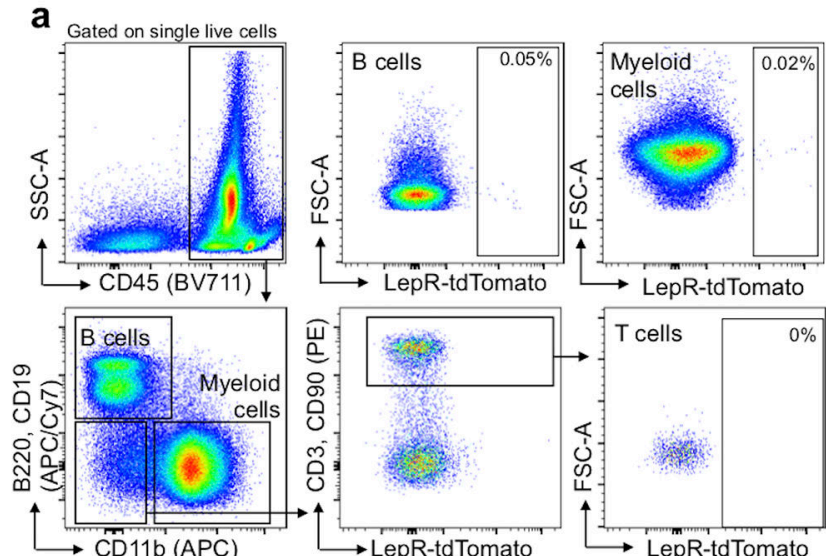

b Gated on single live cells

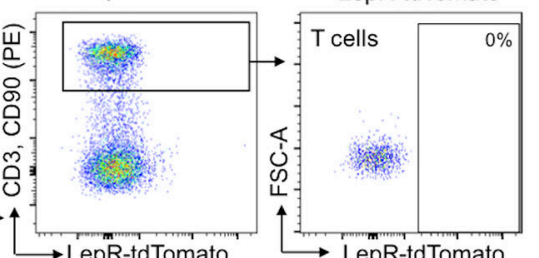

C Gated on single live cells
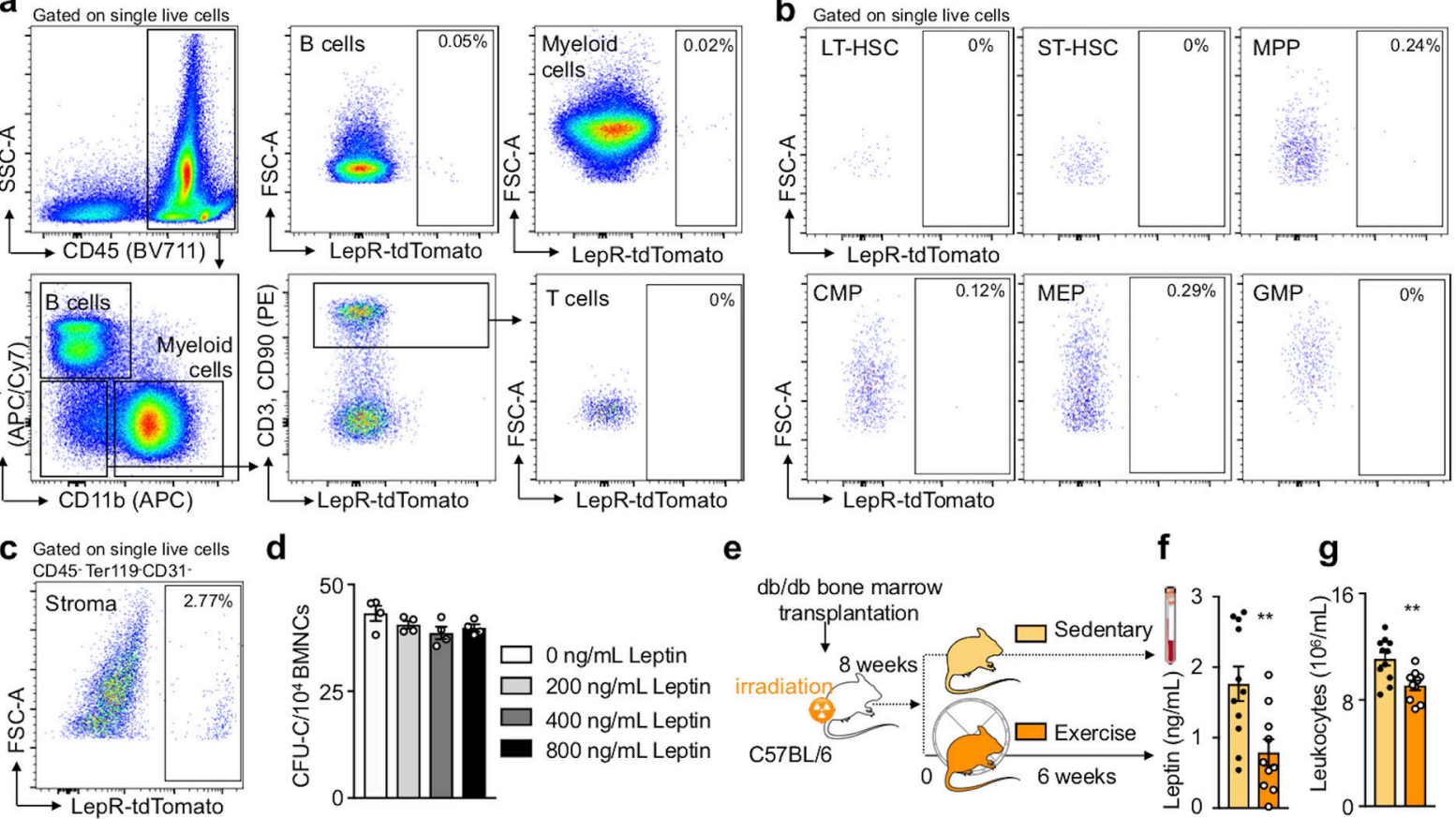

h

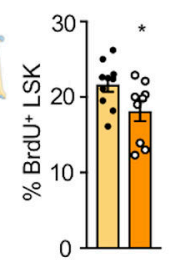

k

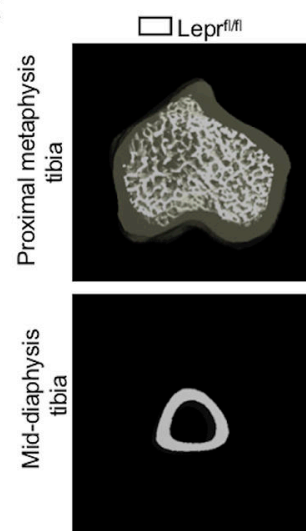

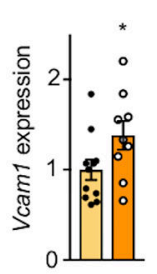
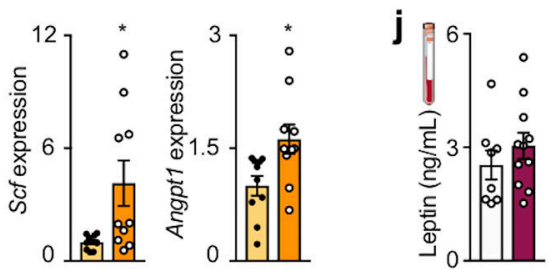

$\square$ Lepifl/fl

$\square$ Prx1-creER ${ }^{\top 2}:$ Lepr $^{\mathrm{fl} / \mathrm{fl}}$
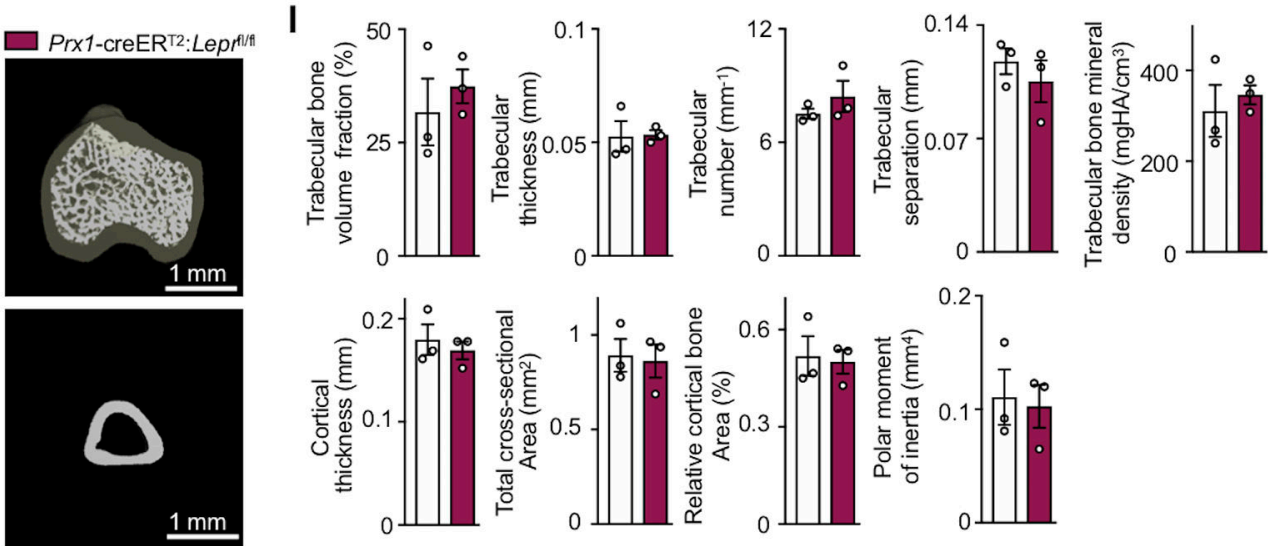

Extended Data Figure 6. Leptin receptor expression in the bone marrow.

(a) Representative flow cytometry dot plots of leptin receptor (LepR) expression in B cells, myeloid cells, T cells, (b) bone marrow long-term hematopoietic stem cells (LT-HSC), short-term HSC (ST-HSC), multipotent progenitors (MPP), common myeloid progenitors (CMP), megakaryocyte erythroid progenitors (MEP), granulocyte macrophage progenitors (GMP) and (c) stromal bone marrow cells ( $\mathrm{n}=3$ independent experiments with similar results). (d) Bone marrow colony forming unit assay (CFU) for complete colonies ( $\mathrm{n}=4$ donor animals). Bone marrow mononuclear cells (BMNCs) were plated with increasing 
concentrations of leptin. (e) Experimental outline for bone marrow transplantation; data shown in panel $\mathrm{f}$-i. Total bone marrow was isolated from $\mathrm{db} / \mathrm{db}$ donor mice and transplanted into wild type recipients. After an 8-week recovery period, mice exercised for 6 weeks or remained sedentary. (f) Leptin levels in serum by ELISA $(* * \mathrm{p}=0.0059, \mathrm{n}=11$ animals for sedentary, $\mathrm{n}=10$ for exercise, 2 independent experiments, two-tailed Student's t-test). (g) Circulating leukocyte levels at Zeitgeber time $7 * * \mathrm{p}=0.0042, \mathrm{n}=11$ for animals sedentary, $\mathrm{n}=10$ for exercise, 2 independent experiments, two-tailed Student's t-test). (h) BrdU incorporation into LSK $22 \mathrm{hrs}$ after intraperitoneal injection ( $\mathrm{p} p=0.045, \mathrm{n}=10$ animals sedentary, $n=9$ for exercise, 2 independent experiments, two-tailed Student's t-test). (i) Gene expression by qPCR in total bone marrow of $C x c 112(* \mathrm{p}=0.042), V$ cam1 $(* \mathrm{p}=0.03), S c f$ $\left({ }^{*} \mathrm{p}=0.014\right)$ and Angpt 1 ( ${ }^{*} \mathrm{p}=0.0168, \mathrm{n}=11$ animals for sedentary, $\mathrm{n}=10$ for exercise, 2 independent experiments, two-tailed Mann-Whitney U test for $C x c 112$ and two-tailed Student's t-test for Vcam1, Scf, Angpt1). mRNA levels were normalized to Actb Ct values. (j) Leptin levels in blood of $\operatorname{Lepr}^{\mathrm{fl} / \mathrm{f}}$ and $\operatorname{Prx} 1$-creER ${ }^{\mathrm{T} 2}: \operatorname{Lepr}^{\mathrm{fl} / \mathrm{fl}}$ mice measured by ELISA ( $\mathrm{n}=8$ animals for $\operatorname{Lepr}^{\mathrm{fl} / \mathrm{fl}}$ and $\mathrm{n}=11$ for $\operatorname{Prx} 1$-creER ${ }^{\mathrm{T} 2}: \operatorname{Lepr}^{\mathrm{fl} / \mathrm{fl}}$ ). (k) Representative microCT

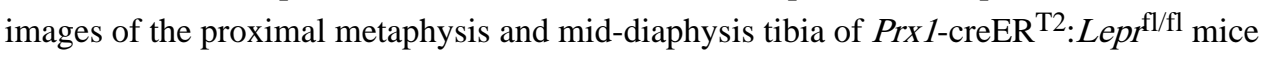
and their $L e p r^{\mathrm{fl} / \mathrm{fl}}$ littermates. (b) Parameters of bone microstructure, including trabecular and cortical thickness, bone mineral density and polar moment of inertia by $\mu$ CT $(n=3$ animals per group). Data are mean \pm s.e.m. 
a

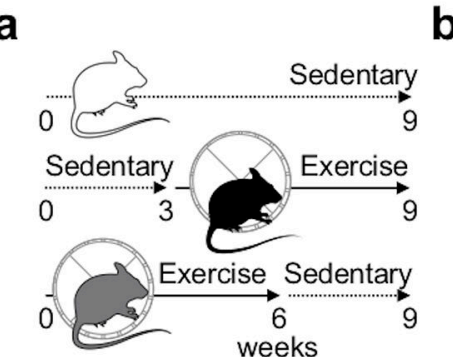

c

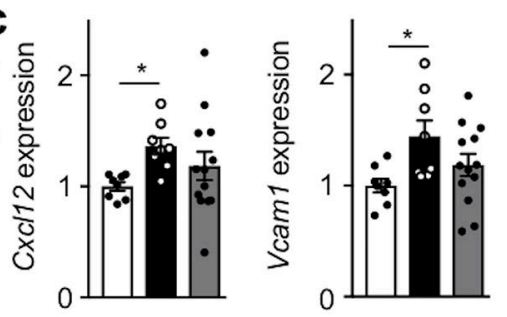

d

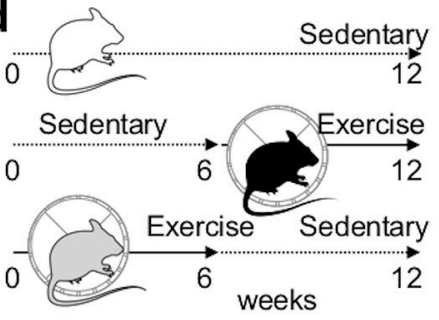

$\mathbf{f}$

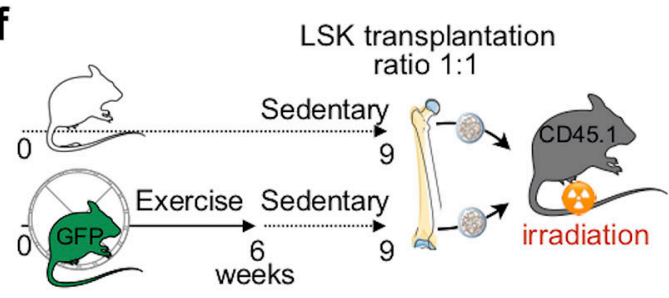

LSK transplantation

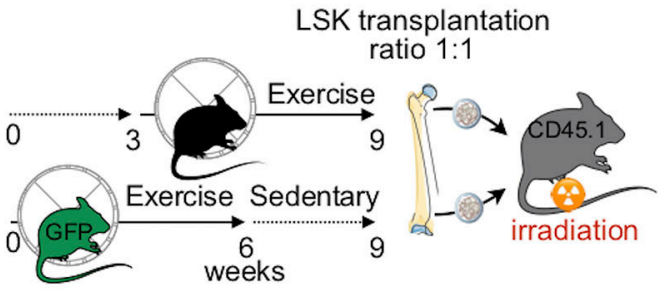

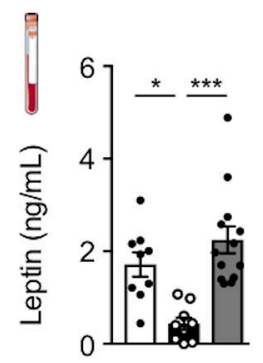
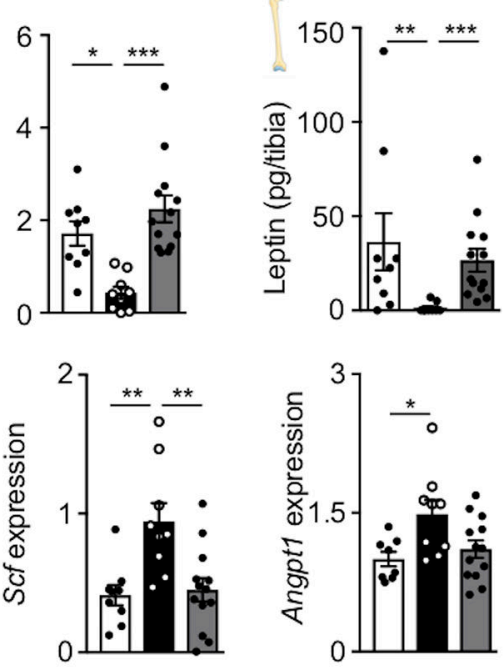

e
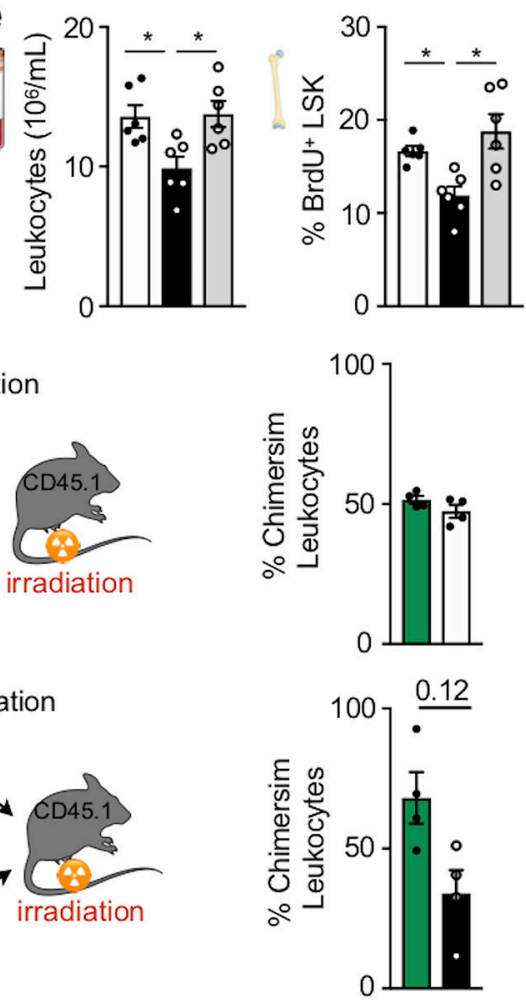

Extended Data Figure 7. Exercise effects wane after 6 sedentary weeks.

(a) Experimental outline for b-c. (b) Blood $\left(* \mathrm{p}=0.012\right.$, *** $\left.\mathrm{p}=8.89 \times 10^{-5}\right)$ and tibial (** $\mathrm{p}=0.0053, * * * \mathrm{p}=0.00079)$ leptin concentrations measured by ELISA ( $\mathrm{n}=9$ animals for sedentary and exercise, $n=13$ animals for post-exercise-sedentary, 3 independent experiments, Kruskal-Wallis with Dunn's post hoc test). (c) Gene expression of niche factors Cxc112 (*p=0.015), Vcam1 $(* \mathrm{p}=0.038), S c f\left(* * \mathrm{p}=0.0037\right.$ sedentary vs exercise, ${ }^{*} * \mathrm{p}=0.0035$ exercise vs post-exercise-sedentary) and Angpt 1 (*p=0.027) in whole bone marrow by qPCR ( $\mathrm{n}=9$ animals for sedentary and exercise, $\mathrm{n}=13$ animals for post-exercise-sedentary, 3 
independent experiments, one-way analysis of variance with Sidak's post hoc test). mRNA levels were normalized to $A c t b \mathrm{Ct}$ values. (d) Experimental outline for e. The post-exercisesedentary group had access to exercise wheels for 6 weeks after which the wheels were removed for the following 6 weeks. Sedentary controls had no access, while the exercise group had access to wheels during the last 6 weeks before sacrifice. (e) Circulating leukocyte levels at Zeitgeber time 7 ( $\mathrm{p}=0.028$ sedentary vs exercise, ${ }^{*} \mathrm{p}=0.045$ exercise vs post-exercise sedentary) and BrdU incorporation into LSK $22 \mathrm{hrs}$ after intraperitoneal injection $\left({ }^{*} \mathrm{p}=0.045\right.$ sedentary vs exercise, ${ }^{*} \mathrm{p}=0.014$ exercise vs post-exercise-sedentary, $\mathrm{n}=6$ animals per group, Kruskal-Wallis with Dunn's post hoc test). (f) Outline of the competitive bone marrow transplantation experiments. LSK were isolated from CD45.2 donors that either exercised for 6 weeks or were sedentary. These were transplanted in a 1:1 ratio into CD45.1 recipients together with LSK isolated from UBC-GFP mice that exercised for 6 weeks and had a 3-week post-exercise-sedentary period. Blood chimerism 8 weeks after transplantation ( $\mathrm{n}=4$ animals per group, $\mathrm{p}=0.12$ for exercise vs post-exercise-sedentary donor chimerism, Wilcoxon matched-pairs signed rank test). Data are mean \pm s.e.m. 


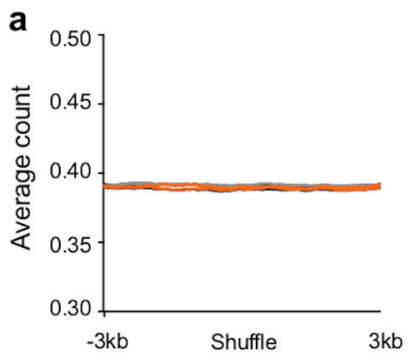

b
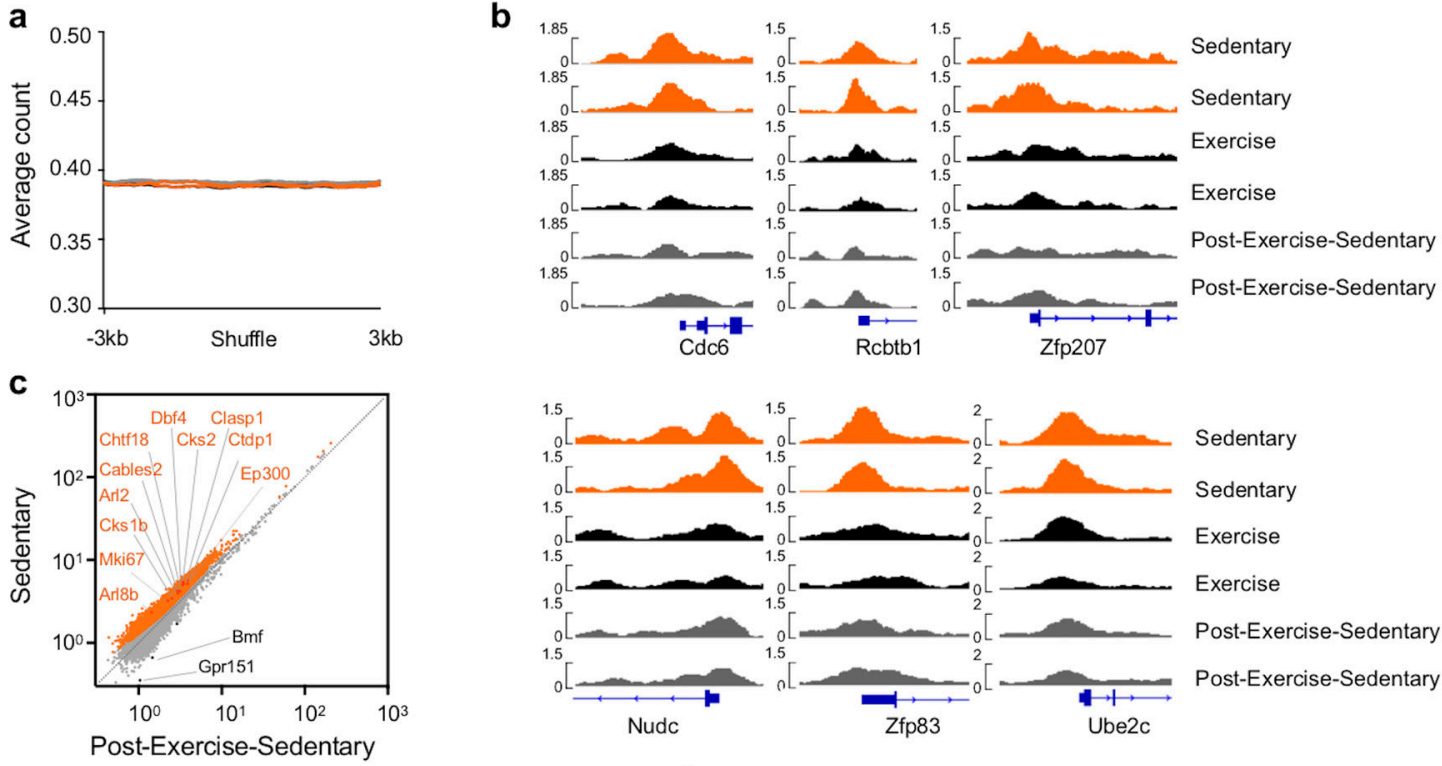

d
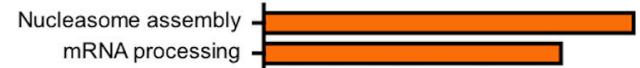
Cell cycle

Ubiquitin-protein transferase activity Chromosome, centromeric region Cadherin binding involved in cell-cell adhesion Transferase activity NuA4 histone acetyltransferase complex Cyclin-dependent protein serine/threonine kinase regulator activity Nucleosome assembly
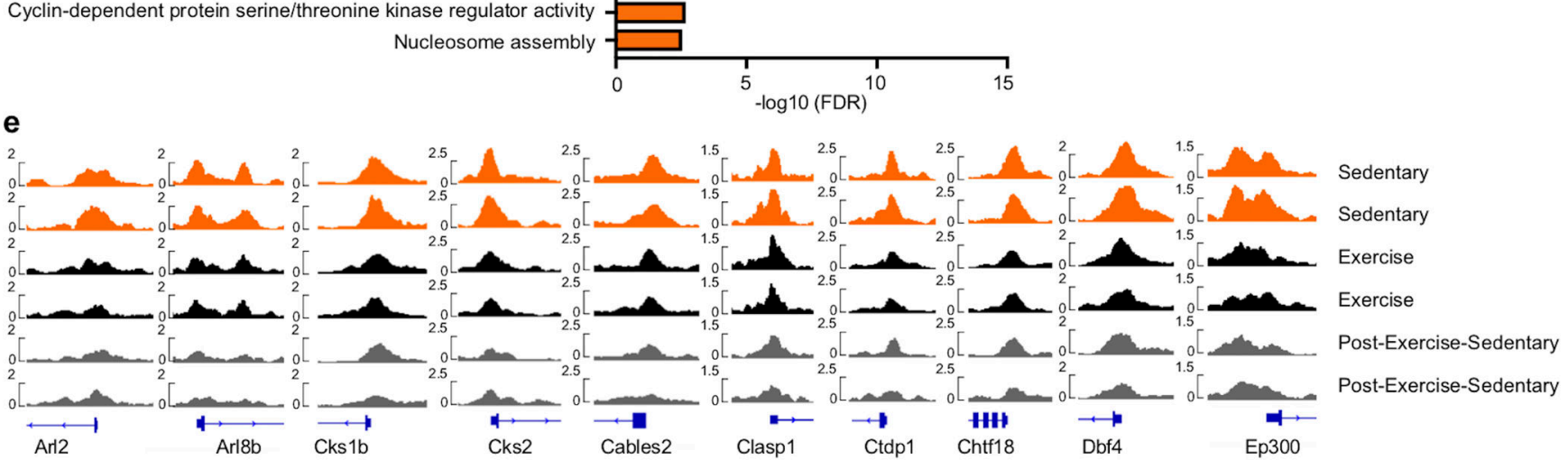

Extended Data Figure 8. Background ATAC-seq signals are similar, while peaks are higher in LSK of sedentary mice.

(a) Average profiles of ATAC-seq tag density among randomly shuffled regions of the same size as the actual ATAC-seq peaks. These profiles are similar among different conditions, suggesting the absence of background shift between ATAC-seq signals. (b) Tracks of normalized ATAC-seq tag density for the loci of additional genes in the top ten significant genes in the cell cycle category as determined by DAVID in Fig. 3n. (c) Scatter plot of normalized tag density at ATAC-seq peaks shows comparison between LSK from sedentary versus post-exercise-sedentary cohorts. Peaks with significantly lower and higher tag density in post-running mice are highlighted in orange and black, respectively (FDR $<0.01$ ). The top ten significant genes in the cell cycle pathway determined by DAVID (refer to d) and Mki67 are indicated; see Supplementary Table 1 for all genes. (d) Functional categories enriched among genes with differential chromatin accessibility in LSK from sedentary versus post- 
exercise-sedentary mice as determined by DAVID. (e) Tracks of normalized ATAC-seq tag density for the loci of the top ten significant genes in the cell cycle category as determined by DAVID in d. 
a

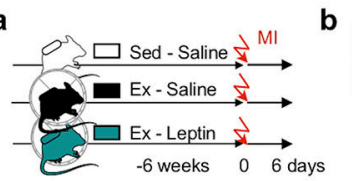

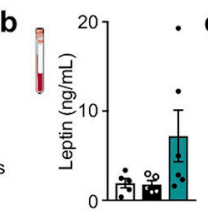

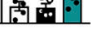
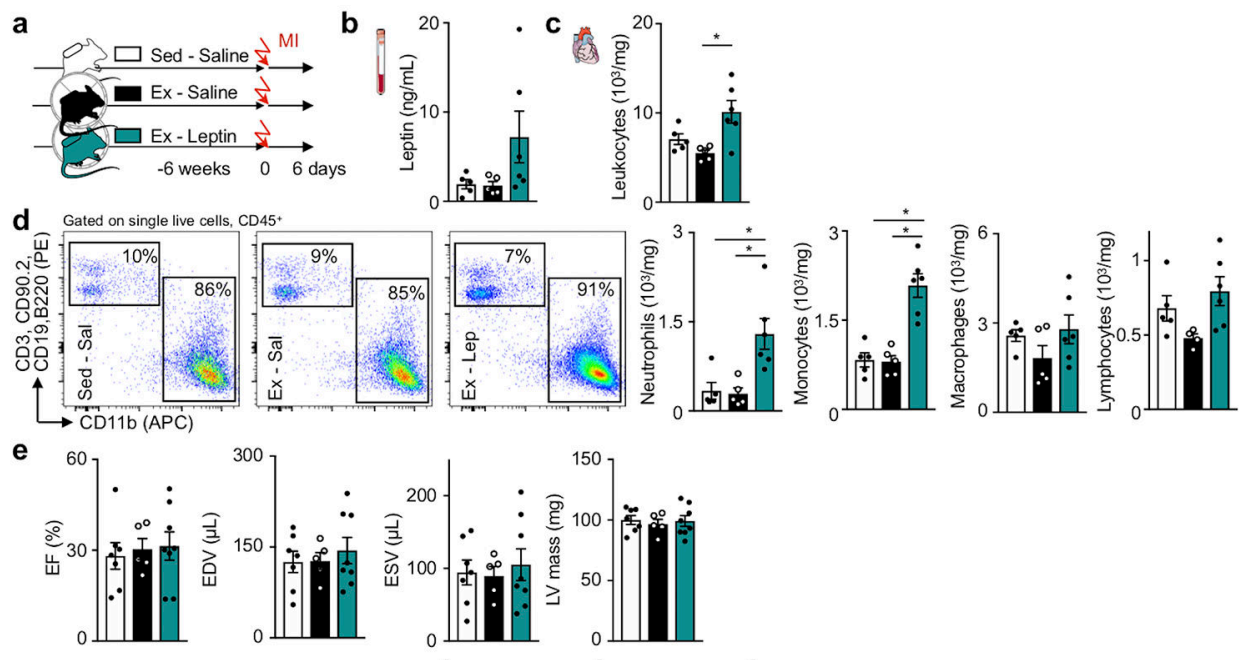

$\mathbf{f}$

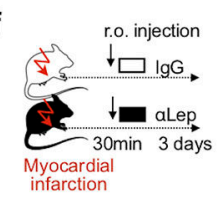

ii
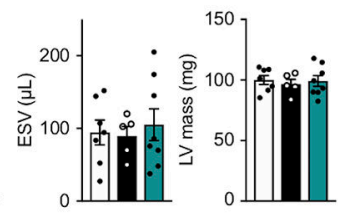

k
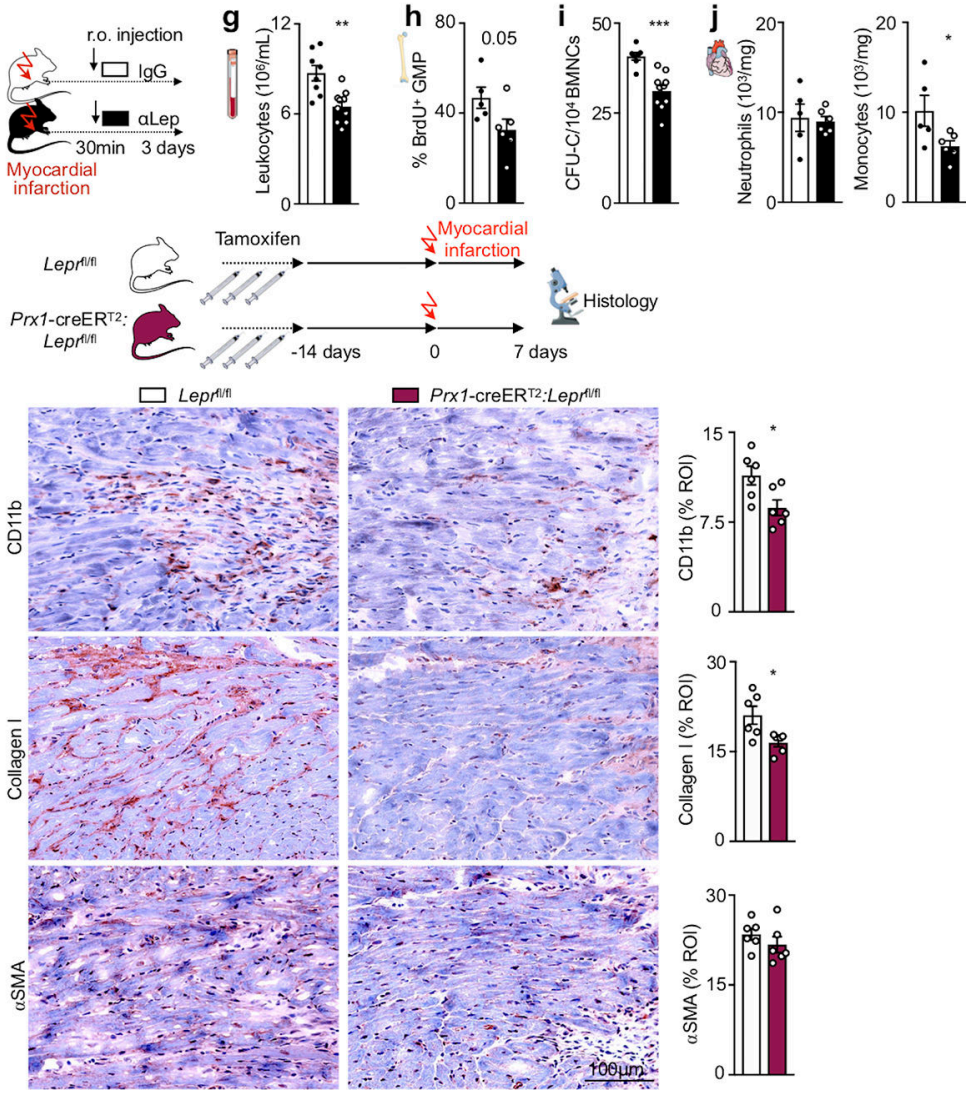

Extended Data Figure 9. Leptin in acute MI.

(a) Experimental outline for b-e. (b) Leptin blood levels on day 6 after MI ( $n=5$ animals for Sed-Saline and Ex-Saline, $\mathrm{n}=6$ for Ex-Leptin, 3 independent experiments). (c) Infarct CD45 ${ }^{+}$leukocyte levels on day 6 after MI $(* \mathrm{p}=0.025, \mathrm{n}=5$ animals for Sed-Saline and ExSaline, $n=6$ for Ex-Leptin, 3 independent experiments, Kruskal-Wallis with Dunn's post hoc test). (d) Flow cytometry gating and quantification of neutrophils ( ${ }^{*} \mathrm{p}=0.039$ Sed-Saline vs Ex-Leptin, *p=0.021 Ex-Saline vs Ex-Leptin), monocytes $(* \mathrm{p}=0.018$ Sed-Saline vs ExLeptin, *p=0.015 Ex-Saline vs Ex-Leptin), macrophages and lymphocytes in the infarct in 
respective cohorts ( $\mathrm{n}=5$ animals for Sed-Saline and Ex-Saline, $\mathrm{n}=6$ for Ex-Leptin, 3 independent experiments, Kruskal-Wallis with Dunn's post hoc test). (e) Cardiac magnetic resonance imaging on day 21 after MI. Ejection fraction (EF), enddiastolic volume (EDV), endsystolic volume (ESV) and left ventricular (LV) mass were determined ( $\mathrm{n}=7$ animals for Sed-Saline, $\mathrm{n}=5$ for Ex-Saline, $\mathrm{n}=8$ for Ex-Leptin, 3 independent experiments). (f) Experimental outline for panels g-j. (g) Circulating leukocytes at Zeitgeber 7 (** $\mathrm{p}=0.0017$, $\mathrm{n}=8$ animals for IgG and $\mathrm{n}=10$ for aLep, 3 independent experiments, two-tailed Student's $\mathrm{t}$ test). (h) BrdU incorporation into granulocyte macrophage progenitors (GMP) 3 days after MI ( $\mathrm{p}=0.05, \mathrm{n}=8$ animals for IgG and $\mathrm{n}=10$ for aLep, 3 independent experiments, two-tailed Student's t-test). (i) Bone marrow colony forming unit assay (CFU) of bone marrow mononuclear cells (BMNCs) for complete colonies ( $* * * \mathrm{p}=0.00041, \mathrm{n}=7$ animals for $\mathrm{IgG}$ and $\mathrm{n}=10$ for aLep, 3 independent experiments, two-tailed Mann-Whitney $\mathrm{U}$ test). (j) Neutrophils and monocytes per mg infarct tissue $(* \mathrm{p}=0.03, \mathrm{n}=5$ animals for $\operatorname{IgG}, \mathrm{n}=6$ for aLep, two-tailed Mann-Whitney U test). (k) Experimental outline for 1. (l) Representative immunohistochemical stainings and quantification of myeloid cells (CD11b), collagen deposition (Collagen I), and myofibroblasts (alpha smooth muscle actin) in the infarct border zone $(* \mathrm{p}=0.026$ for $\mathrm{CD} 11 \mathrm{~b}$ and Collagen $\mathrm{I}, \mathrm{n}=6$ animals per group, two-tailed MannWhitney U test). Data are mean \pm s.e.m. 

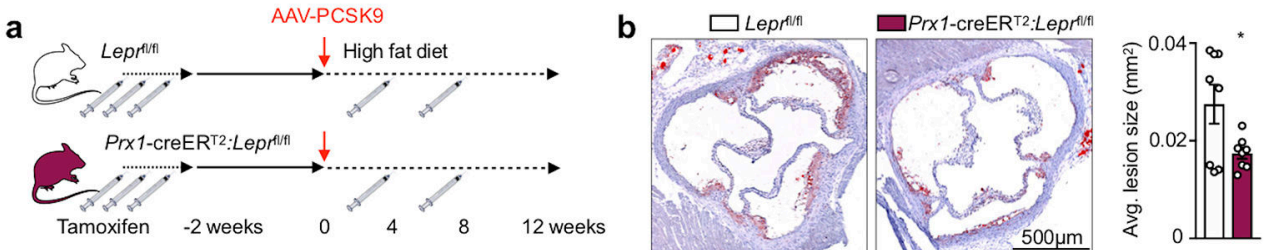

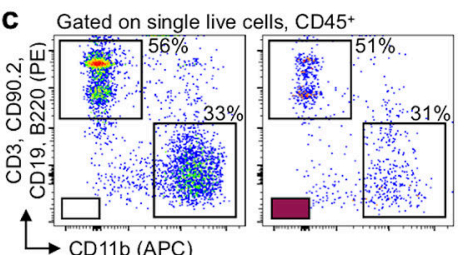

e Gated on single live cells, lineageneg
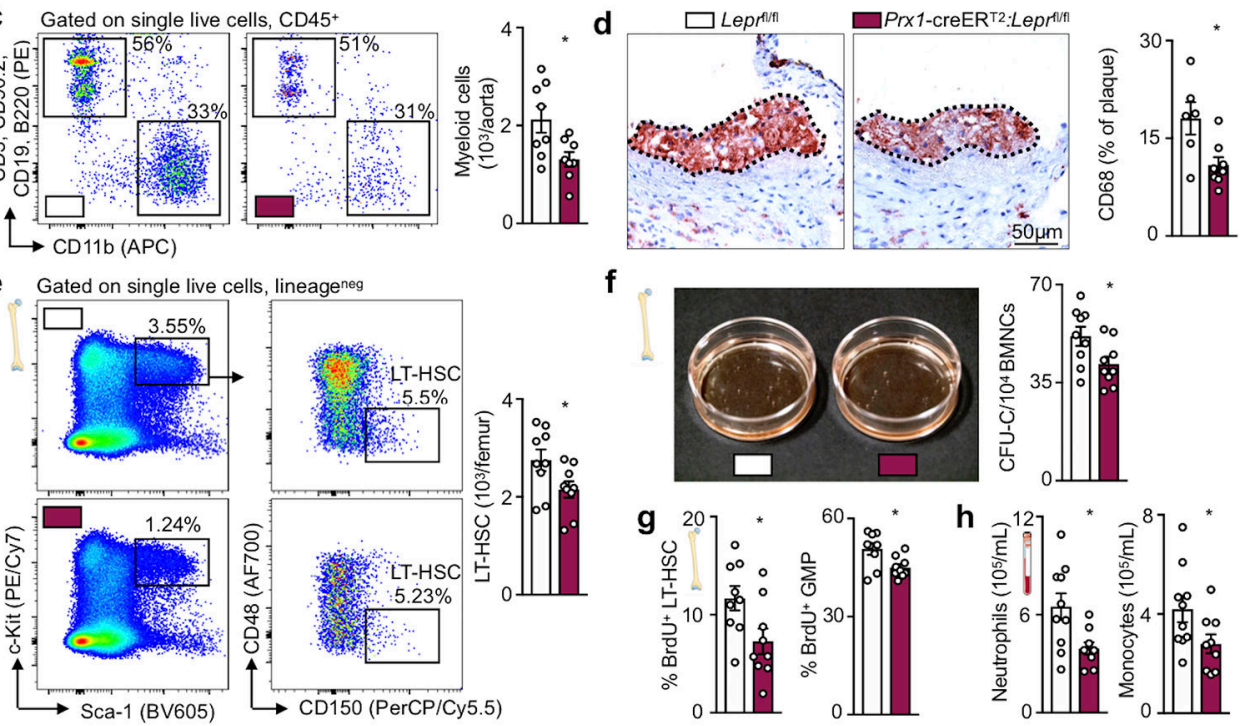
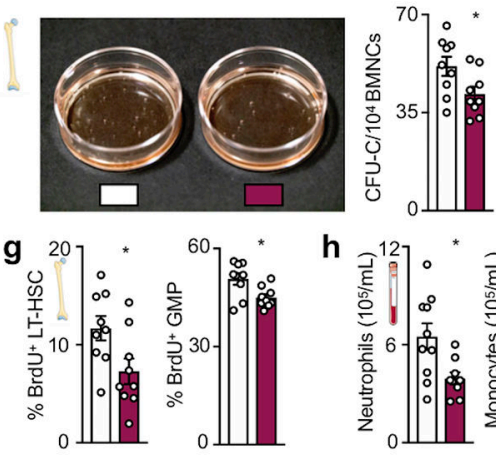

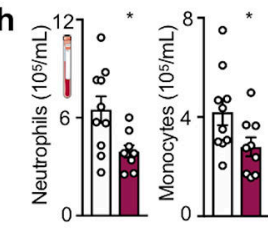

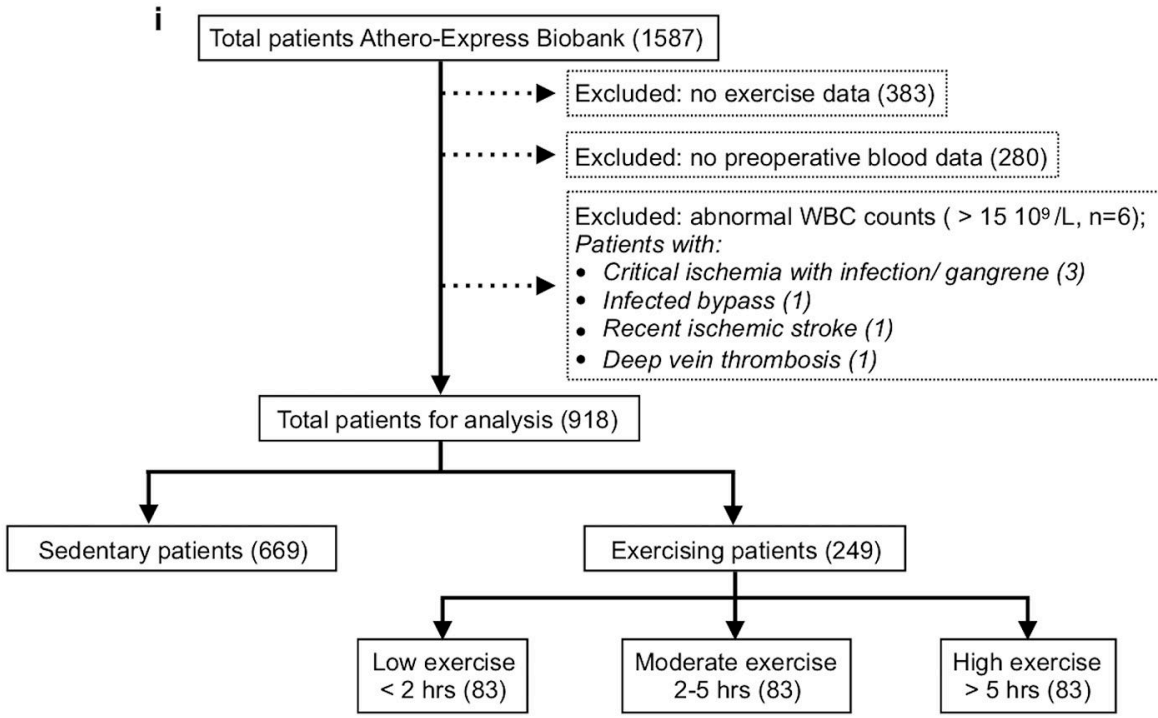

Extended Data Figure 10. Stromal leptin receptor deletion attenuates atherosclerosis, inflammation and hematopoiesis.

(a) Experimental outline for b-h. $\operatorname{Lepr}^{\mathrm{f} / \mathrm{fl}}$ mice and $\operatorname{Prx} 1$-creER ${ }^{\mathrm{T} 2}: \operatorname{Lepr}^{\mathrm{f} / \mathrm{fl}}$ littermates were injected with tamoxifen and received a single IV injection of AAV-PCSK9 followed by a high fat diet for 12 weeks. (b) Representative cross sections of aortic roots stained with Oil red $\mathrm{O}$ and assessment of lesion size $\left({ }^{*} \mathrm{p}=0.042, \mathrm{n}=8\right.$ animals per group, two-tailed Student's t-test). (c) Flow cytometry enumeration of myeloid cells in aortas of Lepr ${ }^{\mathrm{fl} / \mathrm{fl}}$ and $\operatorname{Prx} 1$ creER $^{\mathrm{T} 2}:$ Lepr $^{\mathrm{fl} / \mathrm{fl}}$ mice $\left({ }^{*} \mathrm{p}=0.023, \mathrm{n}=8\right.$ animals per group, two-tailed Student's t-test). (d) 
CD68 histological staining of aortic root lesions. Percentage of positive staining per plaque $\left({ }^{*} \mathrm{p}=0.029, \mathrm{n}=6\right.$ animals for $\operatorname{Lepr}^{\mathrm{fl} / \mathrm{fl}}, \mathrm{n}=8$ for Prx $1-\mathrm{creER}^{\mathrm{T} 2}:$ Lepr $^{\mathrm{fl} / \mathrm{fl} l}$, two-tailed MannWhitney U test). (e) Representative flow plots and statistical analysis of long-term hematopoietic stem cells (LT-HSC) in femur bone marrow $(* \mathrm{p}=0.046, \mathrm{n}=9$ animals per group, two-tailed Student's t-test). (f) Bone marrow colony forming unit assay for complete colonies (CFU-C) of bone marrow mononuclear cells (BMNCs) $(* \mathrm{p}=0.036, \mathrm{n}=9$ animals per group, two-tailed Student's t-test). (g) BrdU incorporation assay 22 hours after intraperitoneal injection for LT-HSC and granulocyte-macrophage progenitors (GMP) proliferation $\left({ }^{*} \mathrm{p}=0.027\right.$ for LT-HSC, ${ }^{*} \mathrm{p}=0.017$ for GMP, $\mathrm{n}=9$ animals per group, two-tailed Student's t-test). (h) Circulating myeloid cells at Zeitgeber time 7 (* $\mathrm{p}=0.014$ for neutrophils, * $\mathrm{p}=0.046$ for monocytes, $\mathrm{n}=10$ animals for $\operatorname{Lepr}^{\mathrm{fl} / \mathrm{fl}}, \mathrm{n}=9$ for $\operatorname{Prx} 1-\mathrm{creER}^{\mathrm{T} 2}: \operatorname{Lepr}^{\mathrm{fl} / \mathrm{fl}}$, twotailed Student's t-test). Data are mean \pm s.e.m. (i) Athero-express cohort. The flow chart illustrates inclusion criteria for patients and separation into sedentary lifestyle and exercise groups.

\section{Supplementary Material}

Refer to Web version on PubMed Central for supplementary material.

\section{Acknowledgements}

We thank Maris Handley, Eric Surette and Amy Galvin of the HSCI-CRM Flow Cytometry Core, MGH, for assistance with cell sorting, the Center for Skeletal Research Imaging and Biomechanical Testing Core (NIH P30 AR066261), MGH, for bone histology and $\mu \mathrm{CT}$ imaging, the Bioanalytics Core at the Diabetes and Obesity Center, part of Christina Lee Brown Envirome Institute, University of Louisville, for mass spectrometry analysis, the BPF Next-Gen Sequencing Core Facility at Harvard Medical School for their support for RNA-sequencing and Kaley Joyes for editing the manuscript. This work was funded in part by federal funds from the National Institutes of Health HL142494, HL139598, HL131478, HL128264, AI07087, DK040561, T32HL076136, the European Union's Horizon 2020 research and innovation program under grant agreement No 667837, the Deutsche Forschungsgemeinschaft (CR 603/1-1, HO 5279/1-2, RO 5071/1-1), and a fellowship from the Netherlands Organisation for Scientific Research (NWO, Rubicon Grant: 835.15.014). We acknowledge servier medical art (www.smart.servier.com) for providing images of mice and components of the cartoon.

\section{References}

1. Ridker PM Residual inflammatory risk: addressing the obverse side of the atherosclerosis prevention coin. Eur Heart J 37, 1720-1722 (2016). [PubMed: 26908943]

2. Ridker PM et al. Antiinflammatory Therapy with Canakinumab for Atherosclerotic Disease. N Engl J Med 377, 1119-1131 (2017). [PubMed: 28845751]

3. Madjid M, Awan I, Willerson JT \& Casscells SW Leukocyte count and coronary heart disease: implications for risk assessment. J Am Coll Cardiol 44, 1945-1956 (2004). [PubMed: 15542275]

4. Nahrendorf M \& Swirski FK Lifestyle effects on hematopoiesis and atherosclerosis. Circ Res 116, 884-894 (2015). [PubMed: 25722442]

5. Tall AR \& Yvan-Charvet L Cholesterol, inflammation and innate immunity. Nat Rev Immunol 15, 104-116 (2015). [PubMed: 25614320]

6. Heidt $\mathrm{T}$ et al. Chronic variable stress activates hematopoietic stem cells. Nat Med 20, 754-758 (2014). [PubMed: 24952646]

7. McAlpine CS et al. Sleep modulates haematopoiesis and protects against atherosclerosis. Nature 566, 383-387 (2019). [PubMed: 30760925]

8. Nagareddy PR et al. Adipose tissue macrophages promote myelopoiesis and monocytosis in obesity. Cell Metab 19, 821-835 (2014). [PubMed: 24807222] 
9. Morrison SJ \& Scadden DT The bone marrow niche for haematopoietic stem cells. Nature 505, 327-334 (2014). [PubMed: 24429631]

10. Lavie CJ, Ozemek C, Carbone S, Katzmarzyk PT \& Blair SN Sedentary Behavior, Exercise, and Cardiovascular Health. Circ Res 124, 799-815 (2019). [PubMed: 30817262]

11. Lee DC et al. Leisure-time running reduces all-cause and cardiovascular mortality risk. J Am Coll Cardiol 64, 472-481 (2014). [PubMed: 25082581]

12. Duggal NA, Niemiro G, Harridge SDR, Simpson RJ \& Lord JM Can physical activity ameliorate immunosenescence and thereby reduce age-related multi-morbidity. Nat Rev Immunol (2019).

13. Meissner $\mathrm{M}$ et al. Voluntary wheel running increases bile acid as well as cholesterol excretion and decreases atherosclerosis in hypercholesterolemic mice. Atherosclerosis 218, 323-329 (2011). [PubMed: 21802084]

14. Fukao $\mathrm{K}$ et al. Voluntary exercise ameliorates the progression of atherosclerotic lesion formation via anti-inflammatory effects in apolipoprotein E-deficient mice. J Atheroscler Thromb 17, 12261236 (2010). [PubMed: 20808053]

15. Pellegrin $\mathrm{M}$ et al. Long-term exercise stabilizes atherosclerotic plaque in ApoE knockout mice. Med Sci Sports Exerc 41, 2128-2135 (2009). [PubMed: 19915507]

16. de Visser L, van den Bos R \& Spruijt BM Automated home cage observations as a tool to measure the effects of wheel running on cage floor locomotion. Behav Brain Res 160, 382-388 (2005). [PubMed: 15863235]

17. De Lisio M \& Parise G Characterization of the effects of exercise training on hematopoietic stem cell quantity and function. J Appl Physiol (1985) 113, 1576-1584 (2012). [PubMed: 23019311]

18. Baker JM, De Lisio M \& Parise G Endurance exercise training promotes medullary hematopoiesis. FASEB J 25, 4348-4357 (2011). [PubMed: 21868472]

19. Agha NH et al. Vigorous exercise mobilizes CD34+ hematopoietic stem cells to peripheral blood via the the $\beta 2$-adrenergic receptor. Brain Behav Immun 68, 66-75 (2018). [PubMed: 29017969]

20. Soppi E, Varjo P, Eskola J \& Laitinen LA Effect of strenuous physical stress on circulating lymphocyte number and function before and after training. J Clin Lab Immunol 8, 43-46 (1982). [PubMed: 7097751]

21. Asada N, Takeishi S \& Frenette PS Complexity of bone marrow hematopoietic stem cell niche. Int J Hematol 106, 45-54 (2017). [PubMed: 28534115]

22. Abella $\mathrm{V}$ et al. Leptin in the interplay of inflammation, metabolism and immune system disorders. Nat Rev Rheumatol 13, 100-109 (2017). [PubMed: 28053336]

23. Bennett BD et al. A role for leptin and its cognate receptor in hematopoiesis. Curr Biol 6, 11701180 (1996). [PubMed: 8805376]

24. Hirose $\mathrm{H}$ et al. Serum leptin level: possible association with haematopoiesis in adolescents, independent of body mass index and serum insulin. Clin Sci (Lond) 94, 633-636 (1998). [PubMed: 9854461]

25. Rostas I et al. In middle-aged and old obese patients, training intervention reduces leptin level: A meta-analysis. PLoS One 12, e0182801 (2017). [PubMed: 28809927]

26. Zhou BO, Yue R, Murphy MM, Peyer JG \& Morrison SJ Leptin-receptor-expressing mesenchymal stromal cells represent the main source of bone formed by adult bone marrow. Cell Stem Cell 15, 154-168 (2014). [PubMed: 24953181]

27. Ding L, Saunders TL, Enikolopov G \& Morrison SJ Endothelial and perivascular cells maintain haematopoietic stem cells. Nature 481, 457-462 (2012). [PubMed: 22281595]

28. Yue R, Zhou BO, Shimada IS, Zhao Z \& Morrison SJ Leptin receptor promotes adipogenesis and reduces osteogenesis by regulating mesenchymal stromal cells in adult bone marrow. Cell Stem Cell (2016).

29. Mercier FE, Sykes DB \& Scadden DT Single Targeted Exon Mutation Creates a True Congenic Mouse for Competitive Hematopoietic Stem Cell Transplantation: The C57BL/6-CD45.1(STEM) Mouse. Stem Cell Reports 6, 985-992 (2016). [PubMed: 27185283]

30. Cao J et al. Joint profiling of chromatin accessibility and gene expression in thousands of single cells. Science 361, 1380-1385 (2018). [PubMed: 30166440] 
31. Lara-Astiaso D et al. Immunogenetics. Chromatin state dynamics during blood formation. Science 345, 943-949 (2014). [PubMed: 25103404]

32. Corces MR et al. Lineage-specific and single-cell chromatin accessibility charts human hematopoiesis and leukemia evolution. Nat Genet 48, 1193-1203 (2016). [PubMed: 27526324]

33. Yu VWC et al. Epigenetic Memory Underlies Cell-Autonomous Heterogeneous Behavior of Hematopoietic Stem Cells. Cell 167, 1310-1322.e17 (2016). [PubMed: 27863245]

34. Golan K, Kollet O \& Lapidot T Dynamic Cross Talk between S1P and CXCL12 Regulates Hematopoietic Stem Cells Migration, Development and Bone Remodeling. Pharmaceuticals (Basel) 6, 1145-1169 (2013). [PubMed: 24276423]

35. Ito $\mathrm{K} \&$ Suda T Metabolic requirements for the maintenance of self-renewing stem cells. Nat Rev Mol Cell Biol 15, 243-256 (2014). [PubMed: 24651542]

36. Tanaka $\mathrm{Y}$ et al. Exhaustive exercise reduces tumor necrosis factor-alpha production in response to lipopolysaccharide in mice. Neuroimmunomodulation 17, 279-286 (2010). [PubMed: 20203534]

37. Mackinnon LT, Chick TW, van As A \& Tomasi TB The effect of exercise on secretory and natural immunity. Adv Exp Med Biol 216A, 869-876 (1987). [PubMed: 3687561]

38. Shirato K et al. Regular Voluntary Exercise Potentiates Interleukin-1 $\beta$ and Interleukin-18 Secretion by Increasing Caspase-1 Expression in Murine Macrophages. Mediators Inflamm 2017, 9290416 (2017). [PubMed: 28133422]

39. Wallerstedt SM, Eriksson AL, Niklason A, Ohlsson C \& Hedner T Serum leptin and myocardial infarction in hypertension. Blood Press 13, 243-246 (2004). [PubMed: 15581339]

40. Rajendran K, Devarajan N, Ganesan M \& Ragunathan M Obesity, Inflammation and Acute Myocardial Infarction - Expression of leptin, IL-6 and high sensitivity-CRP in Chennai based population. Thromb J 10, 13 (2012). [PubMed: 22891684]

41. Engström G, Melander O \& Hedblad B Leukocyte count and incidence of hospitalizations due to heart failure. Circ Heart Fail 2, 217-222 (2009). [PubMed: 19808343]

42. Tsujioka $\mathrm{H}$ et al. Impact of heterogeneity of human peripheral blood monocyte subsets on myocardial salvage in patients with primary acute myocardial infarction. J Am Coll Cardiol 54, 130-138 (2009). [PubMed: 19573729]

43. Swirski FK \& Nahrendorf M Leukocyte behavior in atherosclerosis, myocardial infarction, and heart failure. Science 339, 161-166 (2013). [PubMed: 23307733]

44. Verhoeven BA et al. Athero-express: differential atherosclerotic plaque expression of mRNA and protein in relation to cardiovascular events and patient characteristics. Rationale and design. Eur J Epidemiol 19, 1127-1133 (2004). [PubMed: 15678794]

45. Kelesidis T, Kelesidis I, Chou S \& Mantzoros CS Narrative review: the role of leptin in human physiology: emerging clinical applications. Ann Intern Med 152, 93-100 (2010). [PubMed: 20083828]

46. Johannsen NM et al. Effect of different doses of aerobic exercise on total white blood cell (WBC) and WBC subfraction number in postmenopausal women: results from DREW. PLoS One 7, e31319 (2012). [PubMed: 22363616]

47. Mabuchi T et al. Association between serum leptin concentration and white blood cell count in middle-aged Japanese men and women. Diabetes Metab Res Rev 21, 441-447 (2005). [PubMed: 15724240]

48. Arnett DK et al. 2019 ACC/AHA Guideline on the Primary Prevention of Cardiovascular Disease: Executive Summary: A Report of the American College of Cardiology/American Heart Association Task Force on Clinical Practice Guidelines. J Am Coll Cardiol (2019).

\section{References}

49. Ionita MG et al. High neutrophil numbers in human carotid atherosclerotic plaques are associated with characteristics of rupture-prone lesions. Arterioscler Thromb Vasc Biol 30, 1842-1848 (2010). [PubMed: 20595650]

50. Halliday A et al. Prevention of disabling and fatal strokes by successful carotid endarterectomy in patients without recent neurological symptoms: randomised controlled trial. Lancet 363, 14911502 (2004). [PubMed: 15135594] 
51. ten Berg MJ et al. Linking laboratory and medication data: new opportunities for pharmacoepidemiological research. Clin Chem Lab Med 45, 13-19 (2007). [PubMed: 17243908]

52. Lam SW, Leenen LPH, Solinge WW, Hietbrink F \& Huisman A Evaluation of hematological parameters on admission for the prediction of 7-day in-hospital mortality in a large trauma cohort. Clinical chemistry and Labratory Medicine 49, 493-499 (2011).

53. Groeneveld KM, Heeres M, Leenen LPH, Huisman A, \& L, K. Immunophenotyping of posttraumatic neutrophils on a routine haematology analyser. Mediators of Inflammation 2012, 509513 (2012). [PubMed: 22523451]

54. Mignone JL, Kukekov V, Chiang AS, Steindler D \& Enikolopov G Neural stem and progenitor cells in nestin-GFP transgenic mice. J Comp Neurol 469, 311-324 (2004). [PubMed: 14730584]

55. Méndez-Ferrer $\mathrm{S}$ et al. Mesenchymal and haematopoietic stem cells form a unique bone marrow niche. Nature 466, 829-834 (2010). [PubMed: 20703299]

56. DeFalco J et al. Virus-assisted mapping of neural inputs to a feeding center in the hypothalamus. Science 291, 2608-2613 (2001). [PubMed: 11283374]

57. Bilic-Curcic I et al. Visualizing levels of osteoblast differentiation by a two-color promoter-GFP strategy: Type I collagen-GFPcyan and osteocalcin-GFPtpz. Genesis 43, 87-98 (2005). [PubMed: 16149065]

58. Bjorklund MM et al. Induction of atherosclerosis in mice and hamsters without germline genetic engineering. Circ Res 114, 1684-1689 (2014). [PubMed: 24677271]

59. Rittirsch D, Huber-Lang MS, Flierl MA \& Ward PA Immunodesign of experimental sepsis by cecal ligation and puncture. Nature protocols 4, 31-36 (2008).

60. Konstantinides S, Schäfer K, Neels JG, Dellas C \& Loskutoff DJ Inhibition of endogenous leptin protects mice from arterial and venous thrombosis. Arterioscler Thromb Vasc Biol 24, 2196-2201 (2004). [PubMed: 15458978]

61. Surwit RS, Edwards CL, Murthy S \& Petro AE Transient effects of long-term leptin supplementation in the prevention of diet-induced obesity in mice. Diabetes 49, 1203-1208 (2000). [PubMed: 10909979]

62. Kunisaki Y et al. Arteriolar niches maintain haematopoietic stem cell quiescence. Nature 502, 637643 (2013). [PubMed: 24107994]

63. Orr JS, Kennedy AJ \& Hasty AH Isolation of adipose tissue immune cells. J Vis Exp e50707 (2013). [PubMed: 23728515]

64. Buenrostro JD, Wu B, Chang HY \& Greenleaf WJ ATAC-seq: A Method for Assaying Chromatin Accessibility Genome-Wide. Curr Protoc Mol Biol 109, 21.29.1-9 (2015).

65. Mehta $\mathrm{S}$ et al. Maintenance of macrophage transcriptional programs and intestinal homeostasis by epigenetic reader SP140. Sci Immunol 2, (2017).

66. Li H Exploring single-sample SNP and INDEL calling with whole-genome de novo assembly. Bioinformatics 28, 1838-1844 (2012). [PubMed: 22569178]

67. John $\mathrm{S}$ et al. Chromatin accessibility pre-determines glucocorticoid receptor binding patterns. Nat Genet 43, 264-268 (2011). [PubMed: 21258342]

68. Robinson MD, McCarthy DJ \& Smyth GK edgeR: a Bioconductor package for differential expression analysis of digital gene expression data. Bioinformatics 26, 139-140 (2010). [PubMed: 19910308]

69. Patro R, Duggal G, Love MI, Irizarry RA \& Kingsford C Salmon provides fast and bias-aware quantification of transcript expression. Nat Methods 14, 417-419 (2017). [PubMed: 28263959]

70. Soneson C, Love MI \& Robinson MD Differential analyses for RNA-seq: transcript-level estimates improve gene-level inferences. F1000Res 4, 1521 (2015). [PubMed: 26925227]

71. McCarthy DJ, Chen Y \& Smyth GK Differential expression analysis of multifactor RNA-Seq experiments with respect to biological variation. Nucleic Acids Res 40, 4288-4297 (2012). [PubMed: 22287627]

72. Yu G, Wang LG, Han Y \& He QY clusterProfiler: an R package for comparing biological themes among gene clusters. OMICS 16, 284-287 (2012). [PubMed: 22455463]

73. Bouxsein ML et al. Guidelines for assessment of bone microstructure in rodents using microcomputed tomography. J Bone Miner Res 25, 1468-1486 (2010). [PubMed: 20533309] 
74. Scheller EL et al. Use of osmium tetroxide staining with microcomputerized tomography to visualize and quantify bone marrow adipose tissue in vivo. Methods Enzymol 537, 123-139 (2014). [PubMed: 24480344] 
a

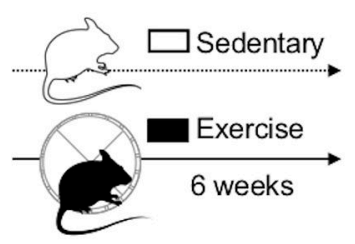

b

Gated on single live cells, lineage

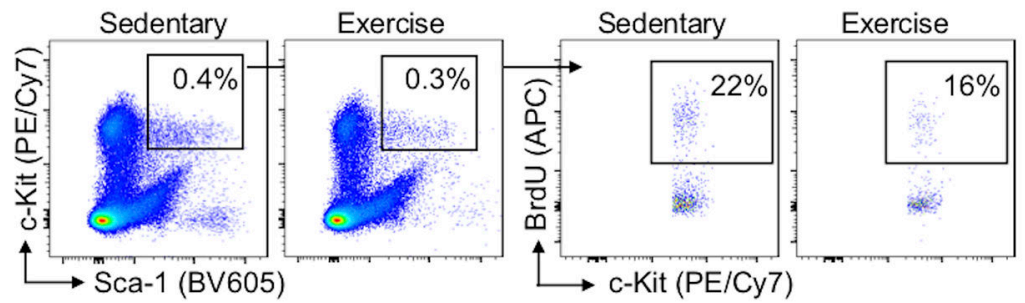

C
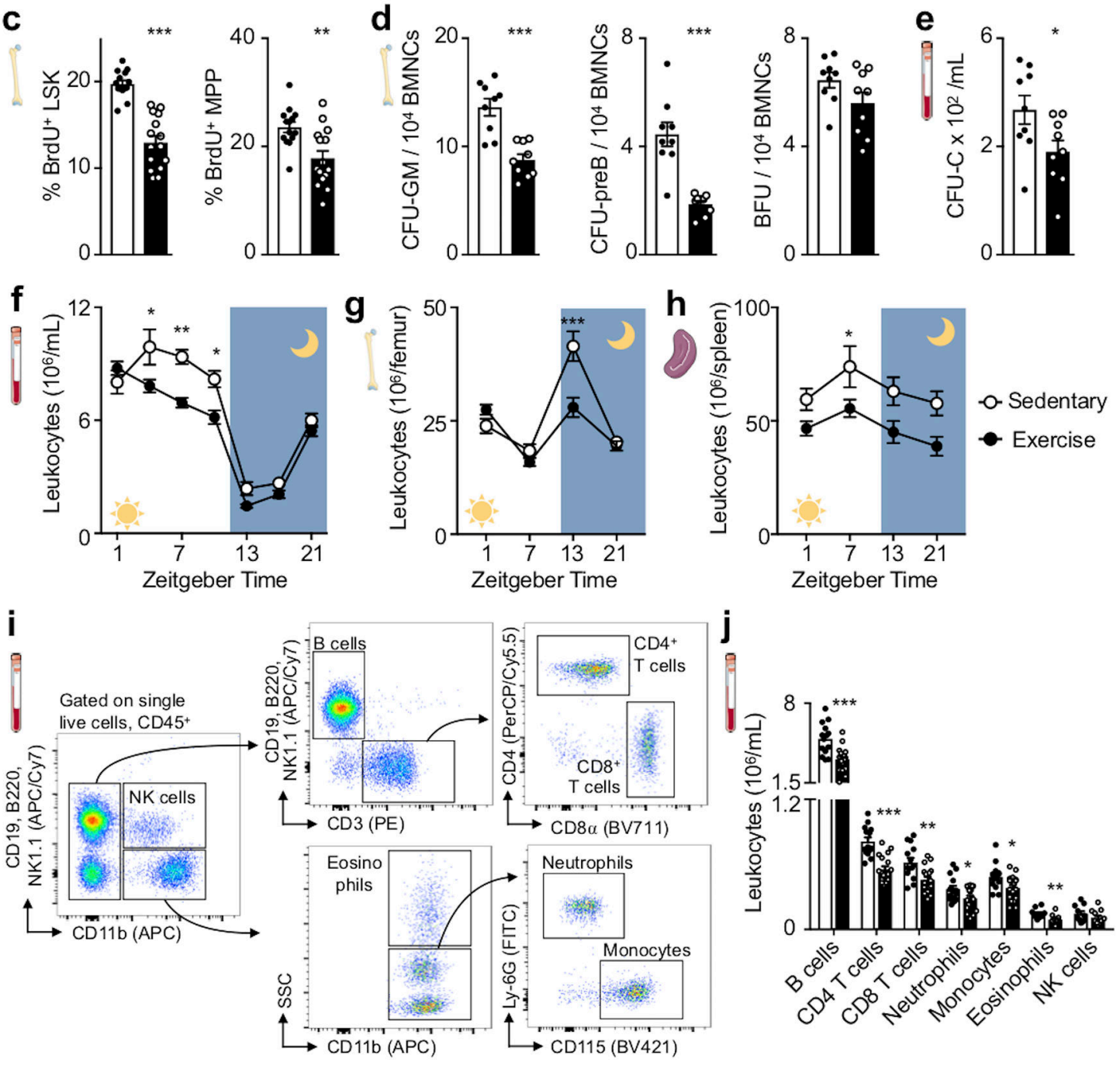

Figure 1. Exercise increases HSPC quiescence.

(a) Experimental outline. Hematopoietic parameters were measured in C67BL/6 mice that had access to exercise wheels for 6 weeks (exercise) or not (sedentary). (b, c) Proliferation of hematopoietic stem and progenitor cells (LSK; $\left.\mathrm{Lin}^{-} \mathrm{Sca}-1^{+} \mathrm{c}-\mathrm{kit}^{+}\right)$and multipotent progenitor cells (MPP), as analyzed by BrdU incorporation using flow cytometry. Representative dot plots for LSK (b) and statistical analysis (c) are shown $(* * \mathrm{p}=0.0023$, $* * * \mathrm{p}=4.25 \times 10^{-8}, \mathrm{n}=14$ sedentary, $\mathrm{n}=15$ exercising animals, 4 independent experiments, twotailed Student's t-test). (d) Colony forming unit assay (CFU) of bone marrow mononuclear 
cells (BMNCs) for granulocytes and macrophages (GM), pre-B cells (preB) and burstforming unit-erythroid (BFU) $\left(* * * \mathrm{p}=0.00012\right.$ for $\mathrm{GM}, * * * \mathrm{p}=4.22 \times 10^{-5}$ for preB, $\mathrm{p}=0.052$ for BFU, $n=9$ animals per group, two-tailed Student's t-test). (e) Circulating stem cells measured by CFU assay for complete colonies ( $* \mathrm{p}=0.018, \mathrm{n}=9$ animals per group, 2 independent experiments, two-tailed Student's t-test). (f-h) Circadian rhythm of leukocyte numbers in the blood (f) ${ }^{*} \mathrm{p}=0.029$ for Zeitgeber time $(\mathrm{ZG}) 5,{ }^{*} \mathrm{p}=0.038$ for ZG 9 , $* * \mathrm{p}=0.0025$ for $Z G \mathrm{Z}, \mathrm{n}=12$ animals for $Z G \mathrm{G}, 5,7,9,21, \mathrm{n}=8$ for $Z \mathrm{G} 13,17$ for sedentary, $\mathrm{n}=17$ for $Z \mathrm{G} 1, \mathrm{n}=18$ for ZG 5, 7, 9, 21, $\mathrm{n}=12$ for ZG 13, 17 for exercise, 3 independent experiments, two-way analysis of variance with Sidak's post hoc test), bone marrow (g) (*** $\mathrm{p}=2.14 \times 10^{-6}, \mathrm{n}=8$ and $\mathrm{n}=11$ animals for $\mathrm{ZG} 1, \mathrm{n}=8$ and $\mathrm{n}=12$ for ZG 7 for sedentary and exercise, respectively, $n=9$ per group for $Z G$ 13, $n=3$ per group for $Z G$ 21; 8 independent experiments, two-way analysis of variance with Sidak's post hoc test) and spleen (h) $\left({ }^{*} \mathrm{p}=0.012, \mathrm{n}=4\right.$ and $\mathrm{n}=5$ animals for $\mathrm{ZG} 1, \mathrm{n}=7$ and $\mathrm{n}=12$ for $\mathrm{ZG} 7$ for sedentary and exercise, respectively, $n=6$ per group for $Z G$ 13, $n=3$ per group for $Z G$ 21, 4 independent experiments, two-way analysis of variance with Sidak's post hoc test). (i) Flow cytometry gating for blood leukocytes at ZG 7. (j) Leukocyte subsets in circulation at ZG 7 (*p=0.044 for neutrophils, ${ }^{*} \mathrm{p}=0.019$ for monocytes, $* * \mathrm{p}=0.0025$ for CD8 T cells, $* * \mathrm{p}=0.0057$ for eosinophils, $* * * \mathrm{p}=0.00022$ for B cells, $* * * \mathrm{p}=4.96 \times 10^{-6}$ for CD4 T cells, $\mathrm{n}=14$ and $\mathrm{n}=18$ animals for B cells, T cells, monocytes, $n=14$ and $n=17$ for neutrophils, $n=10$ and $n=12$ for eosinophils and NK cells for sedentary and exercise, respectively, 4 independent experiments, two-tailed Student's t-test comparing sedentary and exercise for each cell subset). Data are mean \pm s.e.m. We acknowledge servier medical art (www.smart.servier.com) for providing images of mice and cartoon components. 
a

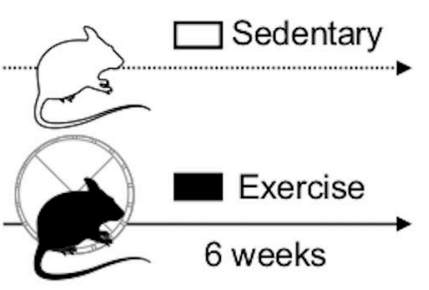

d Gated on single live cells, CD45-Ter119-

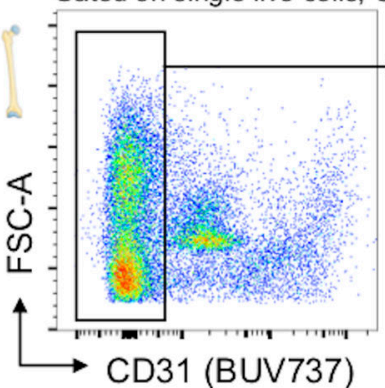

e

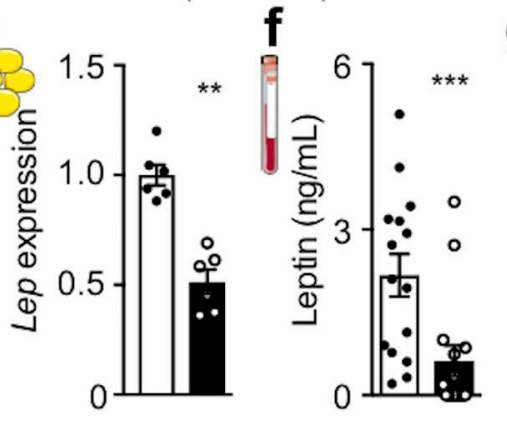

b
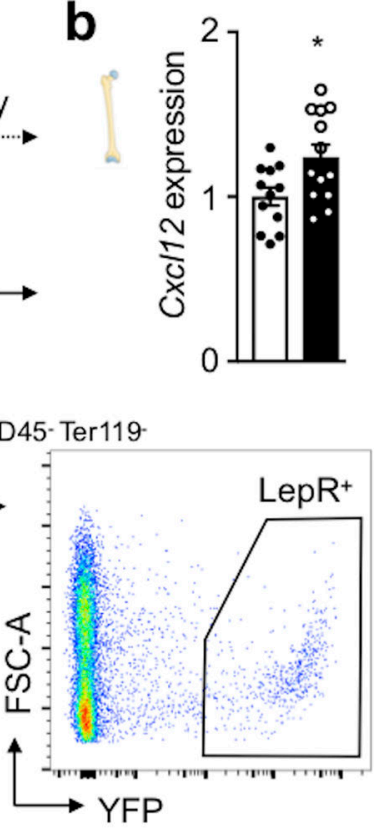

g

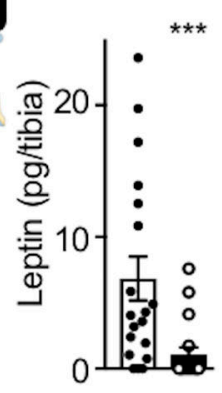

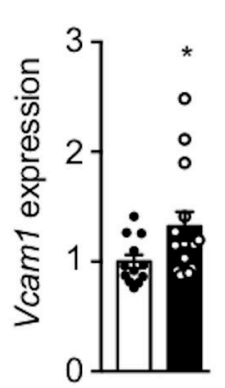
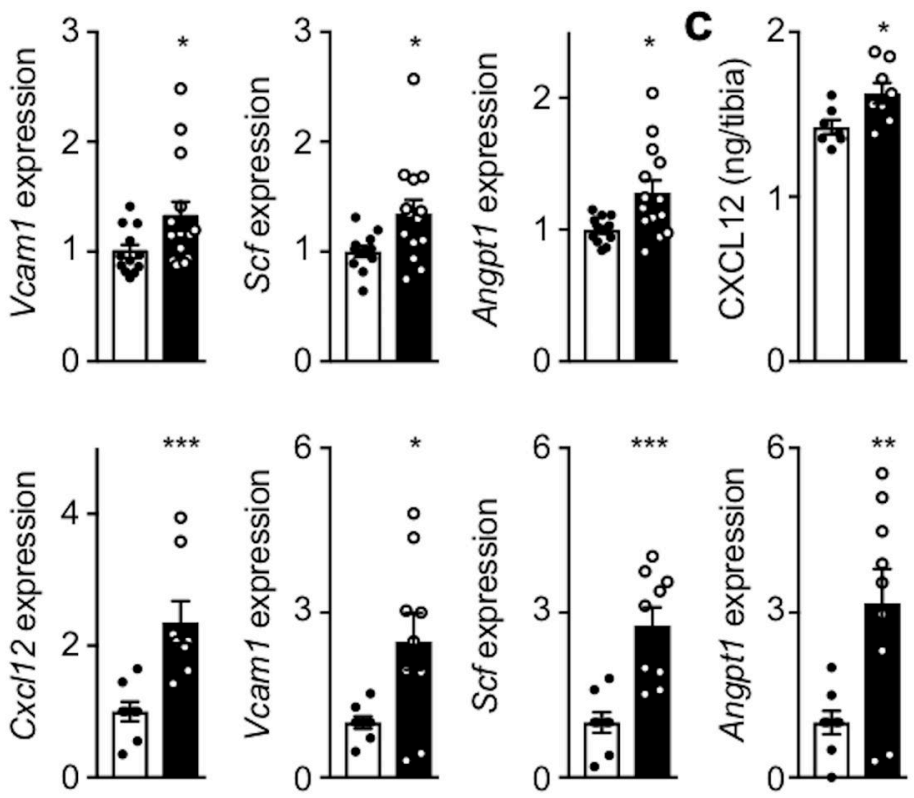

h
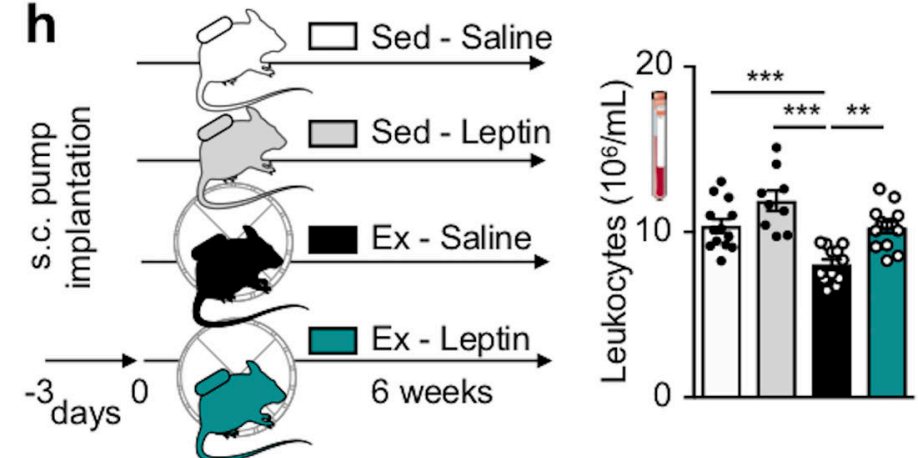

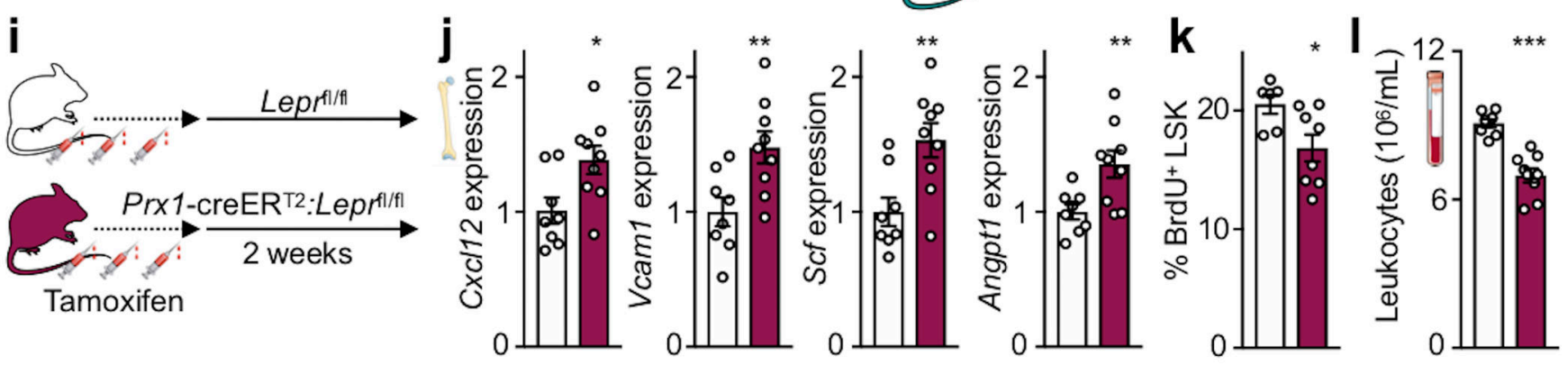

Figure 2. Exercise dampens hematopoiesis by reducing adipose tissue leptin production. (a) Experimental outline for panels b-g. C57BL/6 or LepR-YFP stromal reporter mice had access to exercise wheels for 6 weeks or remained sedentary. (b) Gene expression of maintenance factors in total bone marrow of C57BL/6 mice, as measured by qPCR (* $\mathrm{p}=0.017$ for $C x c 112,{ }^{*} \mathrm{p}=0.047$ for $V c a m 1,{ }^{*} \mathrm{p}=0.022$ for $S c f,{ }^{*} \mathrm{p}=0.01$ for Angpt1, $\mathrm{n}=12$ and n=13 animals for Cxc112, n=12 and n=14 for Vcam1, Scf, Angpt1, for sedentary and exercise, respectively, 3 independent experiments, two-tailed Student's t-test). (c) Protein levels by ELISA in tibia marrow plasma ( ${ }^{*} \mathrm{p}=0.021, \mathrm{n}=7$ animals for sedentary and $\mathrm{n}=8$ for exercise, 2 independent experiments, two-tailed Mann-Whitney U test). (d) Left, 
representative plots for flow sorting LepR-YFP ${ }^{+}$stromal cells. Right, expression of maintenance factors as assessed by qPCR $\left(* * * \mathrm{p}=0.009\right.$ for $C x c 112,{ }^{*} \mathrm{p}=0.018$ for Vcam1, *** $=0.0005$ for $S c f, * * \mathrm{p}=0.0071$ for Angpt $1, \mathrm{n}=8$ animals per group for $C x c 112, \mathrm{n}=8$ and n=9 for Vcam1, Scf, Angpt1 for sedentary and exercise, respectively, 6 independent experiments, two-tailed Mann-Whitney U test). (e-g) Leptin expression, as measured by qPCR in visceral adipose tissue $(* * \mathrm{p}=0.0022, \mathrm{n}=6$ animals per group, 2 independent experiments, Mann-Whitney U test) (e) and blood (***p=0.0007, $\mathrm{n}=15$ animals per group, 3 independent experiments, two-tailed Mann-Whitney U test) (f) and bone marrow (*** $\mathrm{p}=0.0003, \mathrm{n}=19$ animals for sedentary and $\mathrm{n}=18$ for exercise, two-tailed Mann-Whitney U test) by ELISA (g). (h) Left, experimental outline; osmotic minipumps producing saline or leptin were implanted subcutaneously in C57BL/6J mice, which then were allowed to exercise or not starting 3 days after implantation. Right, levels of circulating leukocytes at Zeitgeber time $7{ }^{* *} \mathrm{p}=0.0015$ for Ex-Saline vs Ex-Leptin, ${ }^{* * *} \mathrm{p}=0.0009$ for Sed-Saline vs Ex-Saline, ${ }^{* * *} \mathrm{p}=1.77 \times 10^{-7}$ for Sed-Leptin vs Ex-Saline, $\mathrm{n}=13$ animals for Sed-Saline and Ex-Leptin, $\mathrm{n}=9$ for Sed-Leptin, and $\mathrm{n}=12$ for Ex-Saline, 5 independent experiments, oneway analysis of variance with Sidak's post hoc test). (i) Experimental outline for panels $\mathbf{j}-\mathbf{l}$. $\operatorname{PrX} 1$-creER ${ }^{\mathrm{T} 2}: \operatorname{Lepr}^{\mathrm{fl} / \mathrm{fl}}$ mice or their $L e p r^{\mathrm{fl} / \mathrm{fl}}$ littermates were injected 3 times with tamoxifen every other day and were sacrificed 2 weeks after the last injection. (j) Gene expression in total bone marrow, as measured by $\mathrm{qPCR}\left({ }^{*} \mathrm{p}=0.02\right.$ for $C x c 112, * * \mathrm{p}=0.0094$ for Vcam1, $* * \mathrm{p}=0.0064$ for $S c f,{ }^{*} \mathrm{p}=0.0099$ for Angpt $1, \mathrm{n}=8$ animals for Lepr ${ }^{\mathrm{fl} / \mathrm{fl}}$ and $\mathrm{n}=9$ for $\operatorname{Prx} 1$-creER ${ }^{\mathrm{T} 2}:$ Lepr $^{\mathrm{fl} / \mathrm{fl} 1}, 3$ independent experiments, two-tailed Student's t-test) (k) BrdU incorporation into LSK, as measured by FACS, $22 \mathrm{hrs}$ after intraperitoneal injection ${ }^{*} \mathrm{p}=0.043, \mathrm{n}=6$ animals for $\operatorname{Lepr}^{\mathrm{fl} / \mathrm{fl} \mathrm{l}}$ and $\mathrm{n}=8$ for $\operatorname{PrX} 1-$ creER $^{\mathrm{T} 2}: \operatorname{Lepr}^{\mathrm{fl} / \mathrm{fl}}, 2$ independent experiments, two-tailed Mann-Whitney U test). (l) Circulating leukocyte levels at Zeitgeber time $7\left(* * * \mathrm{p}=1.7 \times 10^{-5}, \mathrm{n}=8\right.$ animals for $\operatorname{Lepr}^{\mathrm{fl} / \mathrm{fl}} \mathrm{n}=9$ for $\operatorname{Prx} 1-$ creER $^{\mathrm{T} 2}:$ Lepr $^{\mathrm{fl} / \mathrm{fl}}, 3$ independent experiments, two-tailed Student's t-test). All mRNA levels were normalized to $A c t b \mathrm{Ct}$ values. Data are mean \pm s.e.m. We acknowledge servier medical art (www.smart.servier.com) for providing images of mice and cartoon components. 

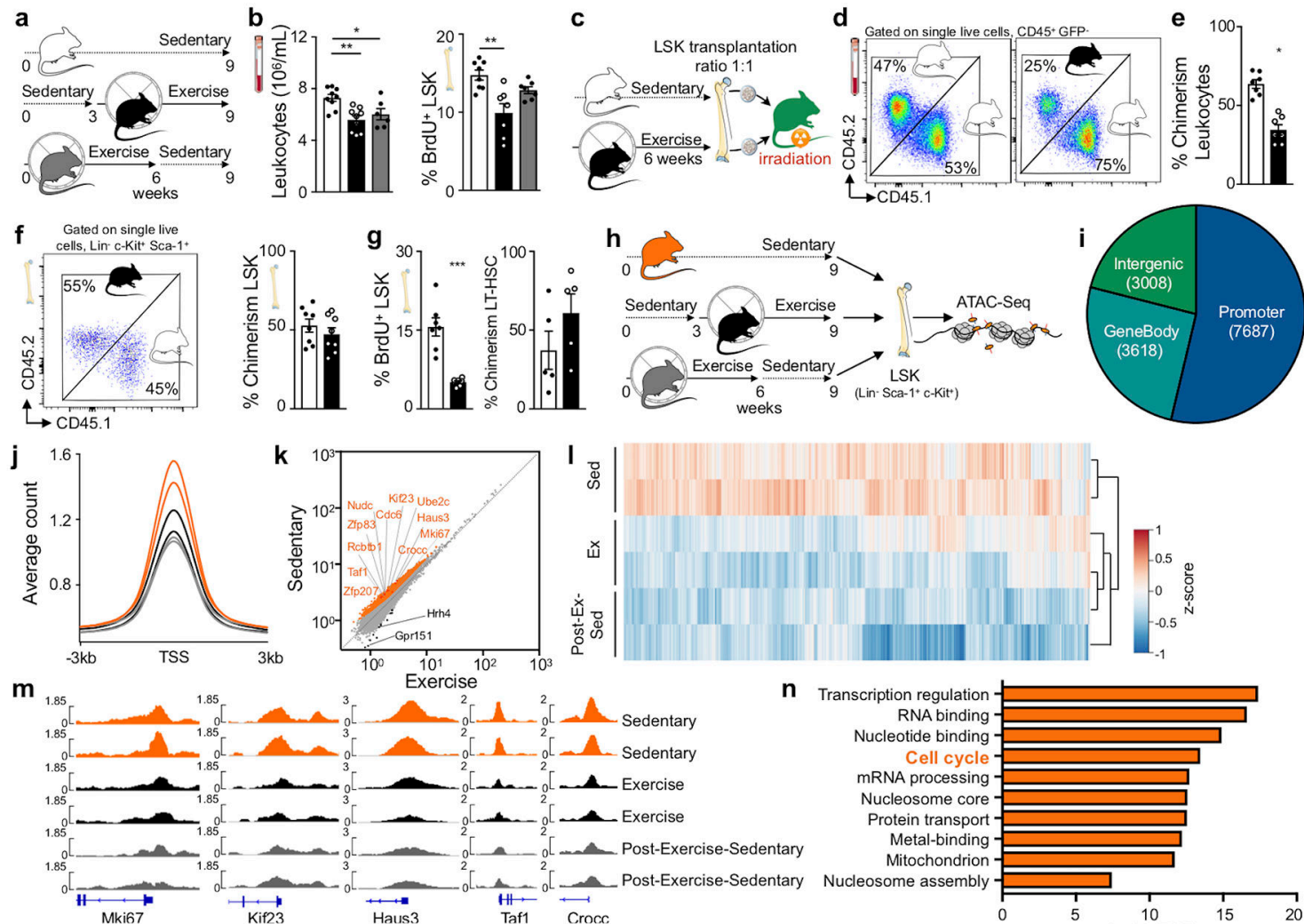

$$
\text { Exercise }
$$
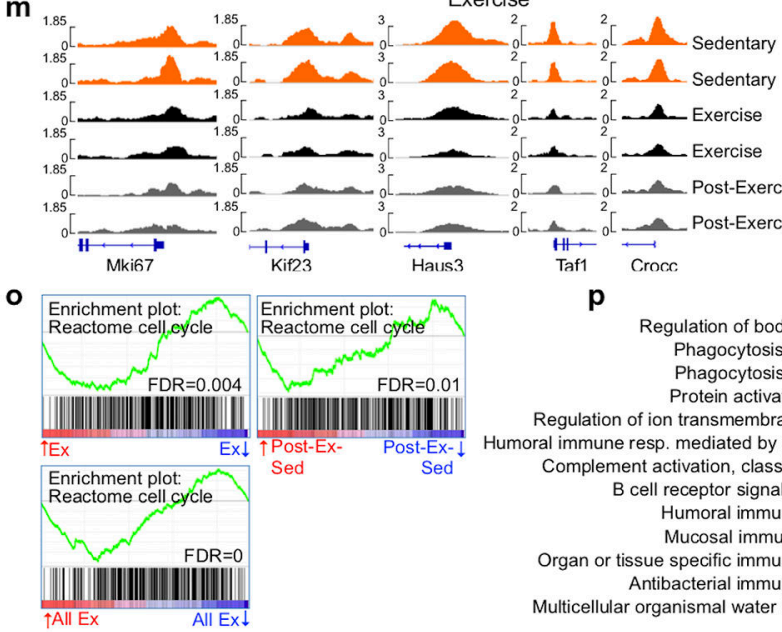

n Transcription regulation
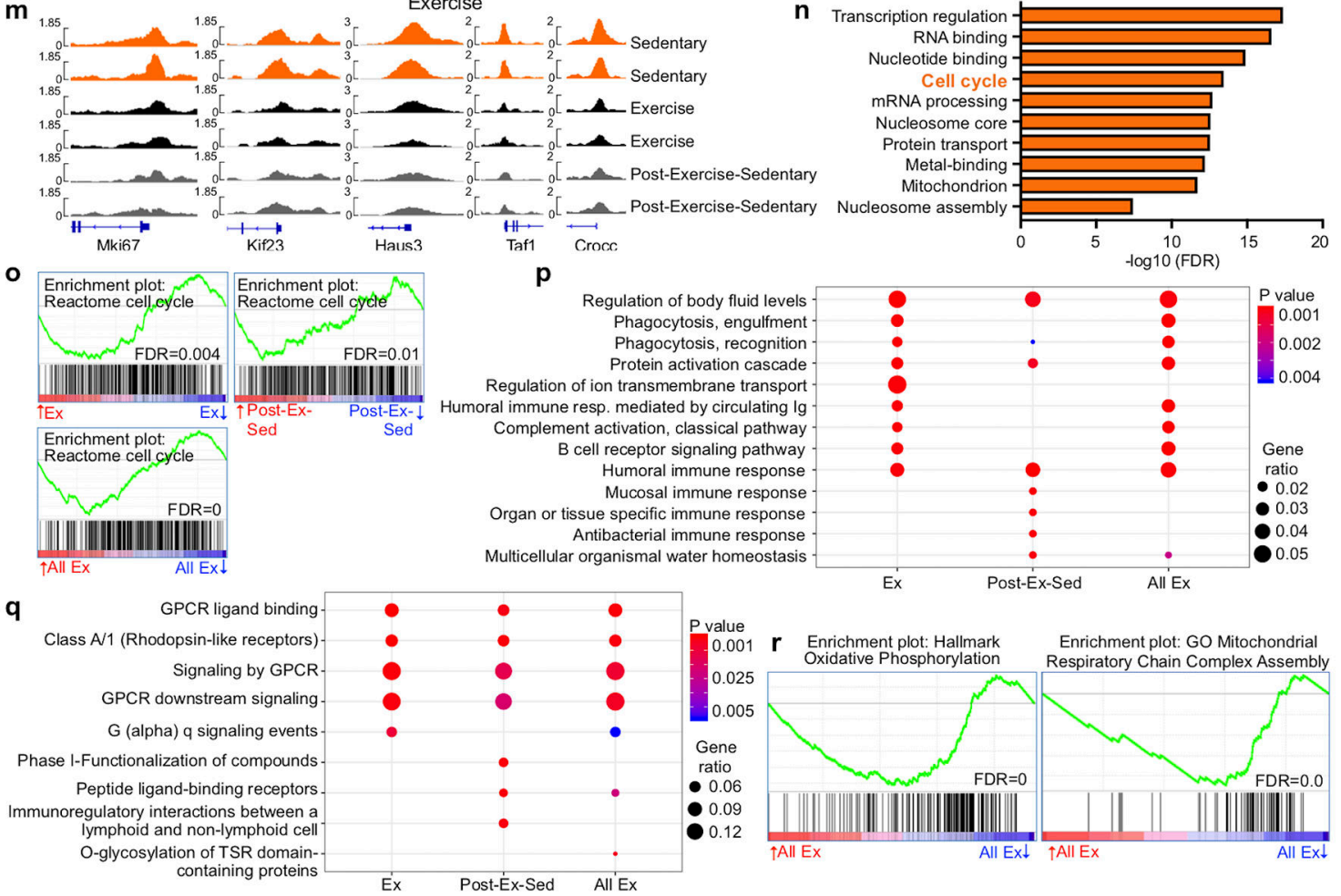

Figure 3. Voluntary running reduces LSK chromatin accessibility.

(a) Experimental outline for $\mathbf{b}$. Sedentary control C57BL/6J mice had no access to exercise wheels (top); the exercise group had access to wheels during the last 6 weeks before sacrifice (middle), and the post-exercise-sedentary group had access to wheels for 6 weeks after which the wheels were removed for the following 3 weeks (bottom). (b) Circulating leukocyte levels $\left({ }^{*} \mathrm{p}=0.033,{ }^{*} \mathrm{p}=0.0025, \mathrm{n}=9\right.$ animals for sedentary and exercise, $\mathrm{n}=6$ for post-exercise-sedentary, 3 independent experiments, Kruskal-Wallis test with Dunn's post hoc test) at Zeitgeber time 7 and BrdU incorporation in LSK, as measured 22 hours after 
intraperitoneal injection $(* * \mathrm{p}=0.0043, \mathrm{n}=8$ for sedentary and $\mathrm{n}=7$ for exercise and postexercise-sedentary, 2 independent experiments, Kruskal-Wallis test with Dunn's post hoc test). (c) Experimental outline of competitive bone marrow transplantation experiments in dg. LSK were isolated from donors that had either exercised for 6 weeks (CD45.2) or were sedentary $\left(\mathrm{CD} 45.1^{\mathrm{STEM}}\right)$ and were then transplanted in a 1:1 ratio into irradiated UBC-GFP recipients. (d) Left, flow cytometry plots of circulating leukocytes after transplantation. The left panel depicts a control that had received LSK from a sedentary CD45.2 mouse and a sedentary CD45.1 ${ }^{\text {STEM }}$ mouse, whereas the right panel depicts the experimental group as diagrammed in c. (e) Blood chimerism 4 weeks after transplantation ( ${ }^{*} \mathrm{p}=0.016, \mathrm{n}=7$ animals per group, Wilcoxon matched-pairs signed rank test). (f) Dot plot and quantification of bone marrow LSK chimerism ( $\mathrm{n}=8$ animals per group). (g) BrdU incorporation in LSK 22 hours after intraperitoneal injection ( $* * * \mathrm{p}=0.0006, \mathrm{n}=7$ animals per group, 2 independent experiments, two-tailed Mann-Whitney $\mathrm{U}$ test) and LT-HSC chimerism ( $\mathrm{n}=5$ animals per group). Data are mean \pm s.e.m. (h) Experimental outline for i-n. LSK were isolated from the experimental groups in a and subjected to ATAC-seq analysis. (i) Genomic distribution of ATAC-seq peaks (numbers in pie chart) in LSK among genes, promoters, enhancers and other intergenic regions. (j) Profiles of average ATAC-seq tag density over all transcriptional start site (TSS)-proximal regions (TSS $\pm 3 \mathrm{~kb}$ ) in LSK. Each curve refers to individual mouse, see $\mathbf{h}$ for color coding. (k) Scatter plot of normalized tag density at ATAC-seq peaks comparing LSK from sedentary versus exercise cohorts. Peaks with significantly lower and higher tag density in running mice are highlighted in orange and black, respectively (FDR $<0.01$ ). The top ten significant genes in the cell cycle pathway, as determined by DAVID (refer to n), and Mki67 are indicated; see Supplementary Table 1 for all genes. (l) Patterns of chromatin accessibility among 3605 TSS-proximal peaks (within TSS $\pm 3 \mathrm{Kbp}$ ) with differential ATAC-seq signal between conditions (FDR $<0.01$ ). Heatmap color indicates the ATAC-seq tag density relative to the average across all samples for the given peak. ( $\mathbf{m})$ Tracks of normalized ATAC-seq tag density for the Mki67, Kif23, Haus3, Taf1 and Crocc loci. (n) Functional pathway categories of differential chromatin accessibility in sedentary versus exercising mice as determined by DAVID. (o) Enrichment analysis of the gene set "Reactome Cell Cycle" in RNA-seq of LSK from mice in exercise and post-exercisesedentary versus sedentary groups. Genes were ranked by log2-fold change. (p,q) Gene ontology biological process categories (p) and Reactome gene sets $(\mathbf{q})$ enriched in genes that are at least two-fold downregulated in exercising mice versus sedentary mice. Gene ratio, fraction of tested genes belonging to each gene set. P-values are from the hypergeometric distribution. (r) Enrichment analysis of gene sets related to oxidative phosphorylation in LSKs from exercising vs. sedentary mice. Genes were ranked by log2-fold change. Experimental groups in o-r are as diagrammed in a (Ex, exercise; Post-Ex-Sed, sedentary after exercise; All Ex, combination of Ex and Post-Ex-Sed). All FDR values were calculated with the Benjamini-Hochberg Procedure. We acknowledge servier medical art (www.smart.servier.com) for providing images of mice and cartoon components. 
a

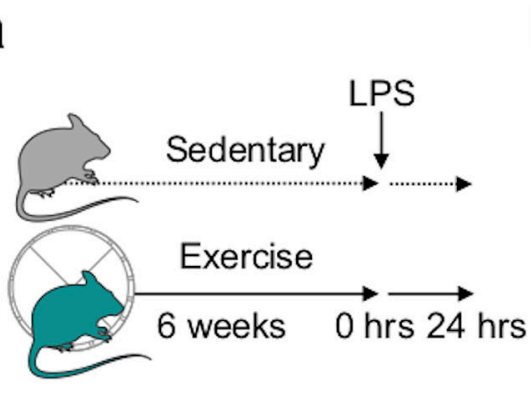

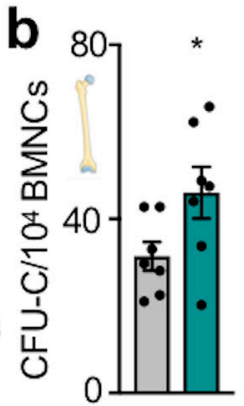
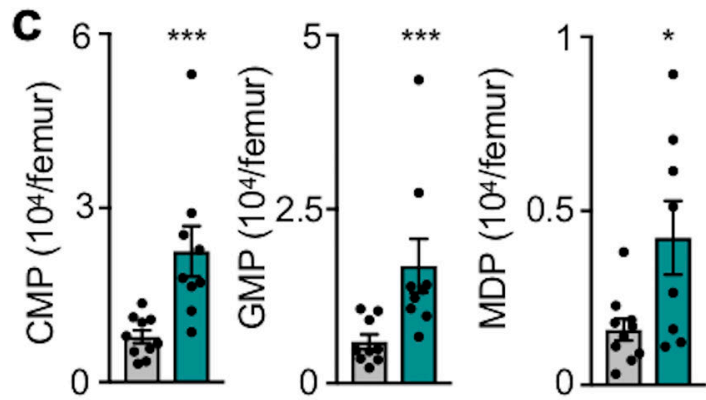

d
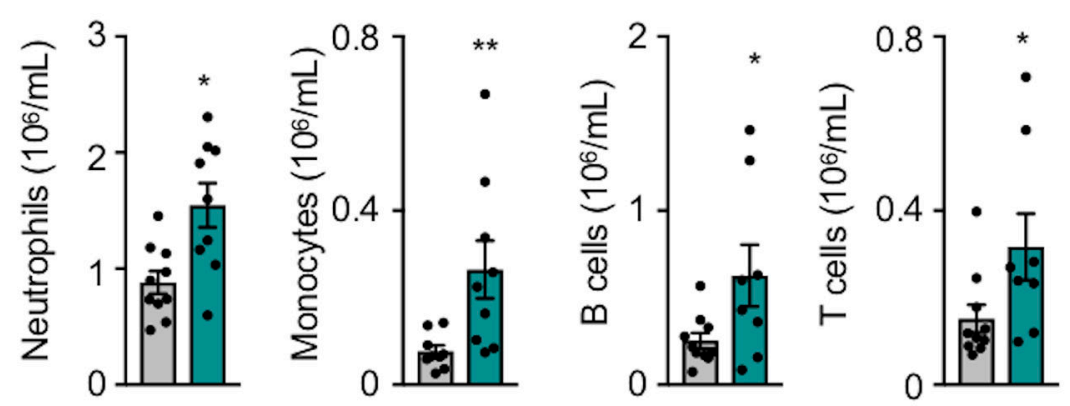

e
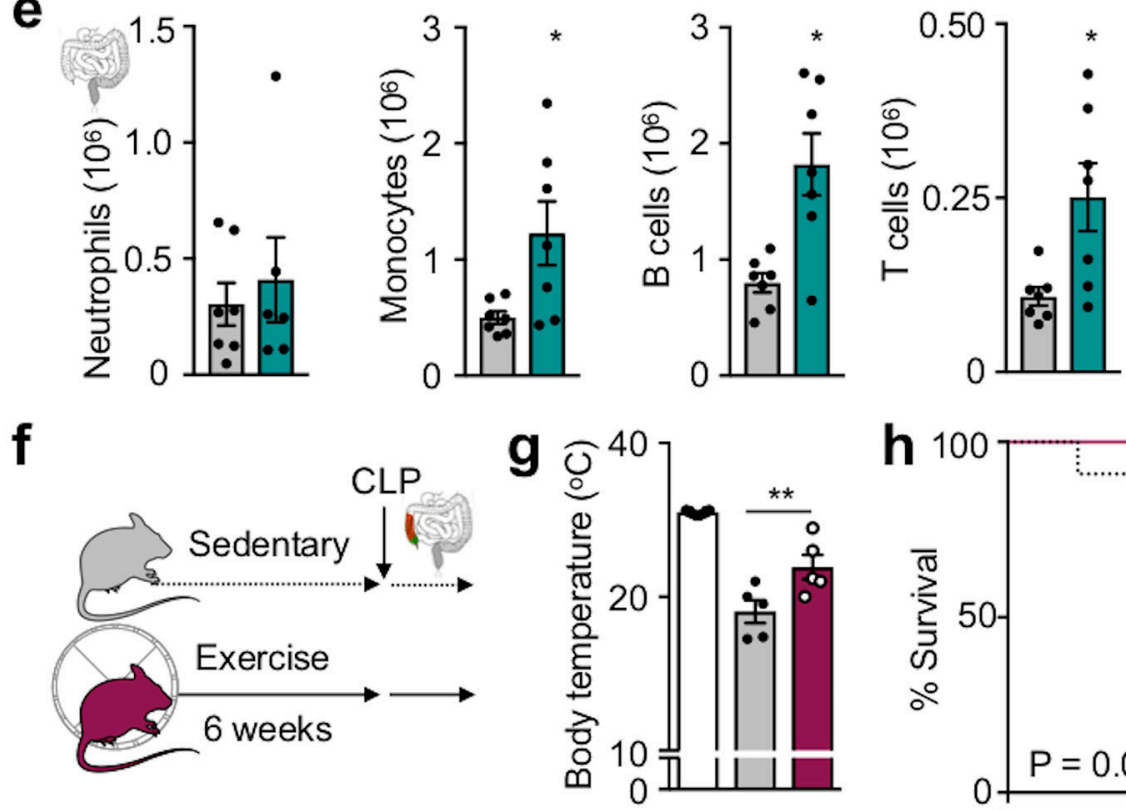

Baseline

Sed-CLP

Ex-CLP

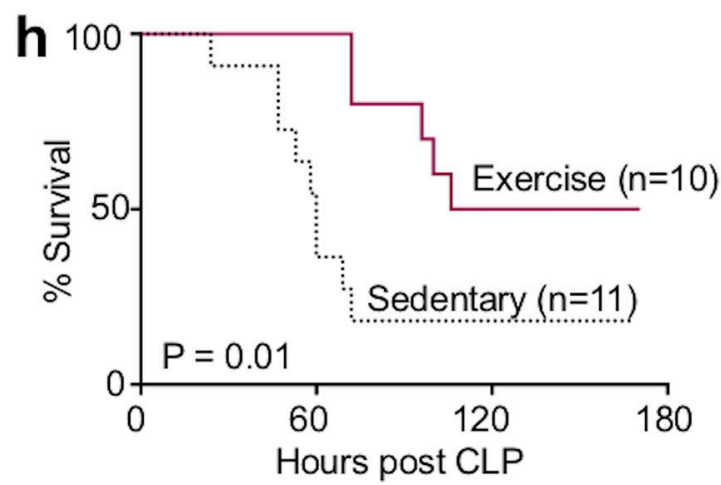

Figure 4. Exercise augments emergency hematopoiesis and improves survival in sepsis.

(a) Experimental outline for panels b-e. C57BL/6J mice received intraperitoneal injections of LPS after 6 weeks of exercise or no exercise. Analysis was performed $24 \mathrm{hrs}$ after LPS injection. (b) Bone marrow colony forming unit assay (CFU) of bone marrow mononuclear cells (BMNCs) $\left({ }^{*} \mathrm{p}=0.048, \mathrm{n}=7\right.$ animals per group, 2 independent experiments, two-tailed Mann-Whitney U test). (c) Bone marrow common myeloid progenitors (CMP), granulocyte macrophage progenitors (GMP) and macrophage dendritic cell progenitors (MDP) 24 hours after LPS injection $(* \mathrm{p}=0.018$, *** $\mathrm{p}=0.0004$ for CMP, $* * * \mathrm{p}=0.0008$ for GMP, $\mathrm{n}=10$ animals 
for sedentary, $\mathrm{n}=9$ for exercise, 3 independent experiments, two-tailed Mann-Whitney $\mathrm{U}$ test). (d) Numbers of neutrophils $(* \mathrm{p}=0.01)$, monocytes $(* * \mathrm{p}=0.0028), \mathrm{B}\left({ }^{*} \mathrm{p}=0.038\right)$ and $\mathrm{T}$ cells $(* \mathrm{p}=0.04)$ in the circulation ( $\mathrm{n}=10$ and $\mathrm{n}=9$ animals for neutrophils and monocytes, $\mathrm{n}=10$ and $\mathrm{n}=8$ for $\mathrm{B}$ and $\mathrm{T}$ cells for sedentary and exercise, respectively, 3 independent experiments, two-tailed Mann-Whitney $\mathrm{U}$ test) and (e) peritoneal cavity after LPS ( ${ }^{*} \mathrm{p}=0.038$ for monocytes, ${ }^{*} \mathrm{p}=0.011$ for B cells, ${ }^{*} \mathrm{p}=0.018$ for $\mathrm{T}$ cells, $\mathrm{n}=7$ and $\mathrm{n}=6$ animals for neutrophils for sedentary and exercise, respectively, $\mathrm{n}=7$ per group for monocytes, $\mathrm{B}$ and $\mathrm{T}$ cells, 2 independent experiments, two-tailed Mann-Whitney U test). (f) Experimental outline for panels $\mathbf{g}$-h. Cecal ligation and puncture (CLP) was induced after 6 weeks of exercise or in sedentary controls. (g) Body core temperature was measured before CLP surgery (baseline) and 48 hours after CLP $(* * \mathrm{p}=0.0043, \mathrm{n}=6$ animals for baseline and $\mathrm{n}=5$ for each CLP group, 2 independent experiments, two-tailed Mann-Whitney U test comparing sedentary and exercise post-CLP). Data are mean \pm s.e.m. (h) Survival after CLP $\left({ }^{*} \mathrm{p}=0.012\right.$, $\mathrm{n}=11$ sedentary and $\mathrm{n}=10$ exercise mice post-CLP, 3 independent experiments, Mantel-Cox log-rank test). We acknowledge servier medical art (www.smart.servier.com) for providing images of mice and cartoon components. 

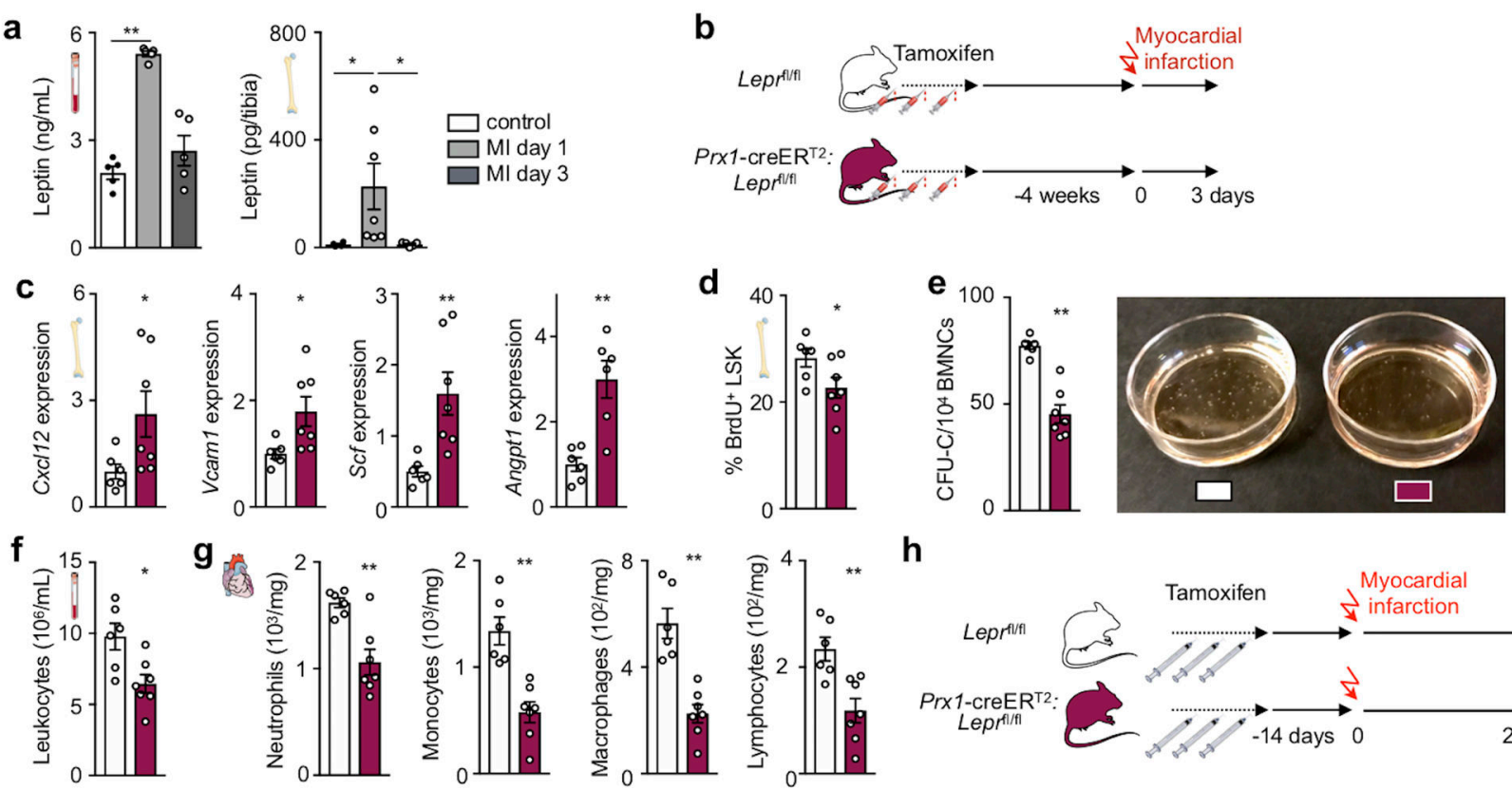

h
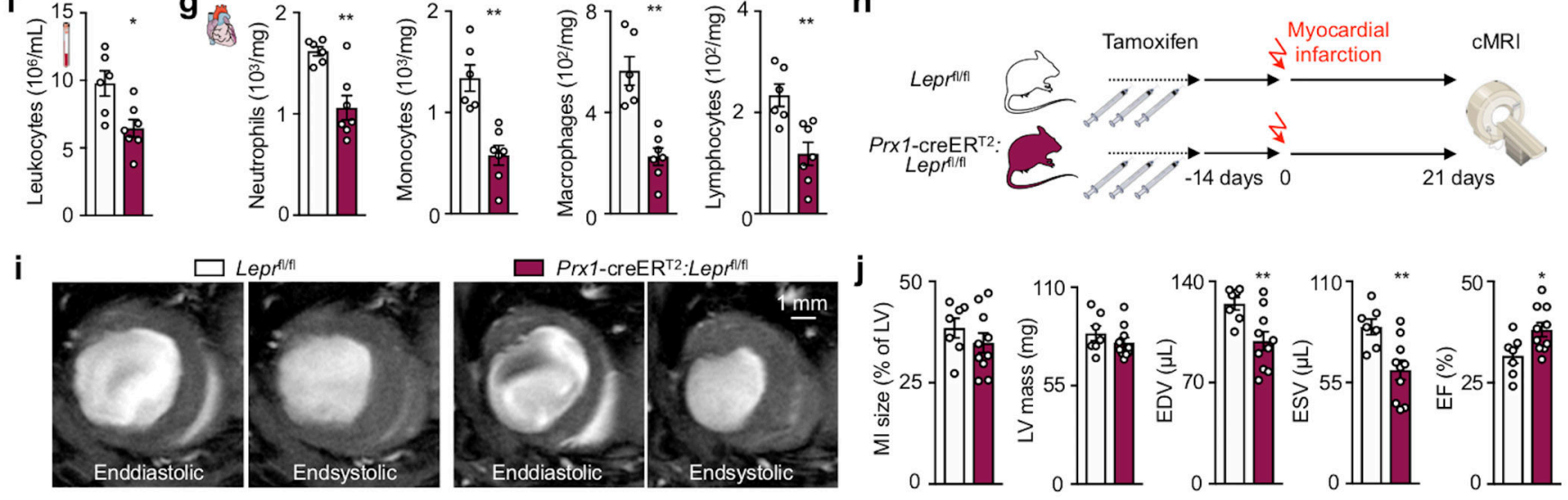

Figure 5. Disrupting leptin signaling reduces hematopoiesis and inflammation in acute myocardial infarction.

(a) Left, serum leptin levels $(* * \mathrm{p}=0.0089, \mathrm{n}=5$ animals per group, Kruskal-Wallis with Dunn's post hoc test) and right, bone marrow leptin levels $(* \mathrm{p}=0.017$ for control vs MI day 1, ${ }^{*} \mathrm{p}=0.015$ for MI day 1 vs day 3, $\mathrm{n}=4$ animals for control, $\mathrm{n}=7$ for MI day $1, \mathrm{n}=5$ for MI day 3, Kruskal-Wallis with Dunn's post hoc test) at days 1 or 3 after MI in C57BL/6J mice or naive controls, as measured by ELISA. (b) Experimental outline for panels c-g. PrX1$\operatorname{creER}^{\mathrm{T} 2}:$ eepr $^{\mathrm{fl} / \mathrm{fl}}$ mice or their $L e$ r $^{\mathrm{fl} / \mathrm{fl}}$ littermates received a myocardial infarct 4 weeks after having been injected 3 times with tamoxifen every other day. Mice were sacrificed 3 days after MI. (c) Gene expression in total bone marrow, as measured by PCR $(* \mathrm{p}=0.035$ for Cxc112, * $\mathrm{p}=0.014$ for Vcam1, ** $\mathrm{p}=0.0023$ for $S c f$, ** $\mathrm{p}=0.0087$ for Angpt1, $\mathrm{n}=6$ animals for Lepr $^{\mathrm{fl} / \mathrm{fl} \mathrm{l}}$ and $\mathrm{n}=7$ for $\operatorname{Prx} 1$-creER ${ }^{\mathrm{T} 2}:$ Lepr $^{\mathrm{fl} / \mathrm{fl}}$ for $C x c 112, V c a m 1, S c f, \mathrm{n}=6$ per group for Angpt1, 2 independent experiments, two-tailed Mann-Whitney U test). mRNA levels were normalized to $A c t b \mathrm{Ct}$ values. (d) BrdU incorporation into LSK $22 \mathrm{hrs}$ after intraperitoneal injection, as measured by FACS (*p=0.022, $\mathrm{n}=6$ animals for $\operatorname{Lepr}^{\mathrm{fl} / \mathrm{fl}}$ and $\mathrm{n}=7$ for $\operatorname{PrX} 1$ $\operatorname{creER}^{\mathrm{T} 2}:$ Lepr $^{\mathrm{fl} / \mathrm{fl}}, 2$ independent experiments, two-tailed Mann-Whitney U test). (e) Left, bone marrow colony forming unit assay (CFU) of bone marrow mononuclear cells (BMNCs) for complete colonies (CFU-C) $\left(* * \mathrm{p}=0.0012, \mathrm{n}=6\right.$ animals for $L e p r^{\mathrm{fl} / \mathrm{fl}}$ and $\mathrm{n}=7$ for Prx 1-creER ${ }^{\mathrm{T} 2}: \mathrm{Lepr}^{\mathrm{fl} / \mathrm{fl}}, 2$ independent experiments, two-tailed Mann-Whitney U test) Right, representative image of assay. (f) Circulating leukocyte levels ( $* \mathrm{p}=0.022, \mathrm{n}=6$ animals for $L e p r^{\mathrm{fl} / f \mathrm{l}}$ and $\mathrm{n}=7$ for $\operatorname{PrX} 1$-creER ${ }^{\mathrm{T} 2}: \operatorname{Lepr}^{\mathrm{fl} / \mathrm{fl} \mathrm{l}}, 2$ independent experiments, two-tailed 
Mann-Whitney U test). (g) Neutrophil (**p=0.0082), monocyte $(* * \mathrm{p}=0.0012)$, macrophage $(* * \mathrm{p}=0.0012)$ and lymphocyte $(* * \mathrm{p}=0.0047)$ numbers in the infarct $\left(\mathrm{n}=6\right.$ animals for Lepr ${ }^{\mathrm{fl} / \mathrm{fl}}$ and $\mathrm{n}=7$ for $\operatorname{PrX} 1$-creER ${ }^{\mathrm{T} 2}:$ Lepr $^{\mathrm{fl} / \mathrm{fl} \mathrm{l}}, 2$ independent experiments, two-tailed Mann-Whitney U test). (h) Experimental outline for panels c-g. Mice received 3 tamoxifen injections every other day and an MI 2 weeks later. Cardiac MRI was done 3 weeks post MI. (i,j) Cardiac MRI in $\operatorname{Prx} 1$-creER ${ }^{\mathrm{T} 2}:$ Lepr $^{\mathrm{fl} / \mathrm{fl}}$ mice and their Lepr $^{\mathrm{fl} / \mathrm{fl}}$ littermates, representative short-axis images (i) and statistical analysis (j) ${ }^{* *} \mathrm{p}=0.0097$ for EDV, $* * \mathrm{p}=0.0046$ for ESV, ${ }^{*} \mathrm{p}=0.043$ for EF, n=7 animals for $L$ epr ${ }^{\mathrm{fl} / \mathrm{fl}}$ and $\mathrm{n}=10$ for $\operatorname{PrX} 1-\mathrm{creER}^{\mathrm{T} 2}: \operatorname{Lepr}^{\mathrm{fl} / \mathrm{fl}}, 3$ independent experiments, two-tailed Mann-Whitney U test). We acknowledge servier medical art (www.smart.servier.com) for providing images of mice and cartoon components. 
a
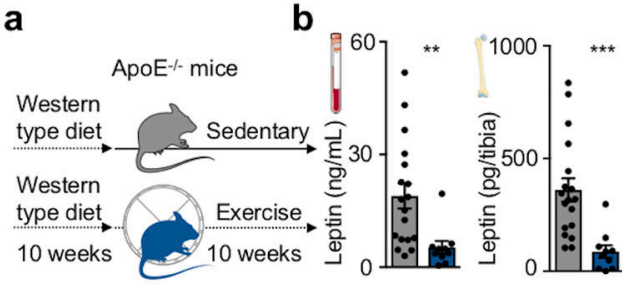

f

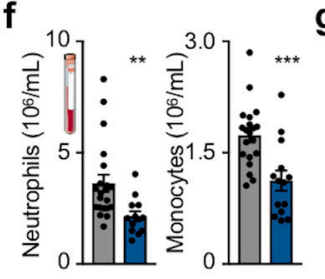

k
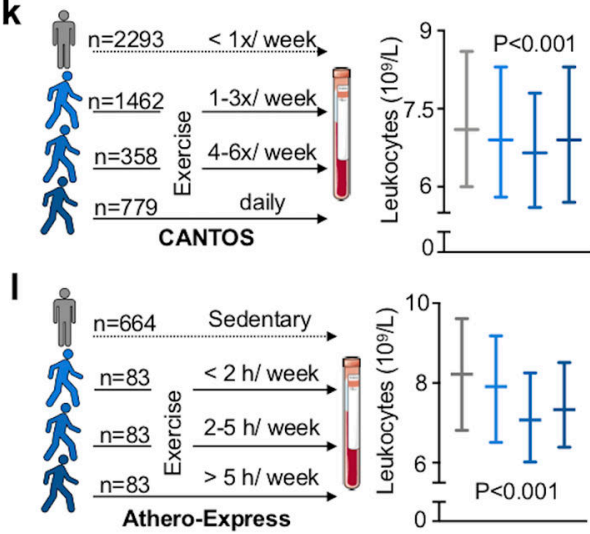
atherosclerosis.
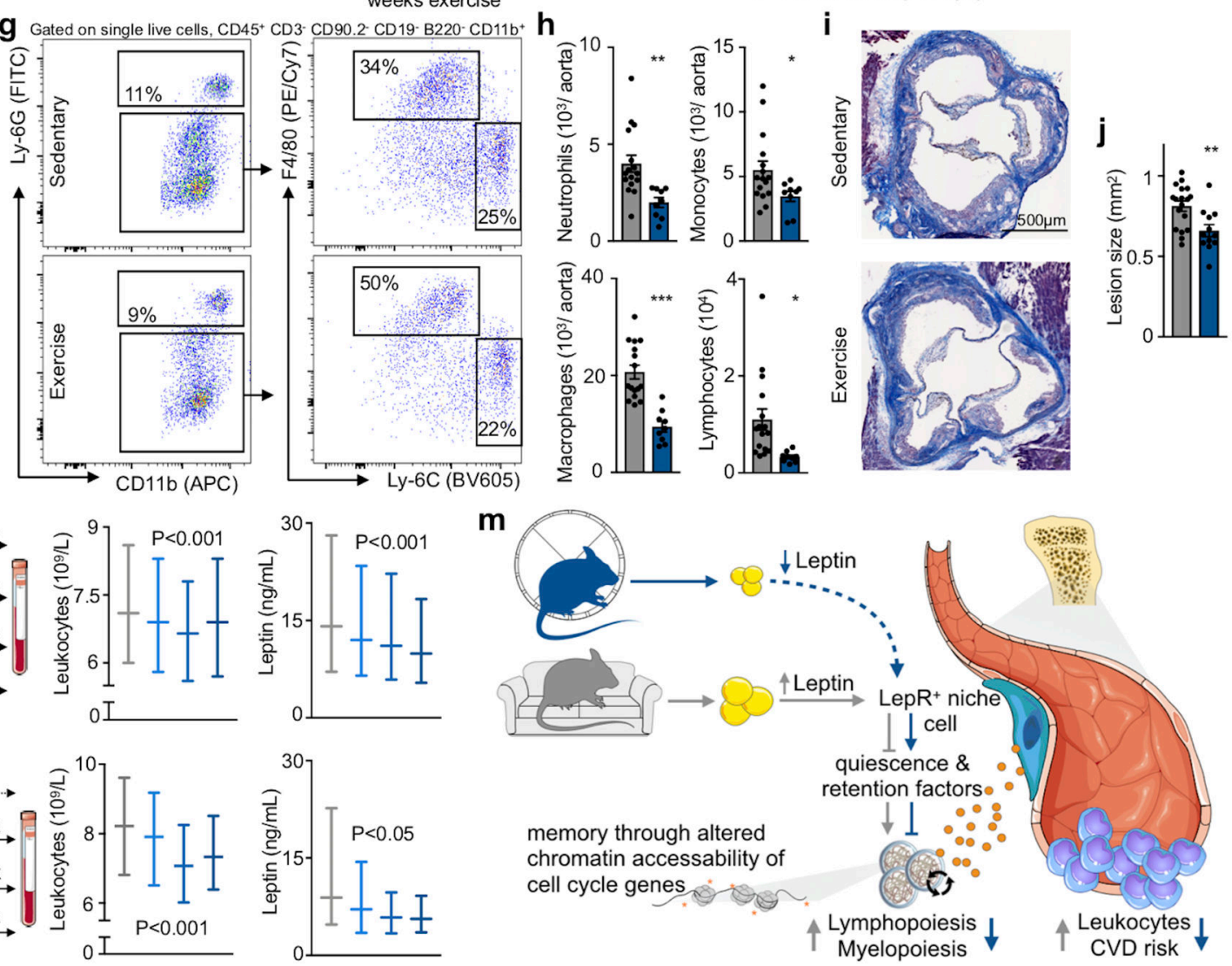

chromatin accessability of
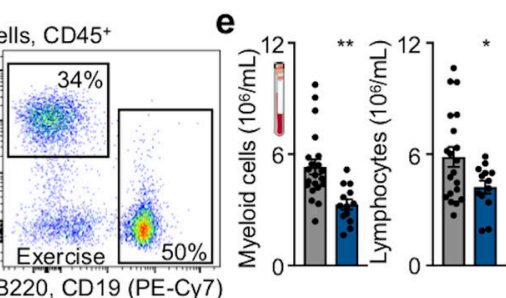

\section{(1)}

, CD19 (PE-Cy7)

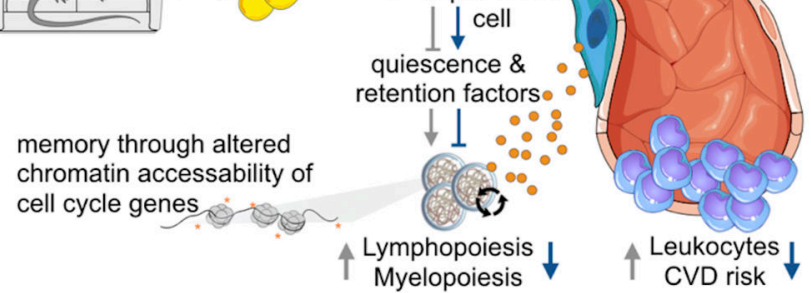

Figure 6. Sedentary lifestyle accelerates leukocyte supply in mice and humans with

(a) Experimental outline for $\mathbf{b}-\mathbf{j}$. ApoE ${ }^{-/-}$mice consumed a Western-type diet for a total of 20 weeks. After 10 weeks, half of them were given access to a running wheel for 10 weeks. (b) Leptin concentration in blood $(* * \mathrm{p}=0.0011)$ and tibia $\left(* * * \mathrm{p}=4.06 \times 10^{-5}, \mathrm{n}=18\right.$ animals for sedentary and $\mathrm{n}=10$ for exercise, 4 independent experiments, two-tailed Mann-Whitney $\mathrm{U}$ test). (c-f) Circulating leukocytes as measured by flow cytometry, during the last ten weeks of diet $(\mathbf{c})\left(* \mathrm{p}=0.017, * * * \mathrm{p}=1.9 \times 10^{-7}\right.$ for 8 weeks, $* * * \mathrm{p}=6 \times 10^{-8}$ for 10 weeks, $\mathrm{n}=19$ and $n=13$ animals for week $0, n=4$ and $n=5$ for week $2, n=20$ and $n=14$ for week $8, n=21$ and $\mathrm{n}=14$ for week 10 for sedentary and exercise, respectively, $\mathrm{n}=5$ per group for week $4, \mathrm{n}=7$ per group for week 6, two-way analysis of variance with Sidak's post hoc test). (d) Flow cytometry gating strategy for leukocytes. (e) Blood myeloid cells $(* * \mathrm{p}=0.0011, \mathrm{n}=21$ animals for sedentary and $n=13$ for exercise) and lymphocytes $(* \mathrm{p}=0.034, \mathrm{n}=20$ for sedentary and $\mathrm{n}=13$ for exercise, 4 independent experiments, two-tailed Student's t-test) in circulation. (f) Neutrophils $(* * \mathrm{p}=0.069, \mathrm{n}=21$ animals for sedentary and $\mathrm{n}=13$ animals for 
exercise), monocytes $(* * * \mathrm{p}=0.00058, \mathrm{n}=20$ and $\mathrm{n}=14), \mathrm{B}(* \mathrm{p}=0.042, \mathrm{n}=20$ and $\mathrm{n}=13)$ and $\mathrm{T}$ cells in circulation ( $n=21$ and $n=14$ for sedentary and exercise, respectively, 4 independent experiments, two-tailed Mann-Whitney U test). (g) Flow cytometry gating in aorta and (h) enumeration of neutrophils $(* * \mathrm{p}=0.0036)$, monocytes $(* \mathrm{p}=0.046)$, macrophages $\left(* * * \mathrm{p}=1.88 \times 10^{-5}\right)$ and lymphocytes $(* \mathrm{p}=0.015, \mathrm{n}=16$ animals for sedentary and $\mathrm{n}=9$ for exercise, two-tailed Student's T test). (i) Masson's Trichrome histology images of aortic root for plaque size analysis $(\mathbf{j})(* * \mathrm{p}=0.0043, \mathrm{n}=18$ animals for sedentary and $\mathrm{n}=12$ for exercise, two-tailed Student's t-test). Data are mean \pm s.e.m. (k) Left, cohorts and numbers among 4,892 participants in the Canakinumab Anti-inflammatory Thrombosis Outcomes Study (CANTOS) according to self-reported exercise levels. Right, median values and interquartile ranges for leptin and the total leukocyte count according to exercise level. Effects were statistically significant across exercise groups for both leptin and leukocyte count in both univariate and multivariate models. (l) Left, cohorts and numbers of patient from the AtheroExpress study according to exercise level. Right, median values and interquartile ranges for leptin and the total leucocyte count (also see Extended Data Fig. 10i and Supplementary Tables 3-5) (one-way analysis of variance and multivariate linear regression models with correction for age, sex, BMI, diabetes, hypercholesterolemia and statin use). (m) Summary cartoon, see text for details. We acknowledge servier medical art (www.smart.servier.com) for providing images of mice and cartoon components. 